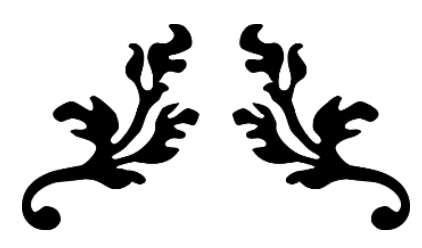

\title{
Modelling the distribution of an oviparous skink, Oligosoma suteri
}

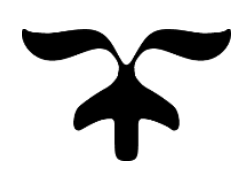

Vaughn I. Stenhouse

A thesis submitted to Victoria University of Wellington in fulfilment of the requirement for the degree of Masters of Ecology and Biodiversity

Victoria University of Wellington

Te Whare Wānanga o te Ūpoko o te Ika a Māui 


\section{Modelling the distribution of an oviparous skink, Oligosoma suteri}

\section{Abstract}

Predicting species distributions relies on understanding the fundamental constraints of climate conditions on organism's physiological traits. Species distribution models (SDMs) provide predictions on species range limits and habitat suitability using spatial environmental data. Species distribution modelling is useful to estimate environmental conditions in time and space and how they may change in future climates. Predicting the distribution of terrestrial biodiversity requires an understanding of the mechanistic links between an organism's traits and the environment. Implementation of mechanistic species distribution models requires knowledge of how environmental change influences physiological performance. Mechanistic modelling is considered more robust than correlative SDMs when extrapolating to novel environments predicted with climate change. I examined the spatial distribution and the impact of climate change on incubation duration of an endemic, nocturnal skink, Oligosoma suteri. My research focused on the ways a microclimate model with local weather data and degree-days can predict $O$. suteri's distribution and affect incubation duration. Using a microclimate model (NicheMapR), I generated hourly soil temperatures for three depths in two substrate types (rock and sand) at a $15 \mathrm{~km}$ spatial resolution for the entire coastline of New Zealand and for seven depths for one substrate type (rock) for the coastline of Rangitoto/Motutapu Island at a $20 \mathrm{~m}$ spatial resolution. I estimated the minimum number of degree days required for successful embryonic development using a minimum temperature threshold for $O$. suteri eggs. I apply the incubation duration predicted by the model to map potential distribution for the two different spatial resolutions ( $15 \mathrm{~km}$ and $20 \mathrm{~m}$ ) and I also include a climate change component to predict the potential effects on incubation duration and oviposition timing. My results from the New Zealand wide model indicate that embryonic development for $O$. suteri may be possible beyond their current distribution, and climate warming decreases incubation duration and lengthens the oviposition period for the New Zealand wide map. I generated maps of predicted incubation duration with depth for a coastal habitat at a higher resolution for Rangitoto/Motutapu Island. Incubation duration varied by depth with 
higher number of days to hatch predicted for greater depths. Temperature data loggers were installed at two different sites at three depths and were compared to the Rangitoto/Motutapu Island microclimate model. Modelled incubation durations were consistently shorter than data logger incubation durations across all three depths at both data logger sites. Species distribution model with coarse spatial and climate data can predict where soil temperatures would be suitable for successful development. A higher spatial resolution can reveal variation in incubation duration within sites indicated as suitable from the coarse resolution map. By using two different spatial extents initial starting points can be identified for which a higher resolution model can be applied to better inform management decisions relating to conservation actions and the effects of climate change for O. suteri and other species.

\section{Acknowledgments}

I would first like to thank my supervisor Nicola Nelson at Victoria University of Wellington who dedicated many hours of her time to provide me with support and feedback through every step of the thesis process. I would especially like to thank Anna Carter at lowa State University, lowa, United States of America who help tremendously with the development and writing of the script for the models as well as help with trouble shooting problems and invaluable comments on the two data chapters. I would like thank Kelly Hare of Open Polytechnic of New Zealand for providing me with the raw data on O. suteri incubation as well as chapter editing, Stephen Hartley of the School of biological Sciences at Victoria University for statistical help with degree day calculations. I would like to acknowledge Michael Kearney of Melbourne University for allowing early access NicheMapR script and to Warren Porter who wrote NicheMapper in the first place.

I would like to thank my co-workers, Steph Price, Patty Ramírez, Evan Brenton-Rule, Jana Dobelmann and Jessica Russell whose energy, constant support, humour and motivation kept me going. My volunteers Chris Woolley and Daniel Leland for helping me catch and tag skinks willingly as well as setting up the data loggers. I would like to thank all the people who help with editing and proof reading the chapters including my sister Paulette Stewart. Finally, I would like to thank my family, especially my Dad, without whom none of this would have been possible. 


\section{Table of contents}

Abstract.

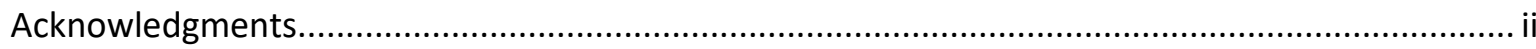

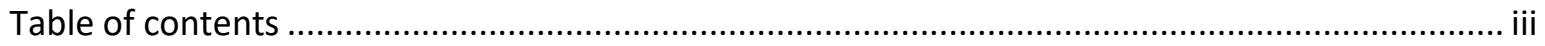

Chapter 1: Modelling the microenvironment in the egg-laying skink, Oligosoma suteri .................. 1

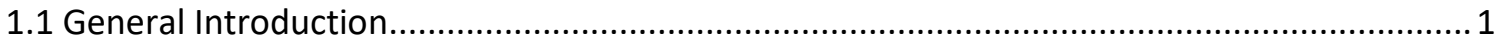

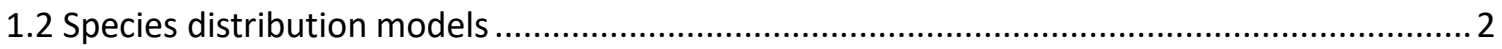

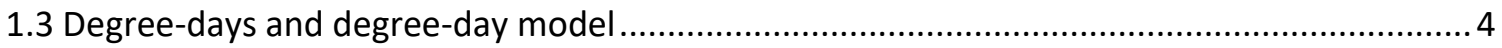

1.4 The egg-laying skink (Oligosoma suteri) life-history ............................................................... 5

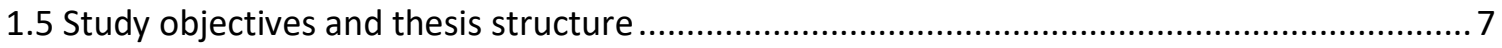

Chapter 2: Modelled soil temperatures indicates wider potential distribution with climate

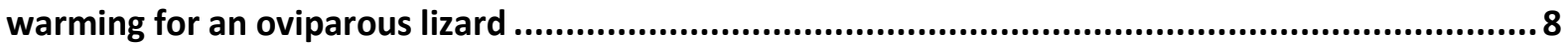

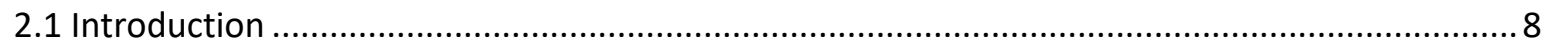

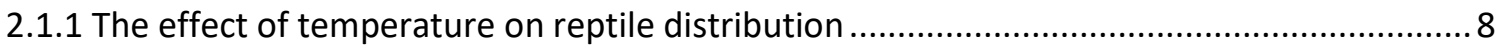

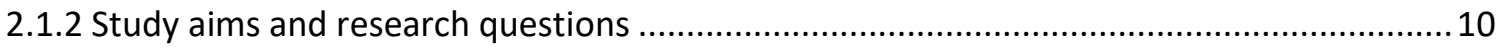

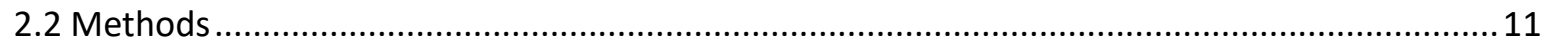

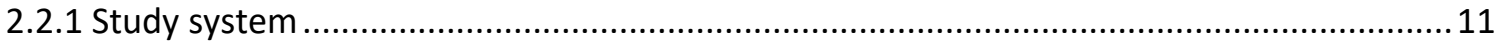

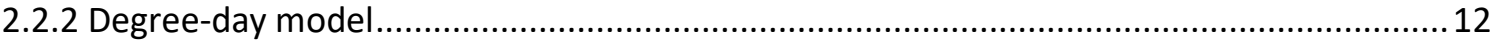

2.2.3 Combining modelled soil temperature with the degree-day model ................................... 13

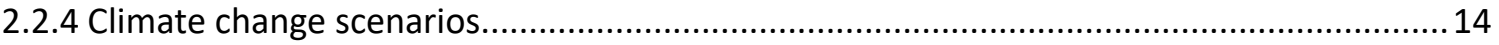

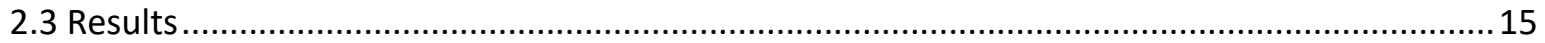

2.3.1 Degree-days as a factor in geographic distribution ............................................................ 15

2.3.2 Effects of climate change on oviposition date and incubation duration ..............................16

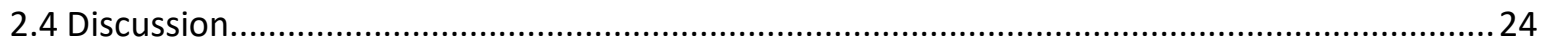

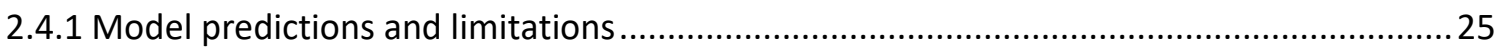

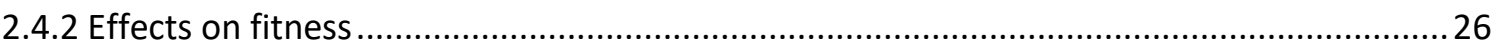

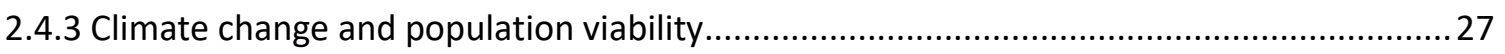

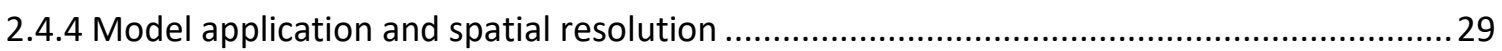

Chapter 3: Using a spatially explicit microclimate model to predict thermal suitability for an

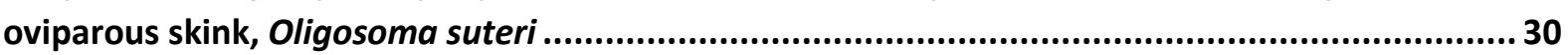

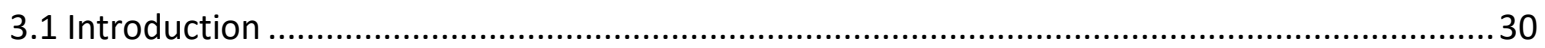

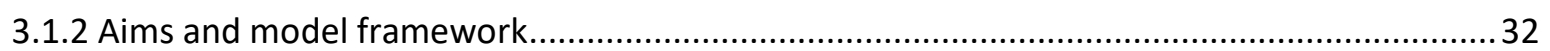

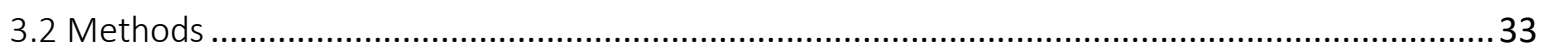

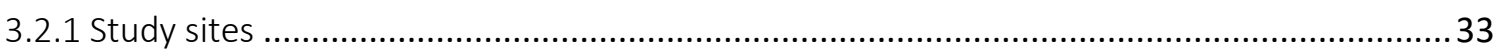

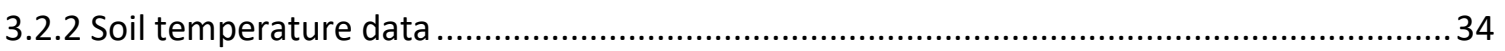

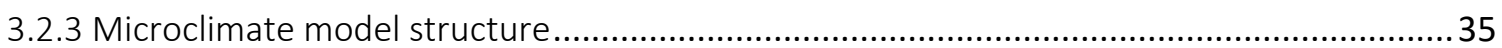




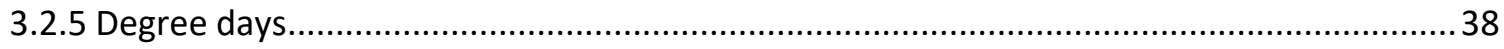

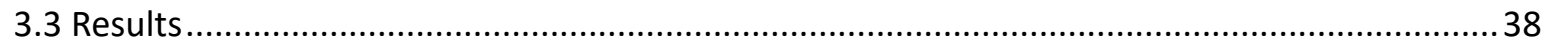

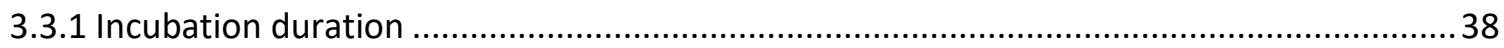

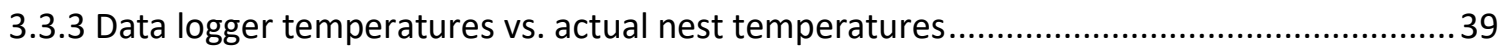

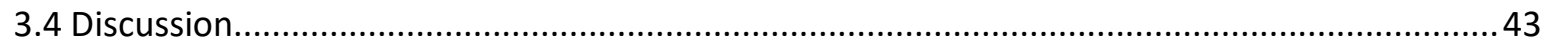

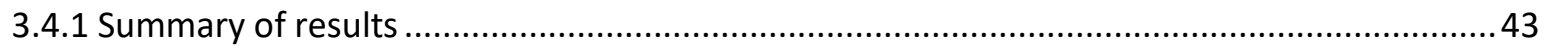

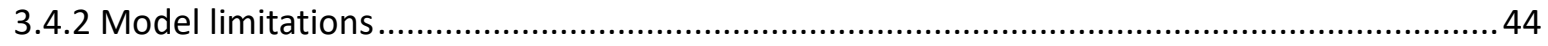

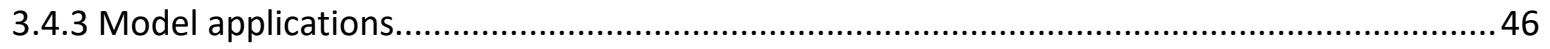

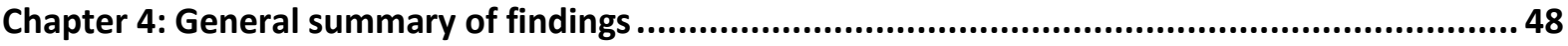

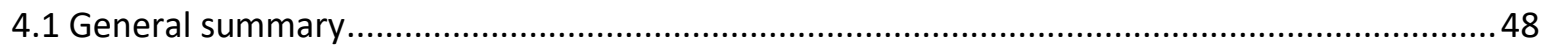

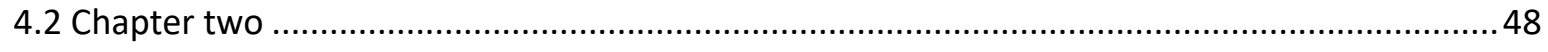

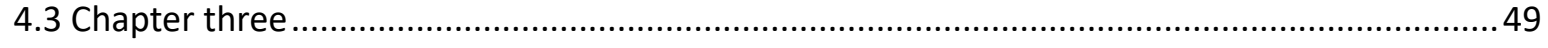

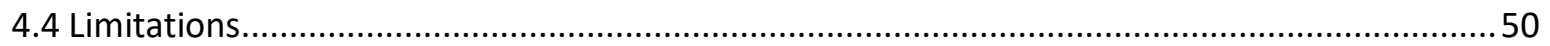

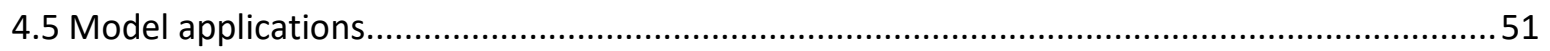

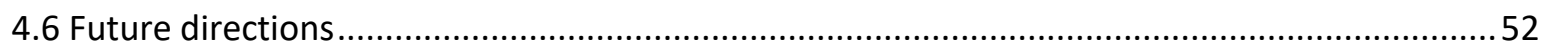

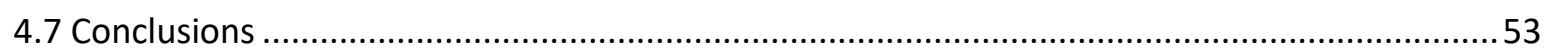

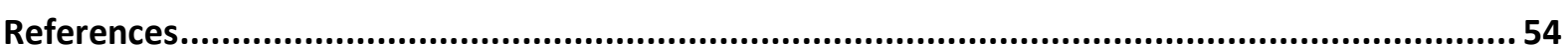

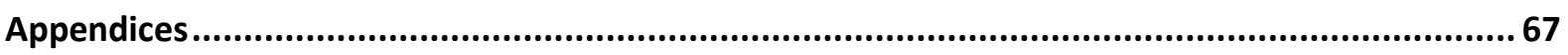




\section{Chapter 1: Modelling the microenvironment in the egg-laying skink, Oligosoma suteri}

\subsection{General Introduction}

Species are distributed heterogeneously across the world. Understanding what drives or constrains the distribution of a species is a long held goal in ecology and biogeography (Andrewartha and Birch 1954; Gaston 2000). Most sources of heterogeneity in environments vary with time and space (Angilletta 2009) and range from natural forces, such as weather patterns, to anthropogenic causes like habitat destruction. Variations in species distributions, life history and physiological traits are correlated with gradients of latitude, elevation, habitat and climate. These variations can affect population growth and reproductive potential. Organisms have to respond by modifying behaviour, moving to suitable habitat or extirpation or extinction can occur (Dobzhansky et la. 1968). An animal's ability to respond to new environments depends on the availability of the same or better conditions as its current environment (e.g. resources or temperature), and life history characteristics (Root et al. 2003).

Temperature is a key environmental variable, and many organisms are physiologically sensitive to temperature change. Ectotherms, for example, reptiles, are particularly affected by temperature as they require an external source of heat for metabolism and as a means of regulating body temperature (Deutsch et al. 2008). Temperature is a complex environmental variable. Although, mean temperatures may inform broad scale species distributions, variability in environmental temperature is a better predictor of limits to distributions (Clusella-Trullas et al. 2011). Understanding responses of reptiles to their thermal environments and limits on their tolerances is relevant to our interpretation of species distributions, conservation management strategies such as translocations, as well as modelling responses for example to climate change (ClusellaTrullas et al. 2011; Schulte et al. 2011).

Temperature effects, as a result of anthropogenic climate change, are predicted to include an increase in global mean surface temperature of $2-5^{\circ} \mathrm{C}$ by 2100 , in addition to increased frequency of droughts and floods, and rising sea levels (IPCC 2014). Climate change may enhance or reduce an organism's fitness depending on life-history traits, latitude and thermal tolerances. Reptiles have evolved a number of mechanisms, in part, to 
cope with variation in temperatures such as dormancy, behavioural thermoregulation and nest site selection. However, additional potential effects of climate change include reduced survival as a result of immunosuppression leading to an increased risk of acquiring diseases (Acevedo-Whitehouse and Duffus 2009), altered distributions of new and existing invasive species (Hellmann et al. 2008), and disruption to the timing of life-history events (e.g. plantpollinator relationships; Both et al. 2009), as well as changes in predator-prey relationships. Also, the rate at which climate is warming (IPCC 2013) may be too fast for many species to adapt (Visser 2008). Tropical species may have a higher risk from climate change effects because species currently live close to their optimal temperature (Deutsch et al. 2008). In contrast, temperate species may experience more extreme events (e.g. higher maximum temperatures) and warmer winters. Short-term exposure to extreme events can be as ecologically relevant as long-term exposure to sub-lethal temperatures (Terblanche et al. 2011). Animals in temperate climates at the margins of their distributional range can experience increased exposure to lethal temperatures and are therefore likely to demonstrate the greatest population fluctuations. There is a critical need to develop tools to predict species distributions and the potential impact of climate change, and in recent years, species distribution models (SDM) have been developed for conservation management. I developed a species distribution model for an egg laying reptile in New Zealand to understand factors affecting its current distribution and predict future distribution based on climate warming scenarios.

\subsection{Species distribution models}

Distributions and ecologies of reptiles closely reflect rainfall and temperature patterns (Bickford et al. 2010). Species distribution models (SDMs) are a method used to predict the distribution of species in geographic space based of the representation of known distribution correlated with climate data such as temperature, precipitation or soil type. The thermal dynamics of an environment can vary among habitats, with latitude and elevation. Within any environment, the microclimate is important to the quality of the habitat.

Differences in vegetation, topography, latitude and altitude can alter the microclimate over a relatively short distance (Ford et al. 2013). When climate becomes unsuitable, microrefugia can potentially buffer species against climate variability (Ashcroft et al. 2012). 
Observed presence of a species can be linked to environmental variables, also known as correlative SDMs, to offer statistical relationships. Correlative SDMs produce indices of habitat suitability based on presence of a species and the climate at the same location. The practical advantage of correlative models is they are easily applicable due to the relatively simple data requirements (Elith and Leathwick 2009). However, although correlative SDMs are useful for broader applications in the current climate, they have a tendency to underestimate or overestimate range sizes under future climates (Thuiller et al. 2004; Morin and Thuiller 2009).

An alternative to correlative models are mechanistic models which have developed as a powerful tool that can mechanistically link distributions or abundances to environmental data (e.g. Kearney et al. 2009a, 2014a). Mechanistic niche models are physiological models that describe the potential niche of a species based on functional traits of the organisms (Kearney and Porter 2009). These models are based on first principles that follow the concepts of biophysical ecology and the conservation laws of thermodynamics (Kearney et al. 2010). Thus, the theoretical basis of mechanistic niche models is grounded in physics and an understanding of the underlying processes that are highly general and transferable, allowing predictions to novel climates and in non-equilibrium situations (Pearson and Dawson 2003; Kearney et al. 2009a). Mechanistic SDMs require more data on species biology and physiological limitations which can make them more complex and more computationally exhaustive than correlative models (Kearney et al. 2014a, but see Dormann et al. 2012). In recent years, advances in this area have improved rapidly with increased computing power and advances in the use of geographical information systems (GIS) to map species distributions at finer scales. Although, mechanistic models require more physiological data than compared to correlative SDMs, mechanistic SDMs results are independent of climate because model parameters are not inferred from current distributions (Hijmans and Graham 2006). Mechanistic models are considered more robust for understanding the relationship between climate and the distributions of species (Davis et al. 1998; Guisan \& Zimmermann, 2000; Dormann 2007). Potentially, validation of mechanistic models is more straight forward than that of correlative models because observed distribution data, for example, are not needed for model calibration and hence provide truly independent test data (Morin and Thuiller 2009). 
Model accuracy as they relate to reality is determined by a number of factors including the complexity of the models used, the quality of the available environmental data layers, the amount and availability of reliable species distribution data as model input, and the influence of various abiotic factors such as barriers to dispersal, geologic history, and biotic interactions. Models of ecological responses to climate change that assume environmental variables measured at large scales are a representation of the smaller-scale biological processes may miss underlying drivers of patterns of distribution if the scales used are larger than the area occupied by the species (Dowd et al. 2015; Miller et al. 2004; Potter et al. 2013). For example, the use of monthly weather data excludes daily environmental variation which may be central to accurately modelling important events that lead to embryo mortality or reproductive failure (Helmuth et al. 2005). The limited types of data that can be collected at wider scales can produce errors in model predictions because species-specific requirements such as nesting habitat are not easily identified (Miller et al. 2004). It is important to note that mechanistic niche models only map the fundamental niche of the species. They aim to identify areas with suitable environmental conditions that can potentially support a viable population independent of current distributions (Elith et al. 2010; Kearney et al. 2010), but they do not inform us which areas are actually occupied (Pearson 2007).

Another fundamental challenge facing ecologists is developing models to predict events that are biologically meaningful and reflective of underlying processes, especially when linear responses are rare, and exponential or threshold effects are important. For example, embryonic development in reptiles is affected by non-linear responses in the degree and length of exposure to temperatures and includes development thresholds for survival, and sex for some species (Georges et al. 2005). To improve the potential for application of my mechanistic models, I translated outputs using degree-day models, in particular for the embryonic growth stage.

\subsection{Degree-days and degree-day model}

A degree day is defined as the total amount of heat required for an organism to develop from one point in its lifecycle to another between an upper and lower temperature threshold (Baskerville and Emin 1968; Wilson and Barnett 1983). Degree days establish a baseline temperature and the required amount of "thermal units" above that temperature 
needed to successfully complete development (Birchard 2004; Kikillus et al. 2010). One way in which degree days can be estimated is by using a Degree Day Model. A degree day model assumes that, for each $1{ }^{\circ} \mathrm{C}$ over a baseline temperature a degree day is accumulated, the sum of which gives the number of available degree days. For example, if the daily temperature over 5 days is $5{ }^{\circ} \mathrm{C}$ above the baseline temperature, this equates to 25 degree days. Degree-day models have been used to predict distributions of species, growth, and the timing of events including pest outbreaks (e.g. Hartley and Lester 2003; Baek et al. 2008; Wilson et al. 1983; Sykes et al. 1996; van Hooidonk and Huber 2009). For oviparous reptiles, environmental conditions within the nest are vital for successful embryonic development. Because reptile egg incubation at constant temperatures in the wild is rare (Birchard 2004), the application of a microclimate model, that includes degree-days for reptiles, is a valuable method to identify suitable habitats for species populations by understanding their ecological requirements (Martínez-Freiría et al. 2008) and for making predictions about potential distributions, particularly in highly thermally variable climates and with climate change (Pearson and Dawson 2003). If conditions alter within the nesting environment it can have significant consequences for embryo development and survival. Warmer incubation temperatures typically result in a shorter development and incubation duration time than cooler incubation temperatures (Ackerman and Lott 2004; Booth et al. 2004). A degree-day model will help establish a developmental zero temperature and a measure of the physiological time above this temperature, measured in degree-days, that are required to successfully complete development, and therefore for application to understanding suitable conditions for embryonic survival.

\subsection{The egg-laying skink (Oligosoma suteri) life-history}

I developed distribution models for the Egg-laying skink (Oligosoma suteri), a medium sized endemic New Zealand reptile. They are predominantly nocturnal but may sun bask, emerging after dark to feed on amphipods and invertebrates in seaweed mats in the intertidal zone (Whitaker 1968). Snout-vent length (SVL) of up $108 \mathrm{~mm}$ is recorded for adults (Gill and Whitaker 1996), but this can vary with location (Towns 1975). O. suteri populations are found in high densities $\left(13 / \mathrm{m}^{2}\right)$ entirely in boulder and stone beaches or rocky platforms in the splash zone (Gill and Whitaker 1996). Geographic distribution is mainly restricted to offshore islands free from predators and current distribution extends from the Three Kings 
Island group $\left(-34^{\circ} 10^{\prime} 0.012 \mathrm{~N}, 172^{\circ} 4^{\prime} 59.988 \mathrm{E}\right)$ to the Alderman Islands $\left(-36^{\circ} 58^{\prime} 0.012 \mathrm{~N}\right.$, $176^{\circ} 4^{\prime} 59.988 \mathrm{E}$ ). Historically, O. suteri are believed to have a more relictual distribution throughout the northern North Island mainland (Towns et al. 2002), however, loss of mainland populations is likely a result of introduced mammalian predators.

O. suteri are capable of over water-dispersal (Whitaker 1968; Gill and Whitaker 1996; Hare et al. 2008b), suggesting that dispersal ability does not limit their distribution. The lack of phylogenetic structure in $O$. suteri populations, together with its restricted latitudinal distribution (below $-36^{\circ} \mathrm{S}$ ), has led to predictions that the distributional limit results from ecological constraints caused by the detrimental effects of cold temperatures on embryos and subsequent hatchlings (Hare et al. 2004, Hare et al. 2008b). Towns et al. (2003) found a strong relationship between the frequency of $O$. suteri occurrence and latitude, and concluded that this was a reflection of climatic constraints on distribution. Additionally, their geographic range falls within the climatic region of 'Northern New Zealand' (Garnier 1958), the only region where mean annual air temperature is above $13^{\circ} \mathrm{C}$ (National Institute of Water and Atmospheric Research, [NIWA] 2016).

Mating occurs from November with females laying 1-3 eggs from late December to mid-January, and hatching three months later. Eggs are laid under large boulders (200-300 $\mathrm{mm}$ in diameter) up to $4 \mathrm{~m}$ from the high tide (Whitaker, 1968), and skinks may also be found underneath the boulders near eggs. Data are based on only a few nests that have been located and documented (Whitaker 1968). Nesting is communal with an average of 5.6 eggs per nest ( $1-11$ range) buried in small chambers up to $20 \mathrm{~mm}$ deep in the gravel/sand substrate directly beneath the boulders (Whitaker 1968). Nest site choice may be restricted for $O$. suteri by suitable habitat (e.g. boulder size and substrate) as they are not known to nest in other habitat types. In laboratory settings, females have been shown to favour warm nest sites over cool sites (Hare et al. 2002). Average incubation duration decreases with increasing temperature $\left(137.9\right.$ days at $18^{\circ} \mathrm{C}, 72.4$ days $22^{\circ} \mathrm{C}$ and 51.5 days at $26^{\circ} \mathrm{C}$; Hare et al. 2002). Hatching success and embryo survival is reduced in laboratory incubated eggs held at cool-constant temperatures of $18^{\circ} \mathrm{C}$ compared to $22^{\circ} \mathrm{C}$ and $26^{\circ} \mathrm{C}$ (Hare et al. 2002). Effects of climate change on $O$. suteri are unclear. Positive effects could include an increased distribution due to current proposed lethal lower thermal limits to their distribution. However, increased sea level might cause a decline in habitat. 


\subsection{Study objectives and thesis structure}

I predict the distributional limits and climate changes effects at different spatial scales on nesting phenology and success in Oligosoma suteri, an oviparous, nocturnal skink, endemic to New Zealand. Specifically, I modelled soil temperatures as one of the conditions required for successful incubation, focusing on incubation duration estimated using degreedays. My two data chapters are prepared as self-contained manuscripts drafted for publication. In chapter two, I predicted potential distributional limits for $O$. suteri based on constraints to successful embryonic development for the current climate and climate change scenarios, focussing particularly on the timing of oviposition and incubation duration. In chapter three, I developed a high-resolution model to map incubation duration for an extant island population. I predicted likely successful nesting sites and ground-tested model data with field data. A summary of general findings, model applications, and areas for further research are provided in chapter four. My thesis will inform management decisions relating to conservation actions for $O$. suteri as well as a starting point for modelling effects of climate change on other species. 


\section{Chapter 2: Modelled soil temperatures indicates wider potential distribution with climate warming for an oviparous lizard}

\subsection{Introduction}

Climate change is progressively becoming the greatest threat to terrestrial biodiversity and will possibly surpass habitat loss as the main driver of biodiversity change (Leadley 2010). Climate change-mediated reductions in habitat suitability drive changes in species distribution (Walther et al. 2002; Parmesan and Yohe 2003; Thomas 2004; Chen et al. 2011; Böhm et al. 2016), as organisms track optimal habitats or adapt to changing conditions in situ by modifying behaviour or physiology (Thomas et al. 2004; Bellard et al. 2012). It is therefore critical to identify the limiting factors that determine geographical boundaries and predict how they may shift as a result of global warming, particularly for rare and endangered species, species with restricted distributions and/or limited dispersal ability.

The physical environment (e.g. soil, climate, physical barriers to dispersal) and biological interactions (e.g. predation, competition) determine geographical boundaries, but the potential area a species can occupy is defined by physiological limitations, which are fundamental constraints on distribution (Hutchinson 1957; Kearney and Porter 2009). While it is unlikely that a single biotic or abiotic factor will capture all the factors that set distributional limits (Gaston 2009; Sexton et al. 2009; Cahill et al. 2014), temperature is identified as the main climatic factor determining species distribution (Jeffree and Jeffree 1994; Bale et al. 2002; Gaston 2003). Understanding how climatic constraints on an organism's life stages can set species distributional boundaries is central to improving predictions of the impacts of climate change.

\subsubsection{The effect of temperature on reptile distribution}

Temperature is considered an important abiotic factor that influences the distribution of reptiles (Schulte et al. 2011). In temperate zones, temperatures can vary annually, seasonally and daily compared to more stable temperatures in the tropics. Variation in temperatures at higher latitudes during spring and summer months, when suitable temperature and moisture regimes for reptile activity are available, creates a 
narrow period of time for many species to undertake critical life-history activities (e.g. reproduction, foraging and mating). Extreme temperatures that exceed or fall below thermal tolerance levels generally associated with higher latitudes, can have significant negative fitness consequences (Deutsch et al. 2008; Sinervo et al. 2010; Buckley and Kingsolver 2012; Kingsolver et al. 2013). For example, at cooler temperatures, embryonic development rates decrease, the incidence of embryonic abnormalities increase, reducing hatching success rates, and influencing potential recruitment and therefore population survival. Cooler incubation temperatures have been linked to morphological deformities (Hare et al. 2002; Shine 2004) and impaired behaviour (e.g. slower locomotion) in hatchlings (Elphick and Shine 1998; Brana et al. 2000). However, species may alter behaviour to avoid critical thresholds that exceed a thermal optimum by moving to shelter or cooler temperatures, by varying activity times and changing microhabitats (Huey 1982; Van Damme et al. 1987), hence species-specific upper critical temperatures can fail to predict biogeography (Sunday et al. 2012).

In oviparous reptiles, the embryonic stage can determine the boundaries for geographic distributions via incubation temperature (Shine 1987; Kearney and Porter 2004; Parker and Andrews 2007). Cold temperatures can prevent oviparous reptile species from inhabiting higher latitudes and altitudes, because the incubation period required to complete development is longer than the period of time during which nutrients (i.e., yolk reserves) are available (Porter et al. 2002; Shine et al. 2004; Parker and Andrews 2007). However, incubation temperatures vary among species as some species can survive at temperatures that would be detrimental to others. If cooler incubation temperatures prevent oviparous species from inhabiting colder regions, then the distributional limits of oviparous reptiles should be predictable from embryonic thermal tolerances and developmental rates (Parker and Andrews 2007).

Temperatures during incubation can fluctuate with environmental conditions. Therefore, using constant incubation temperatures as a measure of incubation temperatures is not representative of conditions in the wild. An alternative is to establish a baseline temperature and the required amount of "thermal units" above that temperature needed to successfully complete development (Birchard 2004; Kikillus et al. 2010). A degreeday is defined as the total amount of heat required for an organism to develop from one 
point in its lifecycle to another between an upper and lower temperature threshold (Baskerville and Emin 1969; Wilson and Barnett 1983). Degree-days are a commonly used measure to predict thermal accumulation primarily in areas such as viticulture (e.g. Tait 2008). Degree-day models have been used in New Zealand to predict the spread of invasive species such as Argentine ants (Linepithema humile; Hartley and Lester 2003); to determine if environmental conditions are sufficient for successful completion of incubation of invasive red-eared slider turtles (Chelodina longicollis; Kikillus et al. 2010); and in Australia to predict the Northern distribution of the Eastern fence lizard (Sceloporus undulatus; Parker and Andrews 2007). Degree-day models can also link emergence phenology and distributional limits for predicting species responses to climate change (Clayton et al. 2015).

\subsubsection{Study aims and research questions}

I investigated the distributional limits of a nocturnal egg laying skink, Oligosoma suteri, using degree-days to evaluate likely success of embryonic development along New Zealand's coastline, and effects of climate warming on oviposition timing and incubation duration. I expected that distributional limits would extend further than their current distribution and that climate warming would affect nesting phenology in terms of incubation duration and oviposition timing. 


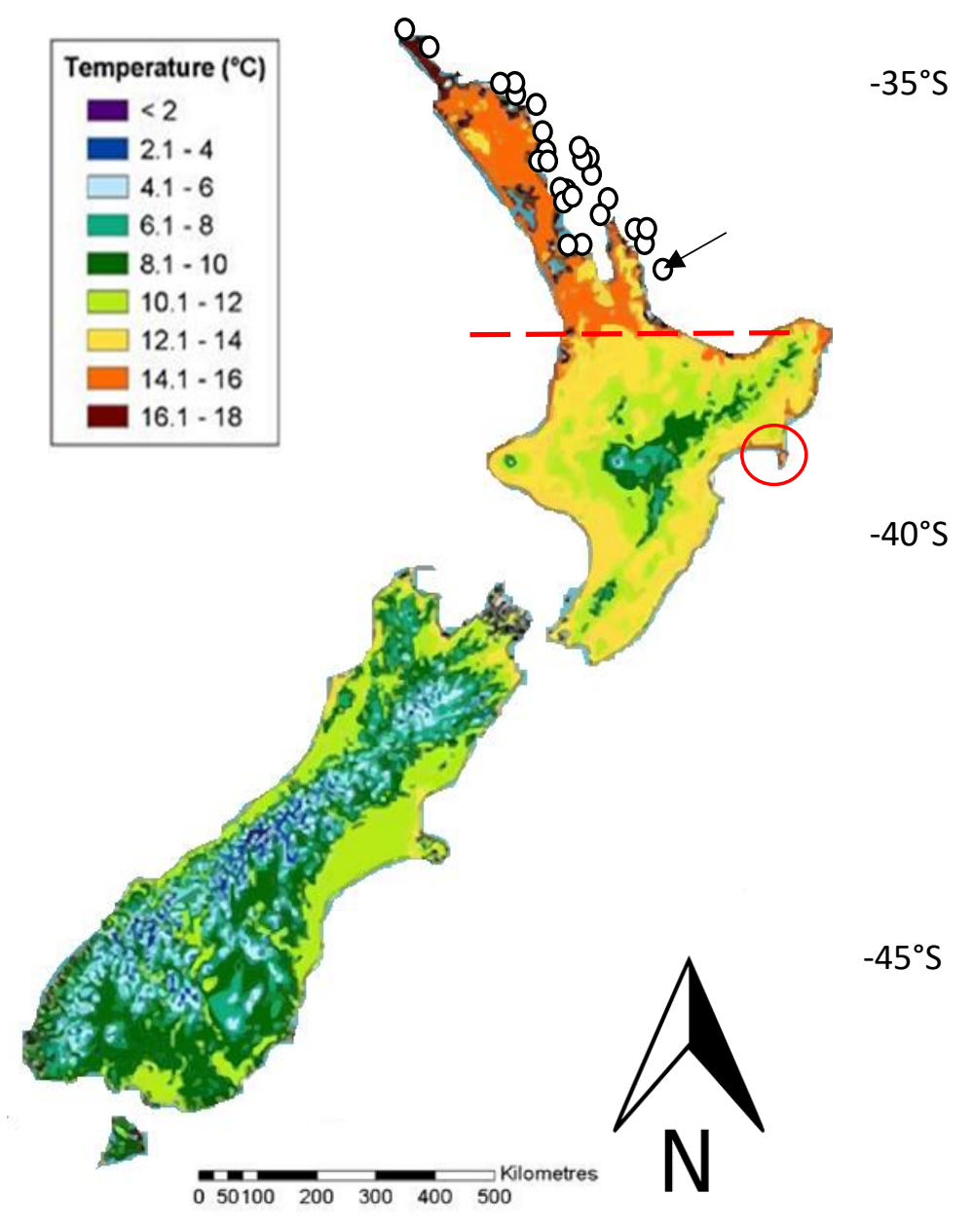

Figure 1. Current distribution of $O$. suteri (white circles; Towns et al. 2002) and mean annual air temperature for New Zealand from 1971 - 2000 (https://www.niwa.co.nz/educationand-training/schools/resources/climate/overview). Southernmost known distribution is the Alderman islands, $-36^{\circ} 58^{\prime} \mathrm{S} 176^{\circ} 05^{\prime} \mathrm{E}$ (black arrow). In 'northern' New Zealand (area above the red dash line) annual mean temperature ranges from $12.1^{\circ} \mathrm{C}$ to $18^{\circ} \mathrm{C}$. The mean air temperature in some locations (below the red dash line) also reach temperatures similar of 'northern' New Zealand (e.g. Gisborne [-3949'S 176 $\left.91^{\prime} \mathrm{E}\right]$; red circle).

\subsection{Methods}

\subsubsection{Study system}

O. suteri are thought to have been previously widespread across the north-eastern portion of the North Island of New Zealand (Towns et al. 2002), yet their current distribution is mainly restricted to offshore islands, primarily as a result of predation by introduced mammals. O. suteri are capable of over water-dispersal (Whitaker 1968; Gill and Whitaker 1996; Hare et al. 2008b), suggesting that dispersal ability does not limit their distribution. 
The lack of phylogenetic structure in $O$. suteri, together with its restricted latitudinal distribution (Fig. $1,-36^{\circ} \mathrm{S}$ to $-35^{\circ} \mathrm{S}$ ), has led to predictions that the distributional limit results from ecological constraints caused by the detrimental effects of cold temperatures on embryos and subsequent hatchlings (Hare et al. 2004, Hare et al. 2008b). Towns et al. (2003) found a strong relationship between the frequency of $O$. suteri occurrence and latitude, and concluded that this was a reflection of climatic constraints on distribution. Additionally, their geographic range falls within the climatic region of 'Northern New Zealand' (Garnier 1958), the only region where mean annual air temperature is above $13^{\circ} \mathrm{C}$ (National Institute of Water and Atmospheric Research, [NIWA] 2016). In O. suteri, nesting takes place over austral summer (Whitaker 1968; Parrish and Gill 2003). Nests are found in sand substrate beneath boulders, above the high-tide line, but below the bush-line (Whitaker 1968; Towns 1975b; Parrish and Gill 2003). O. suteri incubation duration can take up to three months (Whitaker 1968; Towns 1975a). In laboratory settings, females have been shown to favour warm nest sites over cool sites (Hare et al. 2002). Incubation duration is dependent on the incubation temperature as average incubation duration decreases with increasing temperature ( 137.9 days at $18^{\circ} \mathrm{C}, 72.4$ days $22^{\circ} \mathrm{C}$ and 51.5 days at $26^{\circ} \mathrm{C}$; Hare et al. 2002). Hatching success and embryo survival are reduced in laboratory incubated eggs held at coolconstant temperatures of $18^{\circ} \mathrm{C}$ compared to $22^{\circ} \mathrm{C}$ and $26^{\circ} \mathrm{C}$ (Hare et al. 2002).

\subsubsection{Degree-day model}

I used incubation duration and incubation temperature data for $O$. suteri (Hare et al. 2002 ) to calculate the minimum number of degree-days (dd) and minimum temperature threshold required for complete development.

Incubation duration in days and incubation temperatures were used in the linearised Law of Total Effective Temperature (Ikemoto and Takai 2000):

$$
D T=k+t_{0} D
$$

equation 1

where $T$ is temperature, $D$ is incubation duration, $t_{0}$ is a baseline temperature of theoretical zero development and $k$ is a thermal constant measured in units of degree-days (Ikemoto and Takai 2000). The lower temperature threshold, or thermal constant, and number of degree-days required for $100 \%$ development were estimated from the reciprocals of the fitted regression line via a reduced major axis regression of DT vs. D, with the values of $k$ and 
to estimated from the intercept and slope (Fig. 2). During incubation, 22 eggs were shifted from $18^{\circ} \mathrm{C}$ to $22^{\circ} \mathrm{C}$. To account for the shift in temperature and to calculate a constant temperature equivalent $(\mathrm{T})$ applied in equation 1, the following equation was used:

$$
D x T=(\text { days at temperature } 1 \times \text { temperature } 1)+
$$

(days at temperature $2 x$ temperature 2 )

equation 2

Potential distribution is predicted by excluding regions that do not reach the minimum development threshold (Kearney and Porter 2009) within a specific timeframe.

\subsubsection{Combining modelled soil temperature with the degree-day model}

To model soil temperatures where $O$. suteri incubation could potentially succeed, I used a modified version of the microclimate model of the 'NicheMapper' package, NicheMapR, which computes vertical profiles of substrate temperatures based on a onedimensional partial differential equation using above and below-ground boundary conditions (Porter et al. 1973, Kearney et al. 2014a). The inputs required to run the model consists of several environmental parameters (e.g. maximum and minimum daily values of air temperature, wind speed, relative humidity and cloud cover, soil properties) as well as the roughness height, slope and aspect (see Kearney et al. 2014a). For these simulations, I assumed flat ground using a value of 0 for all terrain input (elevation, slope, aspect, horizon angles) due to the coarse spatial resolution layer $(\sim 15 \mathrm{~km})$ and because $O$. suteri are known only to nest in relatively flat areas, adjacent to shorelines. Latitudes and longitudes were extracted from the microclim dataset (15 km horizontal resolution) (Kearney et al. 2014a), and the study extent was restricted to a single pixel width around the coast (i.e., within 15 $\mathrm{km}$ of the shoreline), generating 346 unique sites. Eggs are most commonly found within the sand substrate beneath large boulders and rocks of approximately $100 \mathrm{~mm}-300 \mathrm{~mm}$ in diameter (Whitaker 1968; Stenhouse unpub. data). Therefore, substrate temperatures were generated for three depths $(25,100,300 \mathrm{~mm})$ for two substrate types (rock and sand). Completion of embryonic development in O. suteri generally takes 3 to 5 months (Towns 1975a; Hare et al. 2002) and the earliest oviposition date reported was 21 December (Hare et al. 2002). Therefore, hourly soil temperatures were generated, conservatively, for 6 
months to each of eight proposed oviposition dates with an initial oviposition date of 1 December.

To evaluate site suitability, hourly soil temperatures output from the microclimate model were entered into the degree-day model for $O$. suteri embryos:

$$
d d=\Sigma\left(M_{s t}-t_{0}\right) * 0.042
$$

equation 3

where $M_{s t}$ is the modelled soil temperature, $t_{0}$ is the minimum development threshold temperature from equation 1 and 0.042 is the hourly fraction.

\subsubsection{Climate change scenarios}

To understand how climate warming may affect incubation duration and oviposition timing I incorporated five of the eight proposed mean oviposition dates (1 January, 15 January, 30 January, 14 February, 1 March) for the current climate and two climate change scenarios. The magnitude of change for both climate change projections are specific to New Zealand and based on an all-scenario average with an increase of $0.9^{\circ} \mathrm{C}$ by 2040 (warming scenario a) and $2.1{ }^{\circ} \mathrm{C}$ (warming scenario b) by 2090 (Wratt et al. 2004). These estimates are downscaled and averaged from 12 general circulation models, following the A1B emission scenario (IPCC 2007; Wratt et al. 2004; Ministry for the Environment 2016). The all-scenario average was used because extrapolating one scenario as a more likely outcome than another at a low spatial resolution $(15 \mathrm{~km}$ ) is difficult (Wratt et al. 2004). The average temperature increases were incorporated into equation 4.

$$
\begin{gathered}
\text { scenario } a \\
d d=\Sigma\left(\left(M_{s t}+S_{1}\right)-t_{0}\right) * 0.042 \\
\text { scenario } b \\
d d=\Sigma\left(\left(M_{s t}+S_{2}\right)-t_{0}\right) * 0.042
\end{gathered}
$$

equation 4

where $S_{1}=$ an increase of $+0.9{ }^{\circ} \mathrm{C}$ by 2040 for scenario a and $S_{2}=$ an increase of $+2.1{ }^{\circ} \mathrm{C}$ by 2090 in scenario b. The climate change projections for mean air temperature are assumed to represent soil temperature increases. Analyses were conducted and graphs created in $\mathrm{R}$ using NicheMapR and ggplot2 packages respectively. Maps were created using $\operatorname{ArcMap}^{\mathrm{TM}} \mathrm{v}$ 
10.1 (Environmental Systems Research Institute [Esri] ArcGIS: Redlands, CA, USA, 2012). The microclimate model has a high degree of accuracy $\left(1-2^{\circ} \mathrm{C}\right)$ established for predicted hourly soil temperatures (Kearney et al. 2014a; Carter et al. 2015). Results throughout are reported with \pm 2 standard error (SE).

\subsection{Results}

\subsubsection{Degree-days as a factor in geographic distribution}

Regression analysis estimated that the minimum number of days required for $100 \%$ development is $616 \pm 23.06$ degree-days above a developmental threshold temperature of $13.8 \pm 0.27^{\circ} \mathrm{C}$ are required for complete development of $O$. suteri embryos (fig. 2). From 1 December to 15 January oviposition dates, the number of sites where the minimum temperature threshold requirement was met for both substrate types and all three depths extended as far as $\sim 45^{\circ} \mathrm{S}$, which is more southerly (cooler) than the current distribution. The number of suitable sites decreased from 30 January, with no sites predicted to reach the minimum degree-days required within the six-month timeframe given an oviposition date of 15 March (Fig. 3). There was no variation between sand and rock substrates or with depth in predicted number of sites, except for oviposition dates 30 January and 1 March, where the sand substrate had a higher number of sites that reached 616 degree-days within six months at $100 \mathrm{~mm}$ and $300 \mathrm{~mm}$ depths, compared with the rock substrate (Fig. 3).

Data for $O$. suteri eggs indicate that incubation at temperatures $\leq 18^{\circ} \mathrm{C}$ increases the number of days to hatch from $\sim 75$ days at $\left(22^{\circ} \mathrm{C}\right)$ to $129-140+($ Fig. 2$)$, which has fitness consequences for hatchlings and higher embryo mortality rates (Hare et al. 2002). Additionally, oviposition dates from both field trials (Towns et al. 1975a) and the laboratory study by Hare et al. (2002), suggests oviposition begins in late December. Therefore, I applied a more conservative approach to the distribution maps by modifying the predicted distribution maps (Fig. 3), where oviposition dates prior to 1 January and sites that exceeded 120 days to hatch were excluded (Fig. 4). I also only included 100 and $300 \mathrm{~mm}$ depths because no nests have been found at $25 \mathrm{~mm}$. Using these parameters, successful embryonic development is predicted for only 4 oviposition dates; 1, 15, 30 January and 14 February (Fig. 4). Number of sites for rock substrate decreases for 30 January and 14 February compared to sand substrate from Fig 3. 


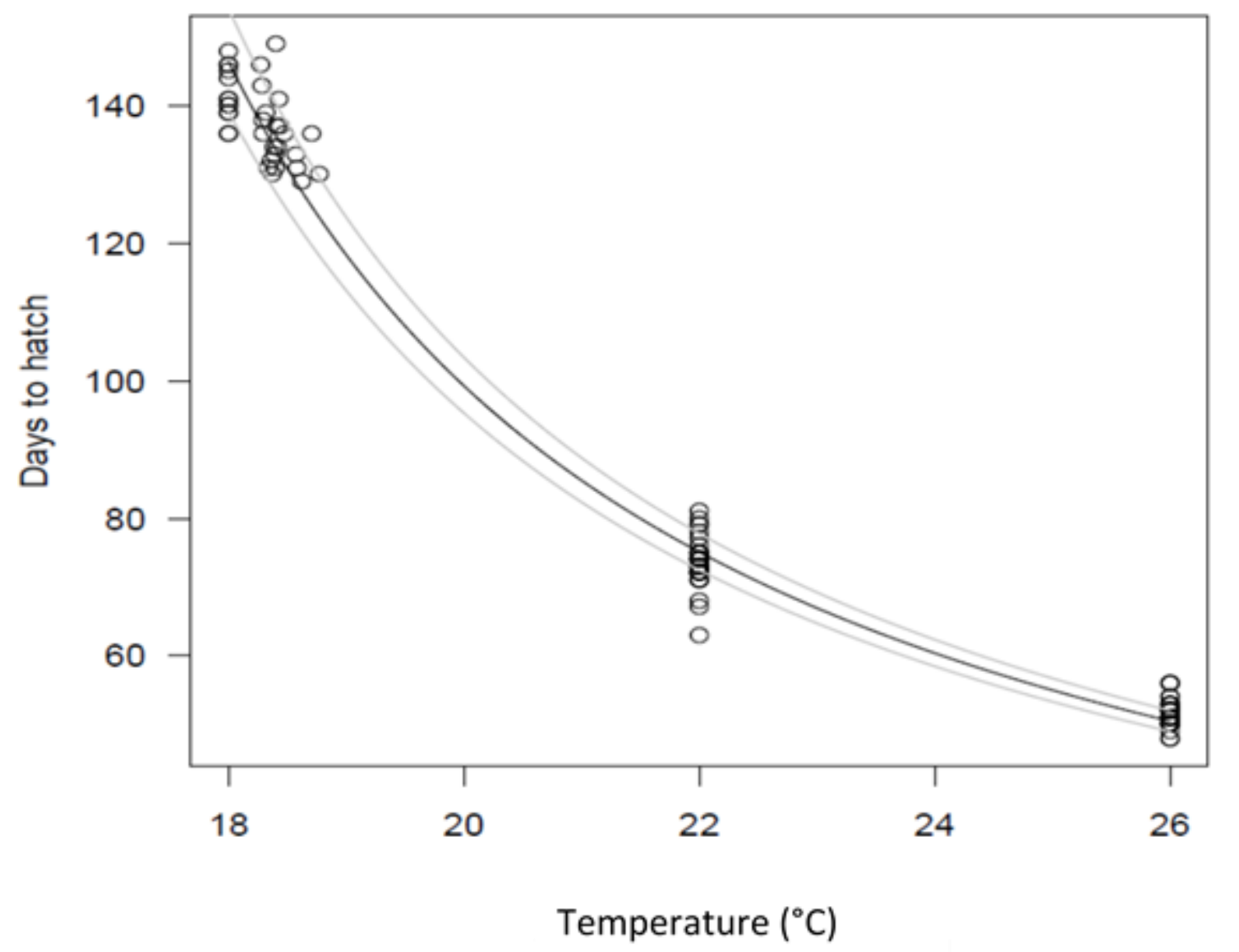

Figure 2. Degree-day relationship between temperature and development time in 0 . suteri. Mean (black line) and +/- 95\% confidence interval (grey line) derived from major axis regression (Legendre 2014) of DxT vs D. For model-fitting, temperature is assumed to be a constant, but for those hatchlings switched between two different incubation temperature regimes, DxT was the sum of the two temperatures (eqn. 2).

\subsubsection{Effects of climate change on oviposition date and incubation duration}

Median incubation duration was higher for the rock substrate than the sand substrate for all three depths at all oviposition dates across the three modelled scenarios (Fig. 5 A-F). Oviposition after 1 March was not predicted to reach the degree-day threshold required for complete development within the 6-month time limit (i.e. within 180 days) for sand and rock substrates under a current climate model. In both climate change scenarios, later oviposition dates resulted in increased incubation duration (Fig. 5). However, under both climate change scenarios for rock substrate, the successful predicted oviposition period extends until the 15 March compared to sand substrate. 


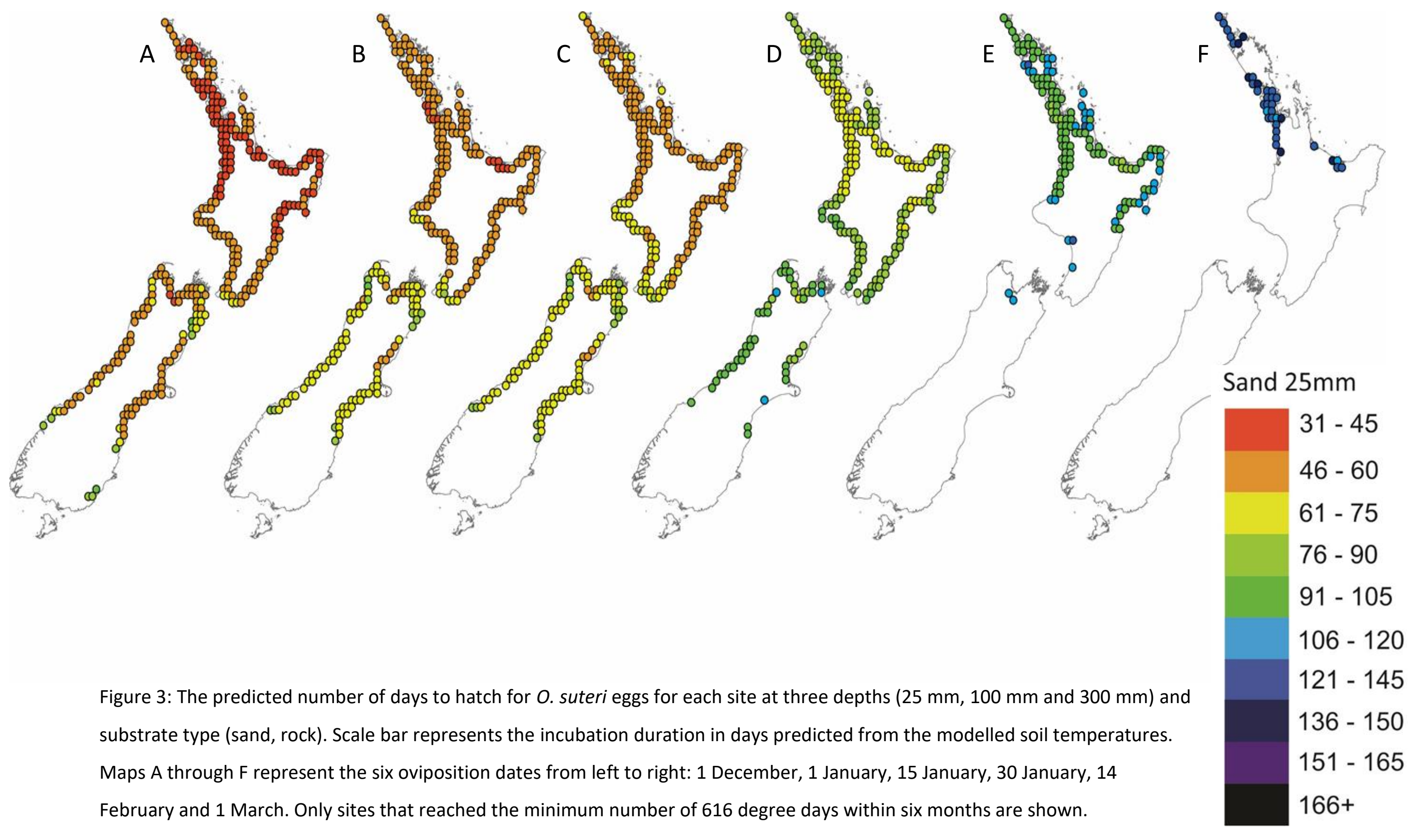




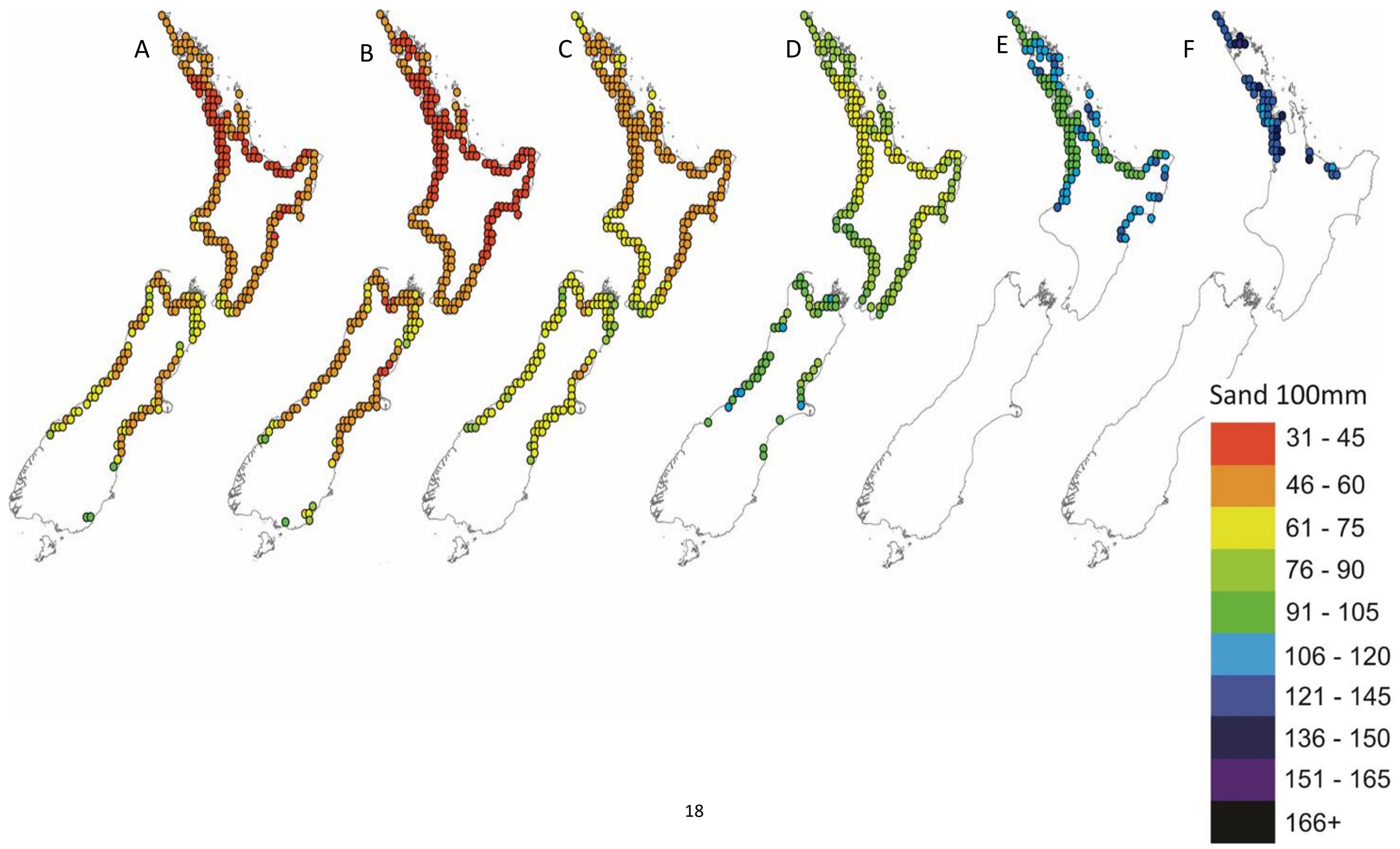




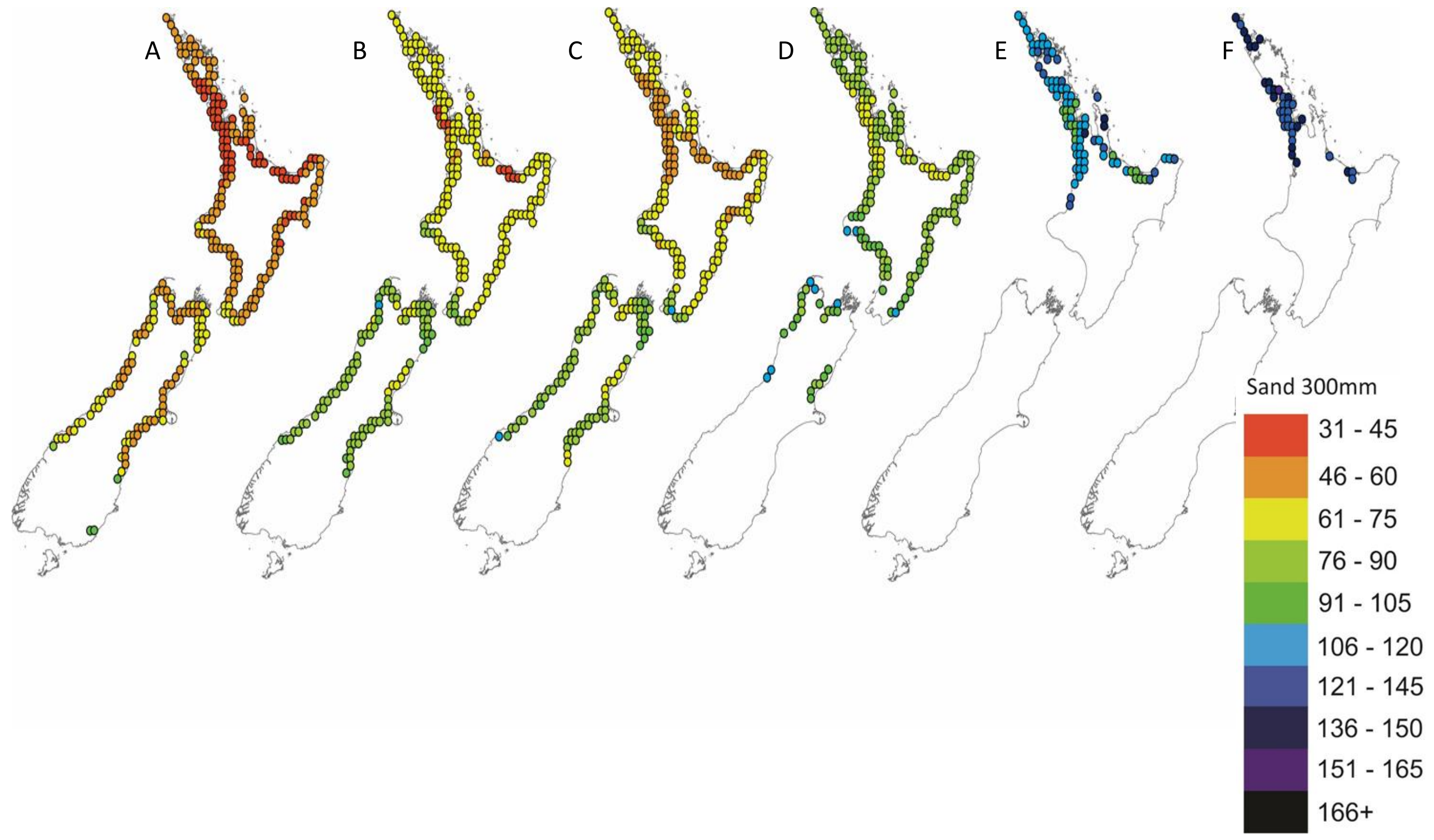




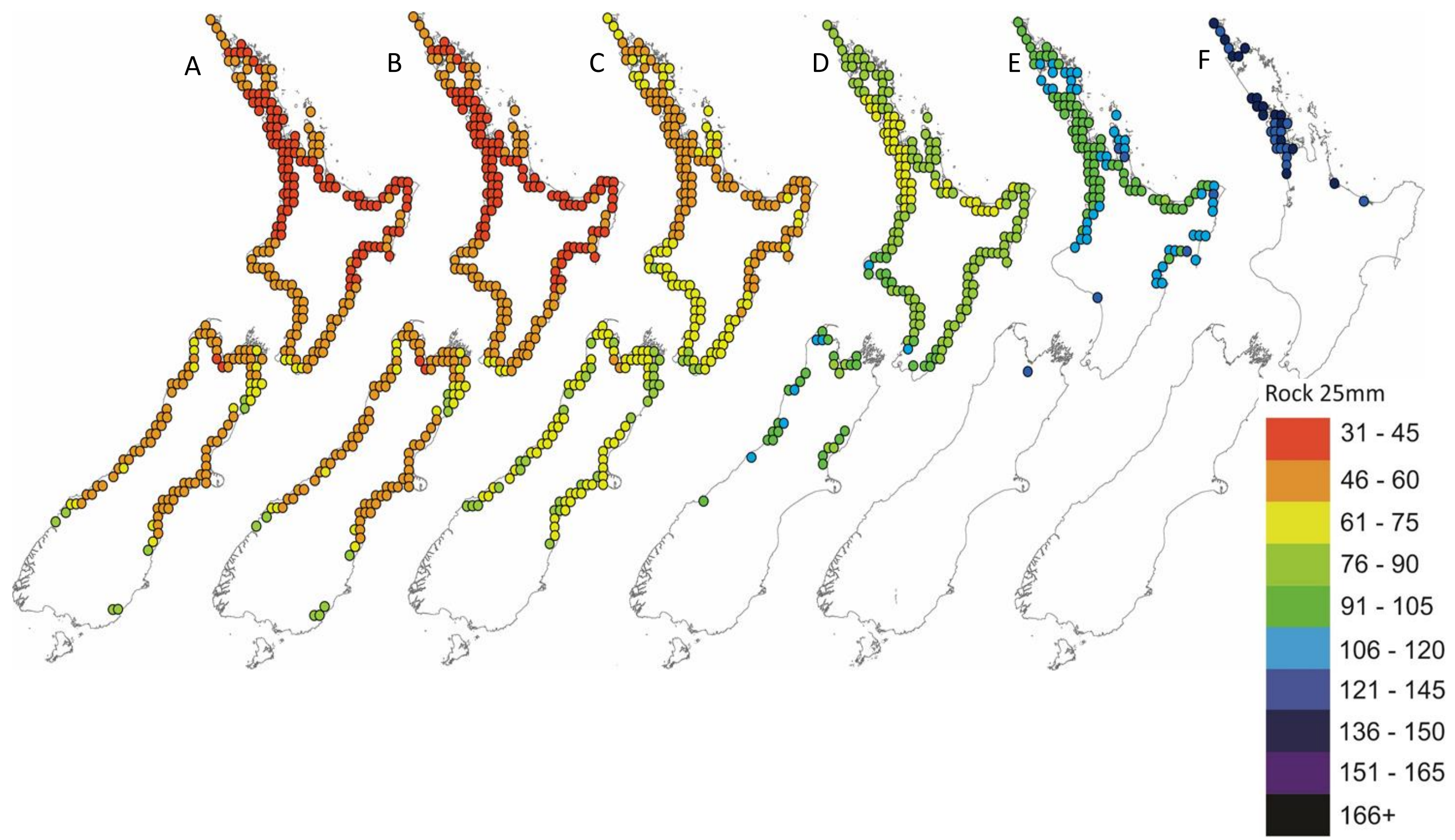




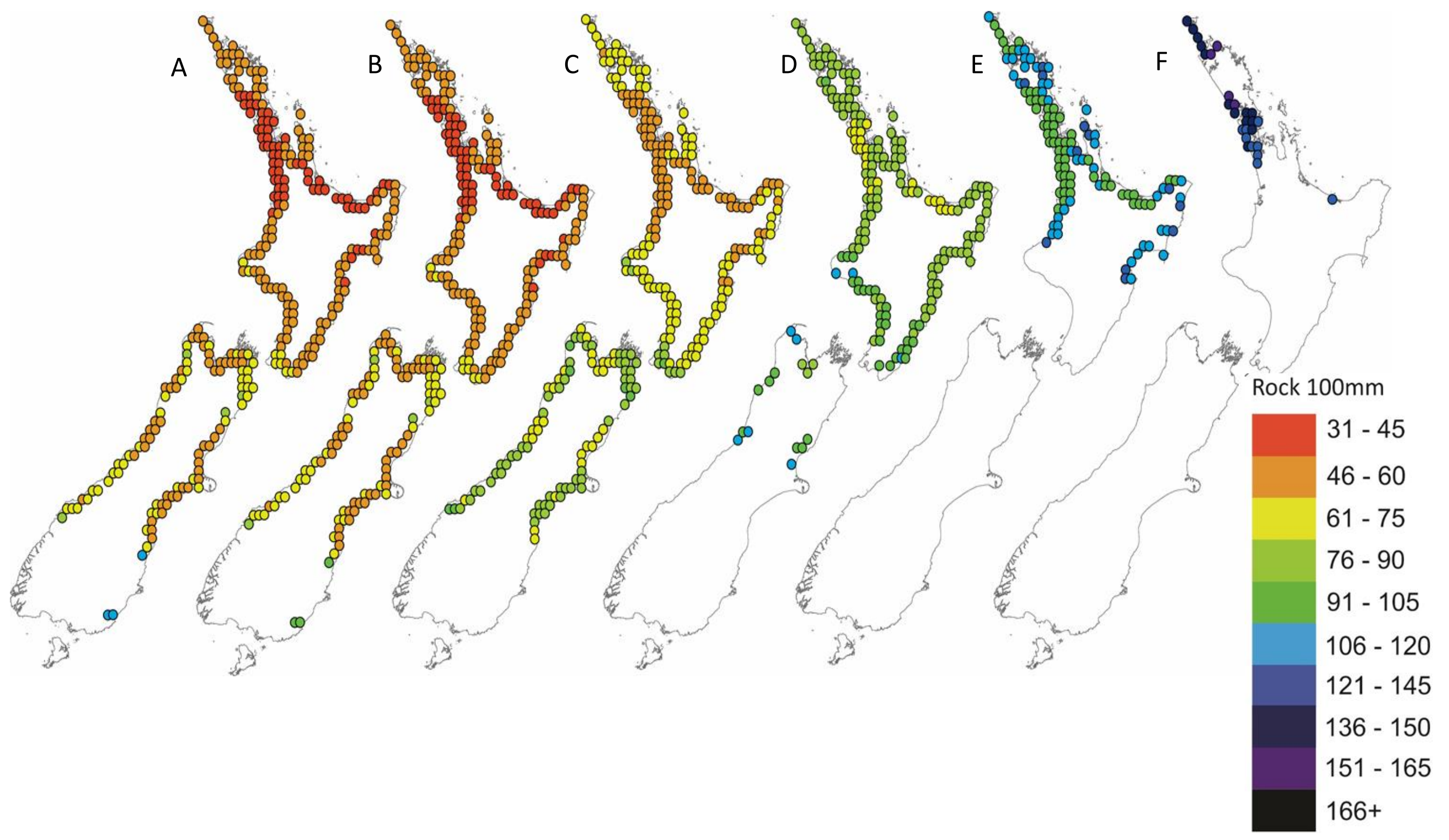




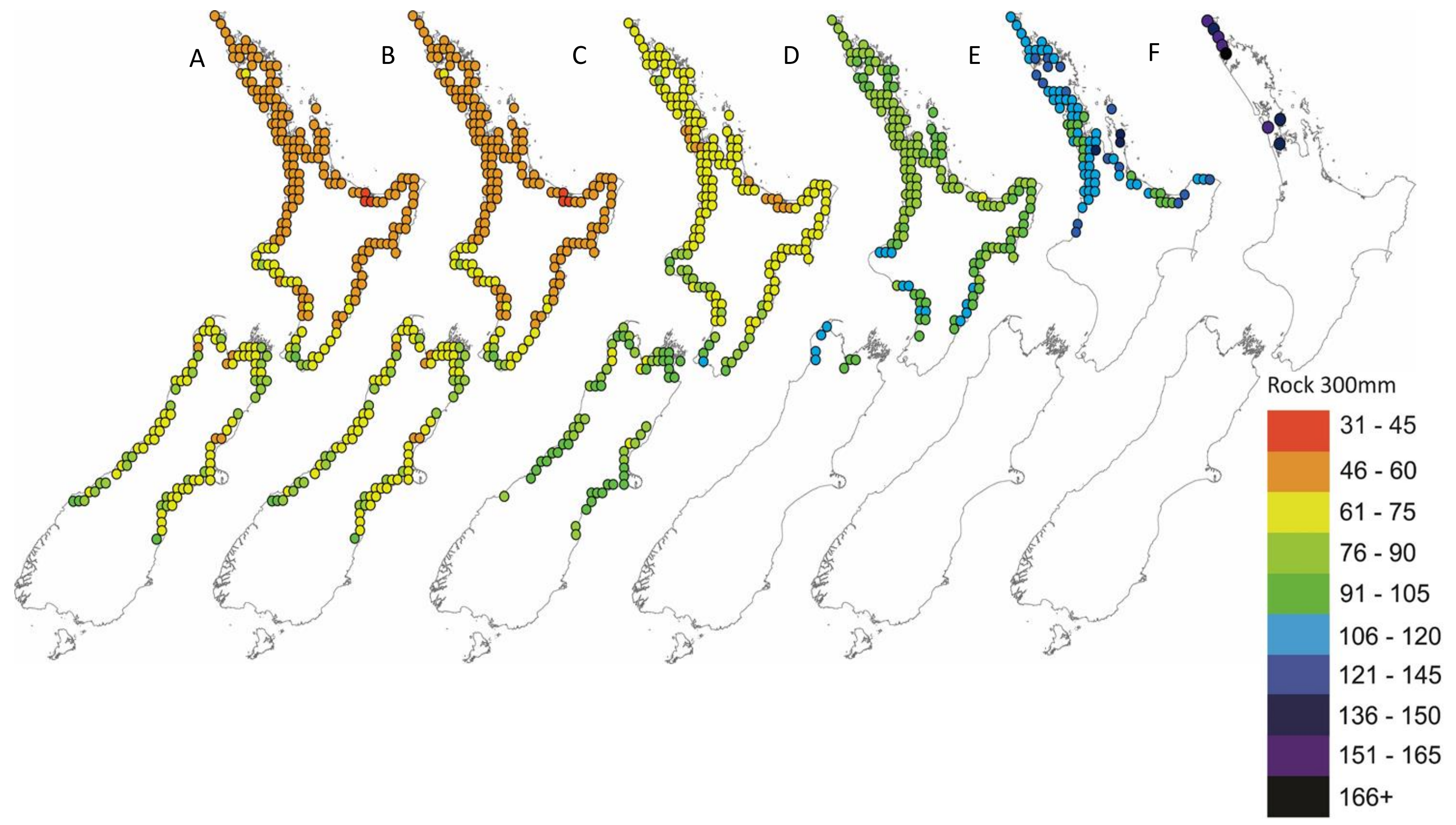



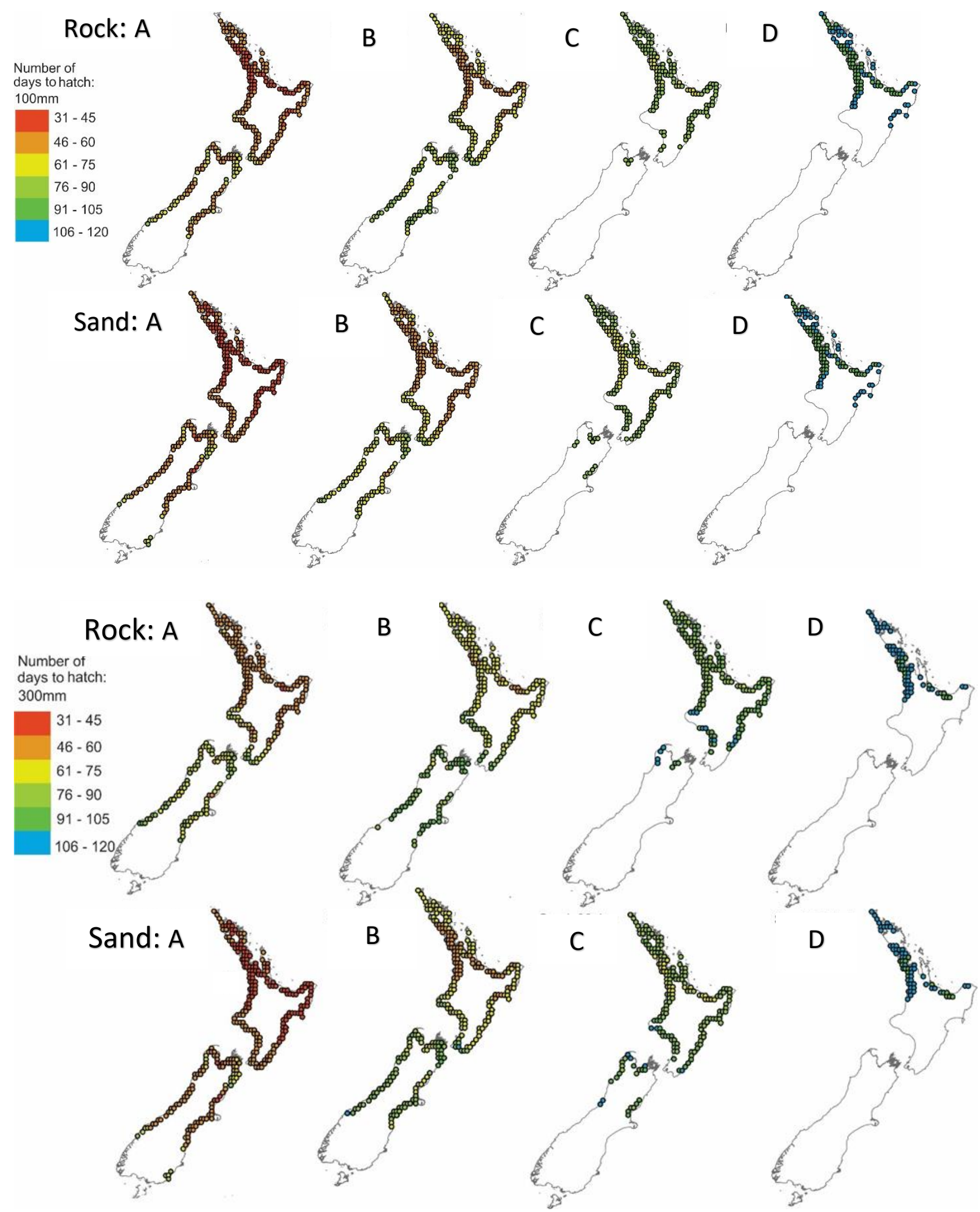

Figure 4. Adjusted distribution predictions for both substrate types for $100 \mathrm{~mm}$ and 300 $\mathrm{mm}$. Using a conservative approach where oviposition dates prior to 1 January and sites that exceeded 120 days to hatch are excluded based on $O$. suteri incubation duration and hatching dates from field and laboratory data. Successful embryonic development is 
predicted for only 4 oviposition dates; 1 (A), 15 (B), 30 (C) January and 14 (D) February and the number of potential sites predicted as suitable for 30 January and 14 February decreases.

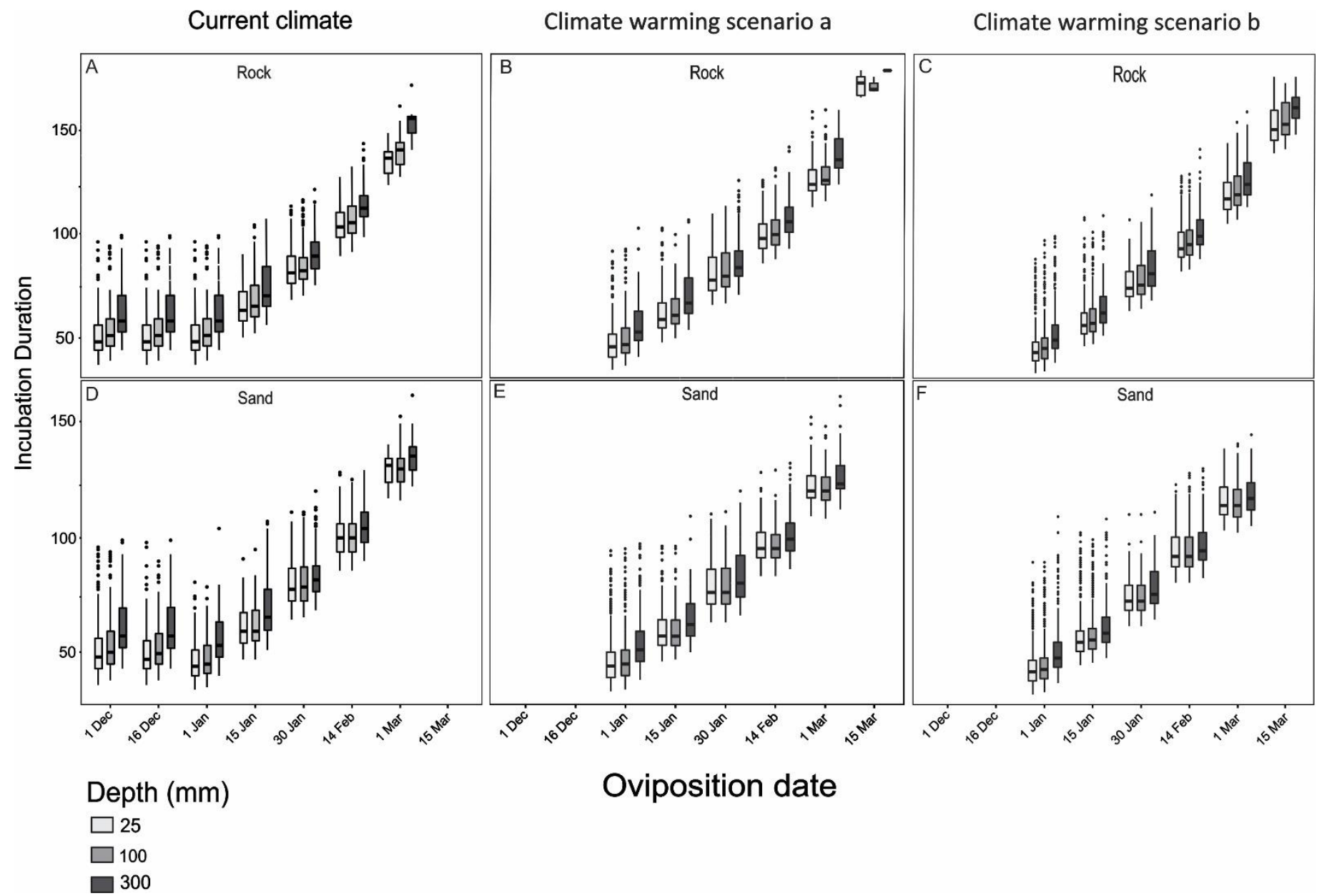

Figure 5. Oviposition dates and incubation duration, in the current climate (A and D) and predicted effects of climate warming scenarios. Under climate change scenarios (B, C, E, F), incubation duration for both substrate types decreases with oviposition date. However, only the rock substrate increases the number of viable oviposition dates up to the 15 March.

\subsection{Discussion}

I generated hourly soil temperatures for three depths in two substrate types at a 15 $\mathrm{km}$ resolution for the entire coastline of New Zealand. For each geographical $15 \times 15 \mathrm{~km}$ pixel (site), modelled soil temperatures and incubation data were used to predict the number of days to hatch that achieved the minimum degree-day requirements for successful embryonic development of $O$. suteri eggs. My model indicated that the distribution of $O$. suteri could extend to higher latitudes and still achieve the required number of degree-days for developmental completion under the current climate. The 
addition of predicted climate change scenarios increased the number of oviposition days available and decreased the number of days to hatch compared to the current climate model. Oviposition date for rock substrate extended by 15 days in both climate change scenarios but did not change oviposition dates for sand substrate.

\subsubsection{Model predictions and limitations}

While development is predicted to occur at more sites and therefore distribution may extend to higher latitudes, I found a difference between $O$. suteri's current distribution and the model predictions. The negative effects of cool-constant temperatures observed in O. suteri during incubation in captivity suggests a more conservative estimate of the actual distribution where population establishment is likely to succeed. A number of reasons exist as to why the model predictions may not represent observed distribution which could prevent the successful establishment of populations.

One limitation of the model is that it does not include an upper thermal threshold. I did not include an upper thermal limit, firstly, because the upper thermal threshold or pivotal temperature at which point temperature becomes detrimental to embryonic development is not known for $O$. suteri. The time allowed for degree-day accumulation was based on development rates of eggs incubated at constant temperatures (Hare et al. 2002). Adult $O$. suteri females tend to favour warmer nest temperatures (Hare et al. 2002). After oviposition, eggs are immobile and are unable to avoid the environment to which they are exposed. During incubation, temperatures may exceed a critical maximum for a period of time in many lower latitude sites with implications for egg survival. Without accounting for temperature fluctuations above a critical threshold is problematic when extrapolating to novel environments such as those predicted under climate change. For example, as some higher latitude sites become thermally suitable under climate change, sites at lower latitudes, already exposed to higher temperatures, may become thermally unsuitable. As our model only included the minimum development threshold, addition of an upper thermal threshold is required to determine which sites may exceed an upper critical threshold for an extended period of time.

I also assumed no development occurs below the minimum development threshold of $13.8^{\circ} \mathrm{C}$. If nests that are laid in higher latitudes where temperatures are more likely to drop below the developmental zero, then no development is assumed to occur. However, at 
the lower extreme of a temperature range, assumptions of the relationship of linearity between temperature and development rate breaks down because developmental rates asymptotes (i.e. never reaches zero; Georges et al. 2005). Because minimal hatching success and increased deformities have been observed in $O$. suteri at the low constant incubation temperature of $18^{\circ} \mathrm{C}$ (Hare et al. 2002), the lower development threshold limit of $13.8^{\circ} \mathrm{C}$ is a conservative estimate of absolute developmental rates.

\subsubsection{Effects on fitness}

The nest environment can have negative or positive consequences for reproductive fitness (Refsnider and Janzen 2010). Mating in O. suteri is thought to occur in spring (September to November) and eggs are retained in females for up to 2 months prior to oviposition (Towns 1975a). Nest temperatures and oviposition dates for O. suteri used in our models are derived from a limited number of nests found in the wild (Whitaker 1968; Stenhouse unpub. data), oviposition of three gravid females held in an outdoor cage (Towns 1975a), and from eggs laid in a thermal gradient in a laboratory (Hare et al. 2002). No nests have been found in the wild prior to January (Whitaker 1968), and the earliest that eggs were laid in captivity or in the lab was 21 st of December in a thermal gradient of $13^{\circ} \mathrm{C}$ to $30^{\circ} \mathrm{C}$ (Towns 1975a; Hare et al. 2002). This suggests that oviposition takes place from midDecember through to February. Finding nests from warmer areas (i.e. lower latitudes) may shift the date range for nesting and oviposition which could alter the model outcomes for different oviposition date scenarios. For example, if oviposition occurs earlier at lower latitudes as they are generally warmer, then the number of degree-days is reached earlier. This may constrain oviposition dates to a narrower time period, as these sites are also likely to experience higher temperatures, especially with climate change. Offspring may benefit through earlier access to resources, and a longer growth period but embryo mortality may increase, reducing egg survival impacting population fitness. Similarly, embryonic development at higher latitudes may proceed too slowly for eggs to hatch before the onset of winter due to decreasing temperatures in the nest environment. Eggs incubated at a constant temperature of $18^{\circ} \mathrm{C}$ had an incubation duration of $129-140+$ days (Fig. 2; Hare et al. 2002), which equates to approximately 4 - 5 months. If this incubation duration is applied to nests in the wild then, depending on oviposition date, hatching would occur from austral autumn into early winter. For example, hatchlings from eggs laid at higher latitudes and 
later in the season (e.g. 1 March), would hatch mid-July (austral winter). Hatchlings would have a lower chance of survival due to an increased chance of developmental deformities, decreased in resources and foraging opportunities, and an increased risk from predators due to slower locomotion of hatchlings (Hare et al. 2008a).

Parental effects (e.g. oviposition-site choice) may be important in mediating the effects of incubation environment (Deeming 2004) because nest site selection by females has a significant impact on offspring phenotype (Noble et al. 2014; Schwanz 2016).

Behavioural maternal nest site choice is a possible mechanism that can compensate, at least partially, for increased temperatures (e.g. climate change; Doody et al. 2006; Telemeco et al. 2009). Maternal nesting behaviour may act as a mechanism that reflects selection to avoid extreme nest temperatures (Refsnider and Janzen 2010), reducing temperature variation experienced by embryos (Doody et al. 2006). Higher latitude sites may experience a cooler temperature range, increasing incubation duration. Maternal nest site-choice is restricted, due to limited suitably warm nest sites, especially when temperatures are too cold for behavioural adjustments (Doody and Moore 2011). Conversely, maternal nest site choice could extend the geographic range when thermally suitable habitat is available (e.g. during El Niño years when air temperatures are above average), beyond the boundary set by critical thermal thresholds of embryos.

\subsubsection{Climate change and population viability}

The magnitude of change in seasonal soil temperatures varies depending on latitude. For example, the average soil temperature at latitudes of $\sim-40^{\circ} \mathrm{S}$ decreases from a mean of $15.7^{\circ} \mathrm{C}$ in March to $8.5^{\circ} \mathrm{C}$ in May (austral autumn) (NIWA 2016). At latitudes above $\sim-40^{\circ} \mathrm{S}$, temperatures decrease earlier. Equally, sites at $\sim 39^{\circ} \mathrm{S}$ and lower only decrease by an average of $3-4^{\circ} \mathrm{C}$ over the same time (NIWA 2016). This change in temperature is likely to fluctuate annually and seasonally, which could mean sites that are marginally thermally suitable for development in some years may be unsuitable in others.

Global warming will increase temperatures, affecting both embryo and adult thermal environments at different life-stages. For example, common lizards (Zootoca vivipara) reproduced earlier in the season, with faster body growth in hatchlings under warmer conditions but lower adult survival (Bestion et al. 2015). Adult $O$. suteri females tend to favour warmer nest temperatures (Hare et al. 2002). Warmer climates increase 
reproductive costs to adults (Shine 2005) by lengthening periods of retreat, as temperatures frequently reach upper critical thresholds that reduce foraging time and cause energetic shortfalls (Kearney et al. 2009b). The compounding effect may prevent any latitudinal distribution shifts while climate change may reduce the number of available sites and the distributional range may contract rather than expand. Climate change may have a positive effect in terms of decreasing incubation duration. Under both the 2040 and 2090 climate change scenarios, the number of days to hatch decreases for all depths. A decrease in incubation duration means offspring are hatched earlier, which may increase foraging time and potential growth before the onset of winter, but the possibility exists of a phenological mismatch between hatching dates and food availability or predator prevalence.

Based on the data available for $O$. suteri, climate data and the model outputs, distribution further than their current distribution may be possible. Nevertheless, I cannot rule out the possibility that the current distribution may be a result of being unable to disperse to higher latitudes because of low temperatures during last glacial maximum (LGM). Temperatures during the LGM were between $3-6^{\circ} \mathrm{C}$ lower than present (Elliot et al. 2005) which is likely to have restricted the distribution of $O$. suteri during the Pleistocene period (Hare et al. 2008b). During warmer periods following the LGM (Wilson et al. 1979; Cook et al. 2002), O. suteri may have re-colonised some areas such as those predicted suitable by our model. Subfossil remains for many of New Zealand's herpetofauna have been found in both the North and South islands where there are currently no surviving populations (Towns and Daugherty 1994), which indicate many species were once more widespread than today. For example, subfossil records of Duvaucel's gecko (Hoplodactylus duvaucelii) have been found as far as latitude $-42^{\circ} \mathrm{S}$ (Pickard and Towns 1988; Worthy 1987). Human colonisation has had a significant impact on New Zealand herpetofauna due to the introduction of mammals (e.g. rats), diseases, habitat destruction/fragmentation and may have led to $O$. suteri's current distribution. Although no similar subfossil record currently exists for 0 . suteri, it is possible that they were once more widespread than today. O. suteri have been recorded on 49 islands around northern New Zealand (Towns et al. 2003) and populations are often isolated by extensive unoccupied coastline on very large islands (e.g., Newman and Towns 1985), suggesting they are able to disperse or have dispersed previously over relatively large distances. However, a lack of evidence for populations in- 
between known populations may simply reflect deficiency in sampling effort, difficulty in detection due to species-specific characteristics (e.g. nocturnal) or local population extinctions.

\subsubsection{Model application and spatial resolution}

The rate of climate change may exceed the ability of some species to adapt or shift distributions to keep pace with the rate of change. Understanding the causes of a species' geographic range limits remain incomplete because empirical studies have lagged behind developments in theory (Gaston 2009). There is evidence that plastic responses to climate warming have occurred (Franks et al. 2014). For example, some insect species appear to be able to keep pace with current warming (Donnelly et al. 2012) as they generally have shorter life-cycles. Problems can occur when attempting to detect long-term responses to gradual warming in species with long generation times, such as changes in nesting phenology and range expansions or contractions, without long-term datasets. Using models that explicitly incorporate aspects of an organism's ecological niche and/or behaviour can improve the uncertainty between suitable and unsuitable sites, especially for populations living in marginal habitat at the boundary edge. Quantifying the various factors of a species' fundamental niche, which depends upon conditions at the microclimate scale, is generally improved with high spatial resolution microclimate layers (Carter et al. 2015). Using higher resolution layers' increases computation time making them currently impractical for large geographical extents (Kearney et al. 2014a). In many cases process-based models are generally preferred over correlative models because correlative models are not ideal for extrapolation to future scenarios (Kearney and Porter 2009; Thuiller et al. 2013). Using simpler species distribution models (SDMs) when coupled with large, coarse spatial extent and extrapolating to predict future scenarios are likely to be more easily generalized to new data sets (Randin et al. 2006; Elith et al. 2010). Using a lower resolution could define areas where a higher resolution surface should be generated to help inform management decisions (Carter et al. 2015). Given the limited data available for O. suteri (i.e. incubation duration, oviposition dates from the field), a more conservative distribution prediction was included, however potential distribution is still predicted to extend further than O. suteri's current distribution. 


\section{Chapter 3: Using a spatially explicit microclimate model to predict thermal suitability for an oviparous skink, Oligosoma suteri}

\subsection{Introduction}

Understanding and predicting future species distributions, changes in ecosystem functions and biodiversity patterns depends on accurately predicting the effects of a changing climate. Many studies use controlled laboratory conditions to measure physiological tolerances, then extrapolate those conditions to define a species' niche using available environmental data. The relationship between organisms and the environmental variables that define their distributional limits varies both spatially and temporally (Wisz et al. 2012). The use of species distribution models (SDMs) commonly involves correlations between the presence of a species at a given location, measuring the climatic conditions from the same area, then using those climatic conditions to define the species' tolerance range/realised niche (Austin 2002; Elith et al. 2006; Kearney and Porter 2009). The fact that, in correlative SDMs, a species' niche is identified as a point on a map rather than the interaction between environmental conditions (e.g. temperature, precipitation) and organism specific traits (behavioural, morphological and physiological) has been identified as critical flaw in their use (Pearson and Dawson 2003; Kearney 2006; Kearney and Porter 2009; Buckley 2010), because they may not be a true reflection of the fundamental niche. The empirical links statistical approaches use to make predictions about species distributions and environmental variables are of limited use where occurrence data is limited (Guisan and Thuiller 2005). When these predictions are applied to novel climates, such as those predicted by climate change, the results can be misleading (Davis et al. 1998; Kearney and Porter 2010; Sinclair et al. 2010).

Recent advances in species distribution models include the development of methods that can explicitly connect the mechanistic functional traits of organisms to climate (Mitchell et al. 2008; Kearney 2009a; Buckley et al. 2010; Kearney et al. 2010, 2014a). The addition of high resolution topographic data (e.g. Light Detection and Ranging, LiDAR), allows for more sophisticated methods that integrate range-limiting factors and spatially-explicit climate data, producing more robust links between species distributions and environmental data (Gusian and Zimmerman 2000; Guisan and Thuiller 2005; Elith et al. 2006). As a result, SDMs 
has been used to address a range of topics including mapping suitable sites for species reintroduction (Pearce and Lindenmayer 1998) and supporting conservation planning and reserve selection (Ferrier 2002; Araujo et al. 2004). For example, translocations are a commonly used conservation practice. Yet, in New Zealand overall low success rates for individual translocation projects give some cause for concern (Sherley et al. 2010), especially if the species in question is critically endangered. Suitable translocation sites need to be identified early if human mediated intervention is necessary to ensure species survival. The ability to predict suitable translocation sites may improve translocation success rates.

The environmental data used in species distribution models are often at global spatial and temporal scales (e.g. Worldclim, Hijmans et al. 2005) which can be appropriate in identifying links between climate and physiological or biogeographical responses over large geographical extents or temporal scales (Chown and Gaston 2008), but at a scale that may not necessarily drive organism responses (Helmuth et al. 2010; Kearney et al. 2014a). As many organisms experience their environment within a small geographical extent (Hutchinson and MacArthur 1959; Porter et al. 2002, 2010; Geiger et al. 2003; Potter et al. 2013; Hannah et al. 2014), measuring the response of an organism to its environment will depend on the scale that the organism experiences it. Ideally, the development of SDMs involves identifying the ecological niche of an organism's distribution based on some knowledge of the species physiological limitations (Helmuth et al. 2005; Chown and Gaston 2008) that are estimated independently of the geographical range or abundance data (Kearney and Porter 2009). If environments are modelled using globally derived gridded environmental data much of the underlying processes or variation of the realised niche may be missed using coarse-scale SDMs (Sears et al. 2011; Carter et al. 2015) because globally derived data generally represent conditions approximately 1-2 m above the ground (Kearney et al. 2014a, 2016). Microclimate conditions can vary substantially depending on abiotic factors such as topography, altitude, vegetation and types of soil (Geiger et al. 2003; Kearney et al. 2016), particularly in a terrestrial setting. Deciding which resolution is used in modelling will depend on what available environmental and species data (e.g. $\mathrm{m}^{2} \mathrm{vs.} \mathrm{km}^{2}$, hourly vs. daily) are used. Generally, higher spatial and temporal resolutions are more likely to capture variations within the microenvironment. SDMs using large grid-cell sizes may substantially overestimate potentially suitable areas in relation to those predicted by using a 
finer grid-cell size (Seo et al. 2009), particularly if the data used to define the initial distribution are sparse.

High or low spatial resolution is relative to the geographic extent of the area of interest and species. For example, a grid-cell with a resolution of $1 \mathrm{~km}^{2}$ can be a high spatial resolution at a global scale (Hijimans et al. 2005), yet if the area of interest is a small island, the resolution would be considered low (Carter et al. 2015) as a $1 \mathrm{~km}^{2}$ grid cell may cover the entire island. A disadvantage of the use of higher-resolution data is that it typically increases computation time and resources (Kearney et al. 2014a).

\subsubsection{Aims and model framework}

My aim for this chapter was to use a microclimate model and degree-day model with high resolution climate and spatial data to generate a temperature-mediated map of incubation duration for an island with an extant $O$. suteri population. I used the microclimate model available in the R package, NicheMapR, to calculate the vertical soil temperatures below ground level to predict the physiological requirements of developing $O$. suteri embryos for Rangitoto/Motutapu Island, a location within their geographic range. I used hourly soil temperatures from the microclimate model for eight depths below ground level (i.e. $0 \mathrm{~mm}$ ) up to $300 \mathrm{~mm}$ deep over 365 days to generate a coastal map of incubation duration for Rangitoto/Motutapu. I applied the degree-day model from chapter one to estimate the minimum number days to hatch as a function of degree-days. I used recorded soil temperatures at three depths for two sites where 0 . suteri populations are located for a comparison of temperatures and incubation duration predictions with model predictions within the same time period. In addition, data loggers were installed in four $O$. suteri nests that were discovered on Korapuki Island, in the Mercury Islands group, in January 2016. I discuss the application of this model for refining conservation management decisions, including translocations; assisting in population monitoring; and the potential to generate habitat suitability maps to evaluate projections for reproductive success. 


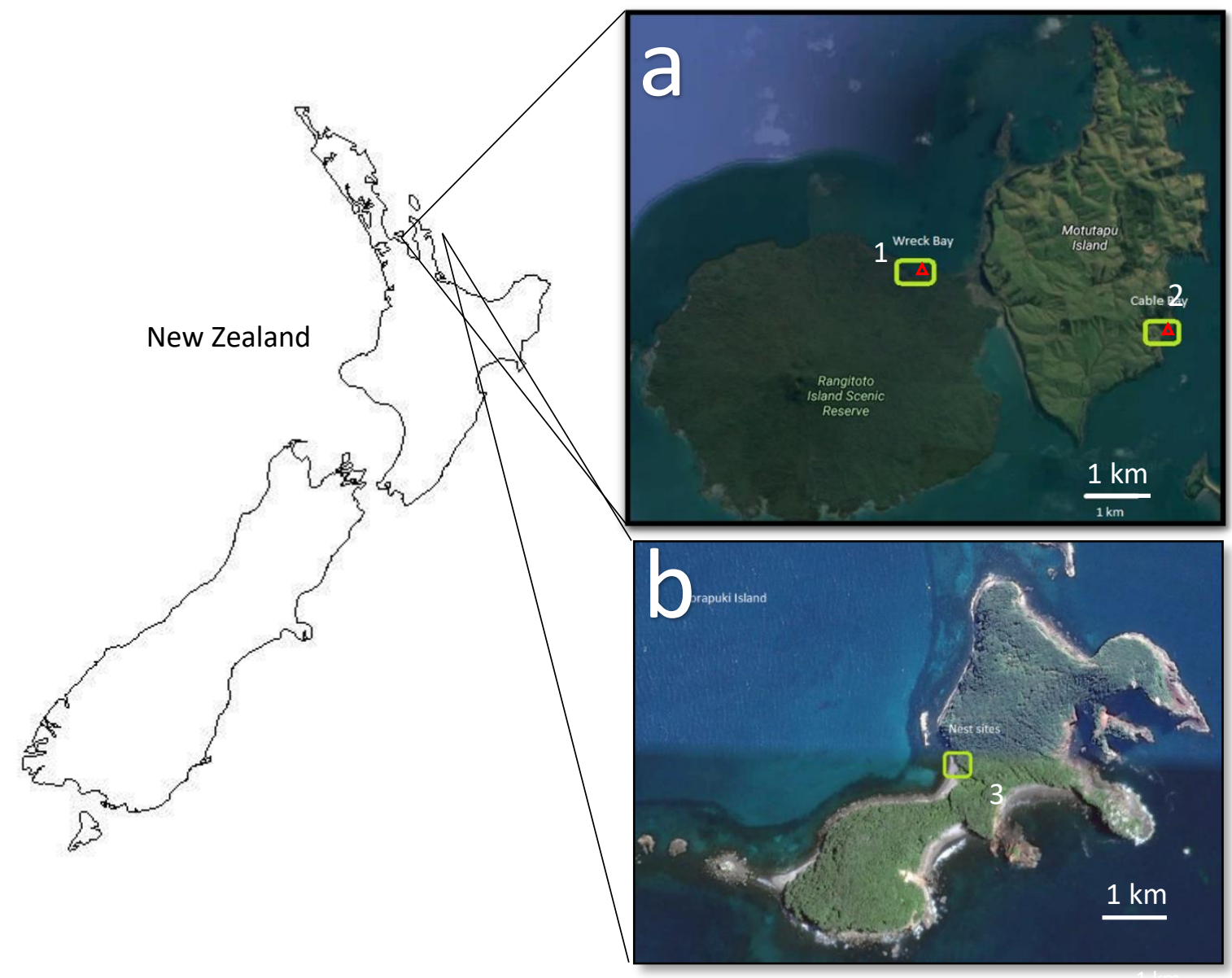

Figure 1. Map of New Zealand showing a) Rangitoto/Motutapu Island and b) Korapuki Island. Green boxes show the three data logger locations. Site 1 is Wreck Bay on Rangitoto, site 2 is Cable Bay on Motutapu, and site 3 is Korapuki Island. At site 3 all data loggers are within the one site separated by a maximum of $13 \mathrm{~m}$ between data loggers. The Red triangles are the sites where model soil temperatures were extracted from the microclimate model as a comparison to the data logger temperatures.

\subsection{Methods}

\subsubsection{Study sites}

Rangitoto/Motutapu Island $\left(-36^{\circ} \mathrm{S}, 174^{\circ} \mathrm{E}\right.$; Fig. 1a) is a 3,820 ha open-access island reserve, administered by the Department of Conservation (DOC) and located approximately $9 \mathrm{~km}$ from Auckland, New Zealand. The island group is made up of two islands that formed independently but were subsequently linked by an artificial causeway. The distinctive cone shape of Rangitoto is New Zealand's youngest island, formed by successive volcanic eruptions that began approximately 6000 years ago, with the most recent eruption, 600 years ago, giving rise to most of the island and the cone apex seen today (Hayward et al. 
2011). Rangitoto consists of steep basalt and scoria covered by a layer of native forest. In contrast, the topography of Motutapu is defined by rolling hills, with a coastline dominated by steep coastal cliffs, rocky shore platforms and steeply backed beaches. Formed approximately $178 \mathrm{Ma}$, Motutapu is today an active sheep and beef cattle farm, interspersed with regenerating native forest, wetlands and remnant forests. Apart from livestock, non-native mammals are not present on the islands.

In August 2011, after an extensive pest eradication program, Motutapu was declared free of introduced mammalian pests (rats; Rattus rattus, R. exulans and R. norvegicus, stoats; Mustela erminea, hedgehogs; Erinaceus europaeus occidentalis, cats; Felis catus and rabbits; Oryctolagus cuniculus; Griffiths et al. 2015). However, the invasive rainbow skink (Lampropholis delicata), native to Australia, is still present on the island, although population size and potential impact is unknown. Since the mammal eradication program, surveys for lizard populations have been conducted regularly, and populations of $O$. suteri have been identified in several locations around the coastline of the island (A. Polkanov pers. comm.). Two locations, Wreck Bay, Rangitoto and Cable Bay, Motutapu, were selected to install data loggers to record hourly subsurface temperatures at three depths as there are populations of $O$. suteri currently located here.

Korapuki Island (Fig. 1a) is an 18 ha nature reserve located approximately $6 \mathrm{~km}$ off the Coromandel coast on New Zealand's east coast. Formed in the late Miocene to early Pliocene period (Hayward 1986) from heavily altered volcanic tuffs and basaltic lava flows (Hicks et al. 1975). The island was declared pest free (rats, Rattus exulans; and rabbits, (Oryctolagus cuniculus) in 1987. Habitats at all three sites are relatively similar in that $O$. suteri populations were located on beaches with small to medium sized boulders $(100-300$ $\mathrm{mm}$ in diameter) interspersed with smaller stones on top on a sandy substrate. Vegetation was located directly next to the beach. Two main differences exist among the three locations. Firstly, Rangitoto and Korapuki are volcanic, Motutapu is sedimentary and secondly, vegetation at Motutapu is mostly low growing grasses and shrubs with grazed farmland approximately $5 \mathrm{~m}$ from the beach.

\subsubsection{Soil temperature data}

In December 2015, 24 data loggers (HOBO ${ }^{\circ}$ pro v2 resolution: $0.02^{\circ} \mathrm{C}$, accuracy: \pm $0.21^{\circ} \mathrm{C}$ ) were installed to measure hourly soil temperature at two locations of known 
populations of $O$. suteri. Site 1 , Wreck bay $\left[-36^{\circ} 77 \mathrm{~S}, 174^{\circ} 87 \mathrm{E}\right]$, is located on the northern side of Rangitoto and site 2 , Cable bay [-36 $\left.77 \mathrm{E}, 174^{\circ} 92 \mathrm{~S}\right]$, is located on the southern side of Motutapu (Fig. 1). At each site, I placed 3 data loggers at 3 depths every $5 \mathrm{~m}$ over a $15 \mathrm{~m}$ transect (12 data loggers in total), with the first set of 3 data loggers placed $2 \mathrm{~m}$ from the high tide line. The data loggers were placed approximately $0 \mathrm{~mm}, 100 \mathrm{~mm}$ and $200 \mathrm{~mm}$ below surface level as most temporal variation declines below 200 mm (Gieger et al. 2003). Hourly temperatures measured for a 3-month period (1 January - 1 April) were collected on 1 April 2017. Each data logger in the array collected approximately 2184 hours over the 3 month period. Additionally, 5 nests were found on Korapuki Island and data loggers were placed in 4 of the 5 nests (Fig. 1) at approximately $120 \mathrm{~mm}, 220 \mathrm{~mm}$, and $270 \mathrm{~mm}$ depths. Two data loggers were placed in potential nest sites (100 mm and $300 \mathrm{~mm}$ deep) at each site on Rangitoto and Motutapu. These sites were selected because they were within the population's geographical extent in similar habitat to nests found on Korapuki Island (i.e. similar rock size) and gravid females were identified at both sites. Hourly temperature data were then compared against temperature data from nests on Korapuki Island. Daily maximum, minimum and mean temperatures were compared between the data loggers at the 3 sites, over the same time period (13 January, 1200 - 18 January 0800 ).

\subsubsection{Microclimate model structure}

The microclimate model is set up to run in the R-environment to generate hourly soil temperatures using the Niche Mapper ${ }^{\mathrm{TM}}$ platform (Kearney and Porter 2016). The model requires as input daily climate variables (maximum and minimum hourly air temperature, wind speed, cloud cover and relative humidity); topographic parameters (elevation, aspect, horizon angle and slope); and site-specific values of shading by vegetation and the physical properties of soil, both of which can be modified by the user (Fig. 2). Clear sky terrestrial solar radiation is calculated with an algorithm based on latitude and longitude (McCullough and Porter 1971). The dispersal of solar radiation due to atmospheric aerosols is integrated using a modified version of the Global Aerosol Data Set (GADS; Koepke et al. 1997).

Substrate temperatures are calculated using a one-dimensional, partial differential equation (Carslaw and Jaeger, 1959; Porter et al. 1973), solving a heat balance equation for different substrate types at ten substrate nodes (Porter et al. 1973; Kearney et al. 2014a, Kearney and Porter 2016) for a given location. 
I assumed a uniform soil type of 'rock' for each island and set the model to calculate soil temperatures for 7 depths below ground level $(0,25,50,100,150,200$ and 300). Two depths of 500 and $1000 \mathrm{~mm}$ were modelled but as it is unlikely that eggs would be found deeper than $300 \mathrm{~mm}$, the $500 \mathrm{~mm}$ and $1000 \mathrm{~mm}$ depths were excluded but are included in appendix 6 for reference. I parameterised the global climate function using environmental parameters obtained from the NIWA CliFlo database (http://www.cliflo.co.nz) for 365 days from the nearest weather station, Auckland City (weather station No. 1434, approximately $10 \mathrm{~km}$ from the study locations). Climate variables were daily cloud cover (expressed as a \%), maximum and minimum humidity [resolution $0.1 \%$ ], rainfall [resolution $0.1 \mathrm{~mm}$ ], wind speed [resolution $0.1 \mathrm{~m} / \mathrm{s}$ ] and minimum and maximum temperature [resolution $0.1^{\circ} \mathrm{C}$ ]. Cloud cover was calculated as the difference between maximum possible sunshine hours over a $24 \mathrm{hr}$ period and total amount of recorded daily sunshine hours [resolution $0.1 \mathrm{hr}$ ] (e.g. 12 hrs maximum daily sunshine possible $-8 \mathrm{hrs}$ of recorded sunshine). Temperature predictions were generated using a value of $0 \%$ for canopy shading. I calculated values for the root-mean-squared deviation (RMSD) for each comparison of predicted hourly soil temperatures with the corresponding observed values at each data logger location, with lower values indicating better agreement between observed and modelled soil temperatures. Normalised RMSD (nRMSD) was calculated as the RMSD value divided by the range of observed hourly soil temperatures (maximum - minimum) for each comparison between predicted and observed values (Kearney et al. 2014b). 


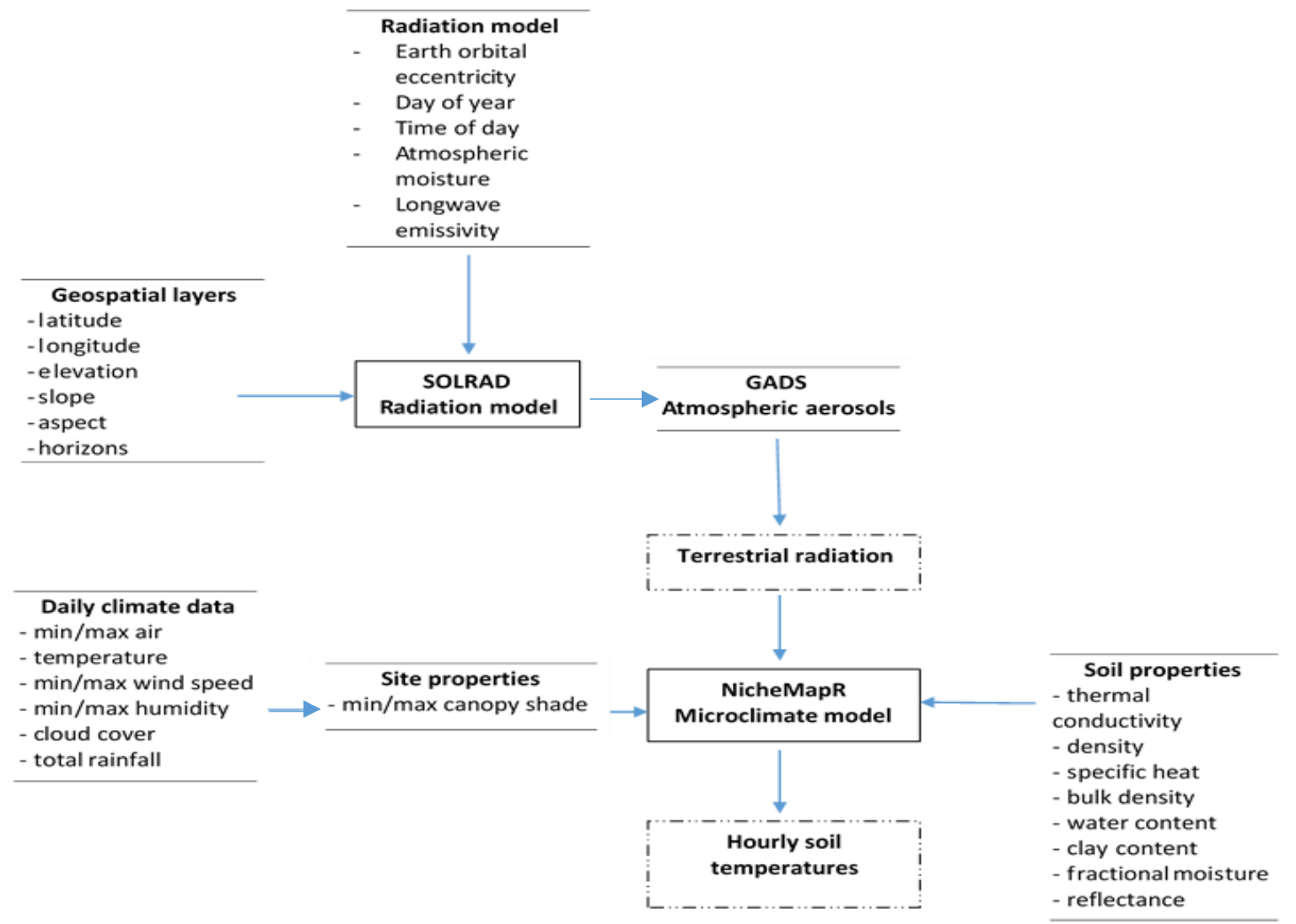

Figure 2. Summary flow chart of the environmental inputs and outputs of the NicheMapR microclimate model to calculate heat-energy balances and estimate hourly sub-surface temperatures (adapted with permission from Carter et al. 2015). Semi-enclosed rectangles designate model inputs, enclosed rectangles are model algorithms, and dashed rectangles are model outputs.

\subsubsection{Geospatial terrain data}

Geospatial data were created using LiDAR point data obtained from the Auckland City Council Geospatial team, from which I generated a gridded Digital Elevation Model (DEM). Latitude, longitude, slope, aspect and elevation values were extracted directly from the DEM. Aspect is derived from the downslope direction as the maximum rate of change in value from each cell to its neighbours. Slope is calculated as the maximum rate of change in value from each cell to its eight nearest neighbours. For each pixel of the DEM, 24 horizon angles were calculated to correct solar radiation values for complicated topography using the r.horizon function in GRASS v. 7.0.1 (GRASS development team 2015). O. suteri are only known to live in boulder beaches so the DEM was restricted to the shoreline with a $500 \mathrm{~m}$ buffer. 
Since a high resolution DEM will increase computation time of model runs (Kearney et al. 2014a), the resolution of the spatial data was reduced from $1 \mathrm{~m}$ to $20 \mathrm{~m}$ by subsampling every 20th pixel of the terrain layers. This reduced the number of sites from 199,605 to 9,980 . While some level of detail may be lost in this approach, the spatial resolution would still be biologically relevant to $O$. suteri, as populations can be found in areas up to $300 \mathrm{~m}^{2}$ (Stenhouse unpub data).

\subsubsection{Degree days}

For both the modelled soil temperatures and the data logger temperatures, degreedays were calculated using the formula in chapter two with an oviposition date of 1 January. Hourly temperatures were summed, and incubation duration in days were extracted for each depth once the minimum number of days to hatch was reached (616). These values, denoted JULDAY in the model, were converted into a raster map of Rangitoto/Motutapu. Incubation duration is summarised in table form for each of the data logger depths (Appendix 1).

\subsection{Results}

\subsubsection{Incubation duration}

Incubation duration varied between eastern and western sides of the islands with higher incubation duration predicted for eastern and northern sites on Motutapu than compared to all the sites on Rangitoto. Number of days to hatch increased with depth with the longest time at $1000 \mathrm{~mm}$ of 105 -365 days predicted for Motutapu. Incubation duration on Rangitoto was relatively uniform for all depths from 53-89 days, whereas incubation duration on Motutapu across all depths ranged between 53 and 122 days (Fig. 3, A-G). For all the depths, the number of days to hatch were within the range of from eggs incubated in the lab at constant temperatures (Hare et al. 2002, Chapter 2). Maximum incubation duration for $0 \mathrm{~mm}-300 \mathrm{~mm}$ ranged between 53 days $(0 \mathrm{~mm}$ ) to 122 days ( $300 \mathrm{~mm}$ ).

Root-mean-squared deviation (RMSD) values between modelled and data logger temperatures were $6-7^{\circ} \mathrm{C}$ at $0 \mathrm{~mm}, 3-5^{\circ} \mathrm{C}$ at $100 \mathrm{~mm}$ and $3-4^{\circ} \mathrm{C}$ at $200 \mathrm{~mm}$ (Fig. 5). At site 1 (Wreck Bay, Rangitoto), $100 \mathrm{~mm}$ and $200 \mathrm{~mm}$ depths were approximately within $3-4$ ${ }^{\circ} \mathrm{C}$ of observed values while $0 \mathrm{~mm}$ depths were within $6-7{ }^{\circ} \mathrm{C}$ of observed. At site 2, (Cable Bay, Motutapu), RMSD values were higher at $100 \mathrm{~mm}$ and $200 \mathrm{~mm}\left(3-5^{\circ} \mathrm{C}\right)$. The lowest 
RMSD values were at $200 \mathrm{~mm}$ depths for both sites $\left(3.02{ }^{\circ} \mathrm{C}\right.$, Rangitoto; $3.47^{\circ} \mathrm{C}$, Motutapu). Normalised RMSD values of the modelled scenario indicate the minimum residual variance is within about $18 \%-23 \%$ of observed values at all 3 depths for site 1 and within $17-32 \%$ of observed values at site 2 .

\subsubsection{Data logger temperatures vs. actual nest temperatures}

Hourly data logger temperatures among the three sites differed by $3{ }^{\circ} \mathrm{C}$ to $15^{\circ} \mathrm{C}$ (Fig. 6). Rangitoto site was the coolest with the lowest variation in temperatures $\left(20-24{ }^{\circ} \mathrm{C}\right)$, Korapuki Island ranged between 18 to $32^{\circ} \mathrm{C}$ while Motutapu ranged between $17-35^{\circ} \mathrm{C}$. Maximum temperatures on Korapuki and Rangitoto occurred between 1800 and 2100 hours whereas maximum temperatures on Motutapu occurred between 1500 and 1600 hours. This is likely a reflection of the different aspects of each site (i.e. both Rangitoto and Korapuki have North-West aspects and Motutapu has a South-East aspect). Average temperatures from the nests were warmer than the representative nest site at Rangitoto (Fig. 6; Appendix 2 \& 3). Similar temperatures were observed between nests on Korapuki Island and the potential nest site on Motutapu over the same time period, but Rangitoto values were closer to the minimum values from Korapuki and did not reach similar maximum temperatures, e.g. did not exceed $25^{\circ} \mathrm{C}$. 
A) $0 \mathrm{~mm}$

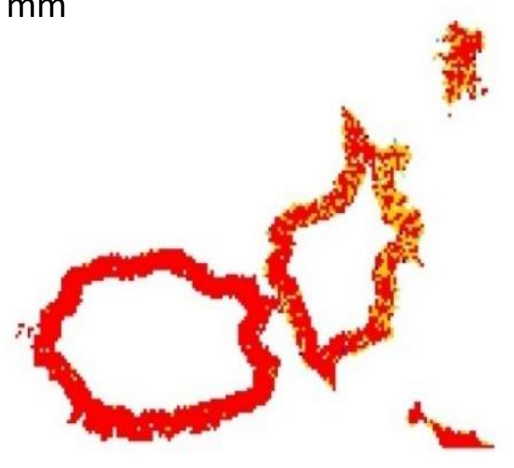

C) 50

$\mathrm{mm}$

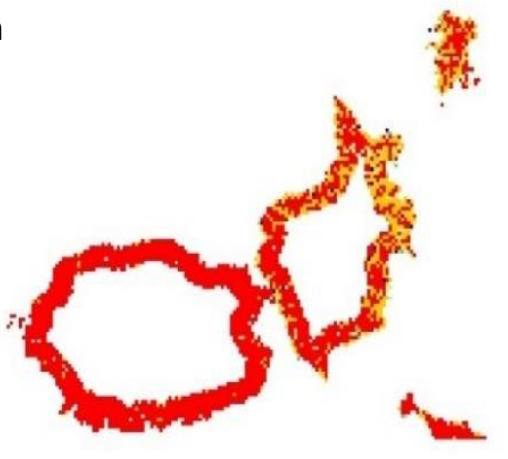

E) $150 \mathrm{~mm}$

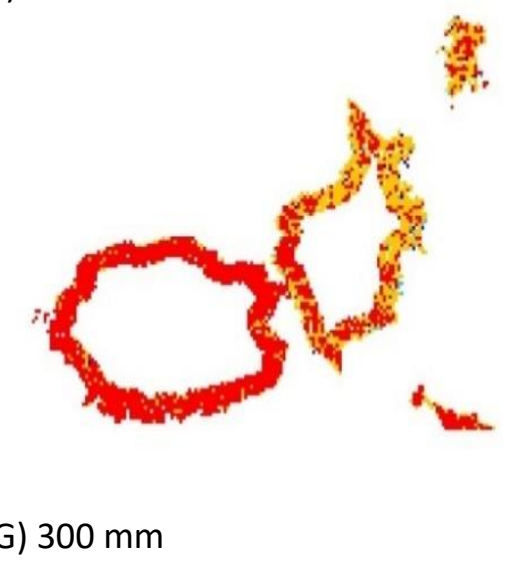

B) $25 \mathrm{~mm}$

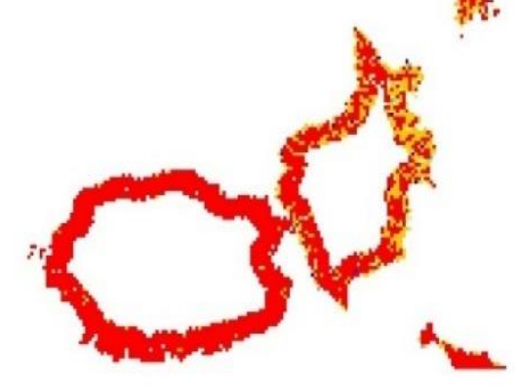

D) 100

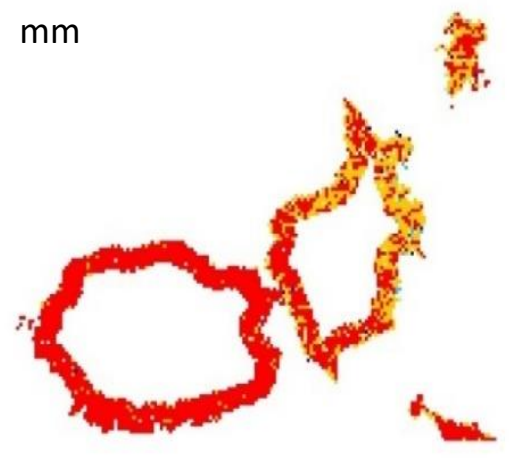

F) $200 \mathrm{~mm}$

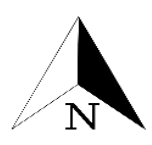

Number of days to hatch

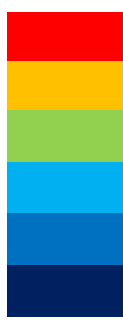

$53-65$

$66-80$

$81-95$

$96-110$

$111-125$

$126+$

Figure 3. Distribution of incubation duration for the Rangitoto/Motutapu coastline for each soil depth $(0,25,50,100,150,200$, and $300 \mathrm{~mm})$ generated from the microclimate model. The degree-day formula from chapter two was used to convert hourly soil temperatures 
starting from 1 January into number of days for 0 . suteri eggs to reach $100 \%$ development based on the minimum development threshold (616 degree-days above 13.8).
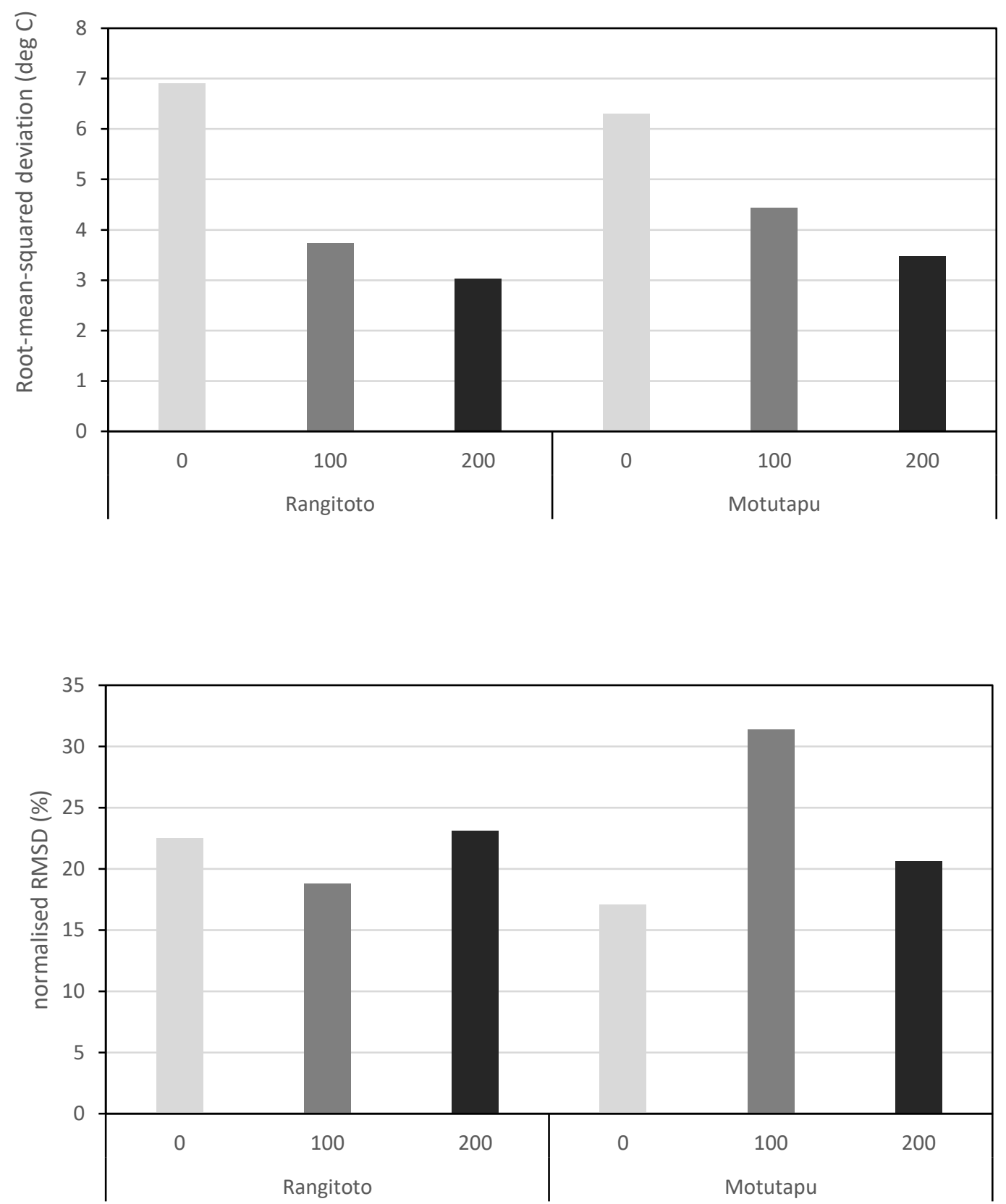

Figure 4. Summary statistics comparing observed and modelled hourly soil temperatures. Light grey bars show comparisons $0 \mathrm{~mm}$, grey bars show comparisons at $100 \mathrm{~mm}$ and dark grey bars show comparisons at $200 \mathrm{~mm}$. Modelled soil temperatures from the nearest sites 
to the data loggers were used. All modelled temperatures values were averaged across 5 sites at 0,100 and $200 \mathrm{~mm}$ (2,184 values per site).

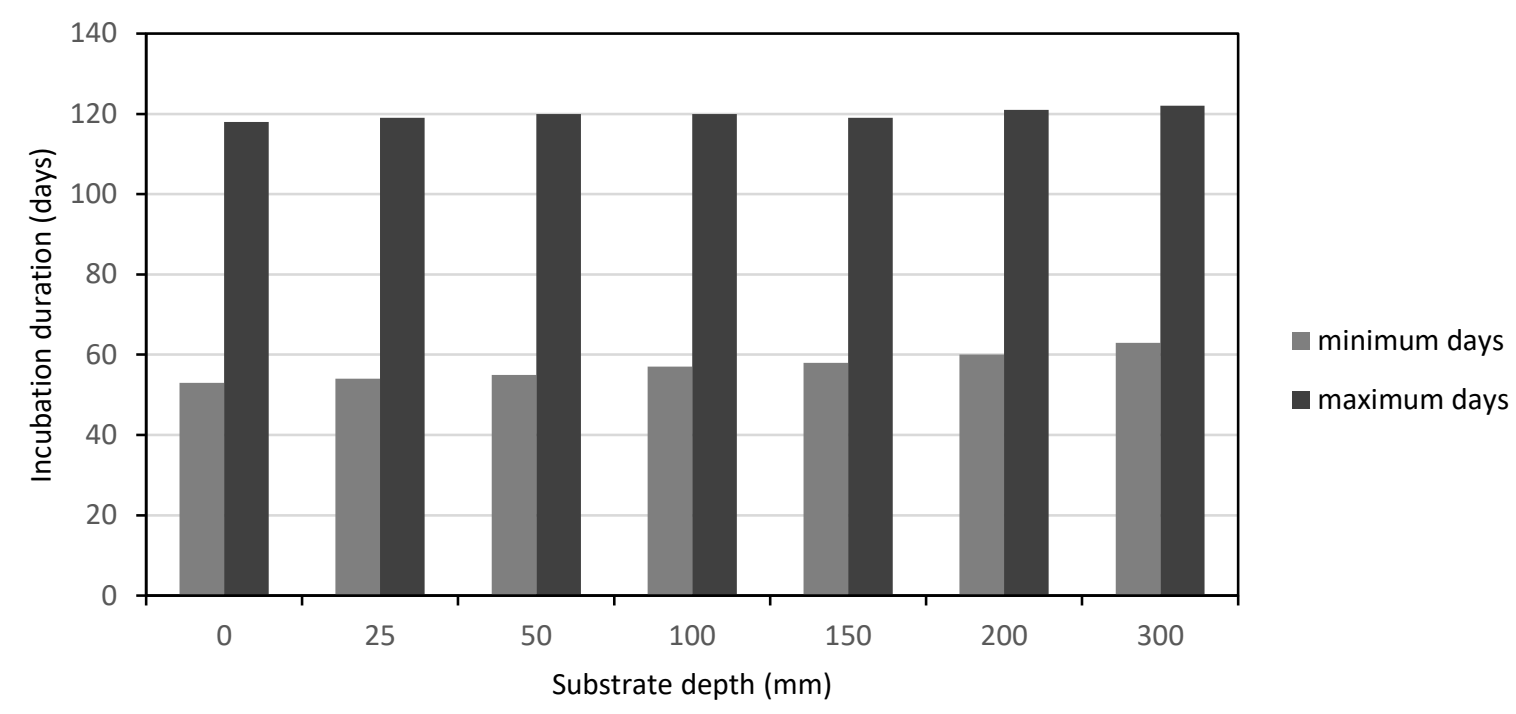

Figure 5. Incubation duration in days for each depth predicted by the microclimate model. Minimum and maximum number of days to hatch generated by the microclimate model for seven depths and across all sites for Rangitoto/Motutapu.

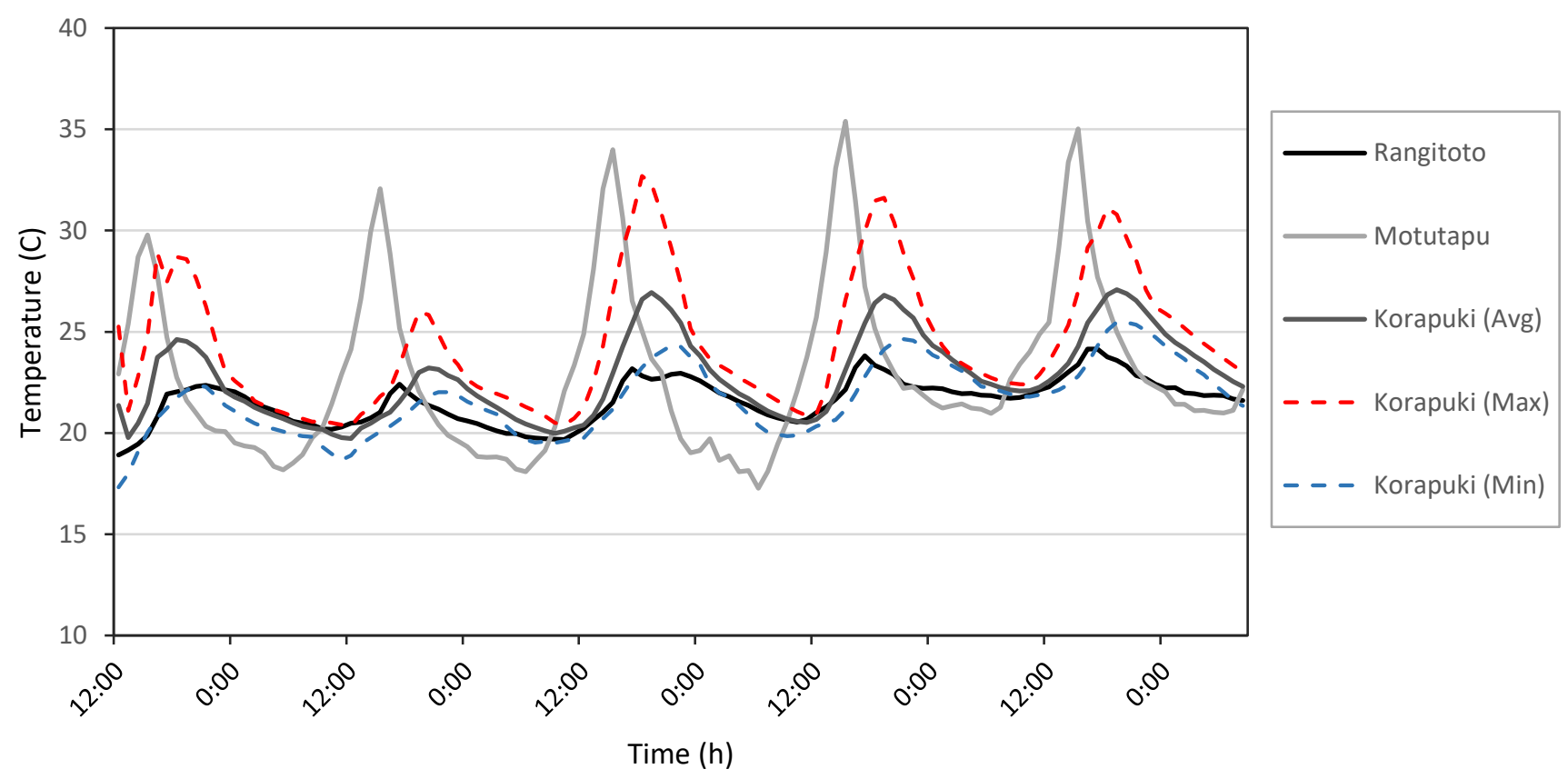

Figure 6. Nest temperature compared to representative nest temperatures. Measurements are from data loggers from nests found on Korapuki Island compared to data loggers from representative nest sites on Rangitoto/Motutapu. All data are for the same time period (midday 13 January to $8 a m 18$ January, 2016). Average, minimum and maximum values for 
5 data loggers are shown for Korapuki. Sites on Rangitoto/Motutapu were selected as nests sites due to the similarities in habitat and because gravid females were found within the same area.

\subsection{Discussion}

\subsubsection{Summary of results}

I generated hourly soil temperatures using a mechanistic model of the fundamental niche of a nocturnal skink Oligosoma suteri and generated maps of predicted incubation duration with depth for a coastal habitat at a high resolution. This shows that $O$. suteri could potentially nest successfully over the entire coastal area of Rangitoto/Motutapu Island where suitable habitat exists. I compared the microclimate model temperatures and incubation duration outputs against measurements from data loggers. Modelled incubation durations were consistently shorter than data logger incubation durations across all three depths at both data logger locations. Incubation duration from the model for 0, 100 and 200 $\mathrm{mm}$ ranged between 57 - 64 days (Rangitoto) and $67-87$ days (Motutapu), but incubation duration from the data loggers at 0,100 and $200 \mathrm{~mm}$ ranged between $63-89$ days (Rangitoto) and 69 - 90 days (Motutapu, Appendix 1). As expected, incubation duration varied by depth with higher number of days to hatch predicted for greater depths. Modelled scenarios generated hourly soil temperatures within $6-7^{\circ} \mathrm{C}$ at $0 \mathrm{~mm}$, within $4-5^{\circ} \mathrm{C}$ at 100 $\mathrm{mm}$, and within $3-4^{\circ} \mathrm{C}$ of soil temperatures measured at $200 \mathrm{~mm}$ depth. Normalised RMSD values indicated that the minimum residual variance was within $16-23 \%$ at $0 \mathrm{~mm}, 18-32 \%$ at $100 \mathrm{~mm}$ and within about $20-24 \%$ of observed values at $200 \mathrm{~mm}$.

Data logger temperatures were comparable to model temperatures, but temperatures recorded from data loggers were on average lower and had less variation in extremes (i.e. lower maximums and minimums) than the modelled soil temperatures, although this varied among data loggers. Variation in incubation duration between the model compared to data logger measurements could be a result of the spatial scale of the climate variables used. Climate data used in the model were taken from a weather station approximately $11 \mathrm{~km}$ away. Variation between model output and data logger measurements may be caused by several factors such as exposure of Rangitoto to the open ocean and a difference in the elevation compared to the inland location of the weather 
station data. Weather data sourced at the site would have been optimal and could have improved accuracy, but were not available. However, the accuracy of my approach is still likely to be higher than using weather data available at coarser resolution such the global climate data available from worldclim.org (i.e. $10^{\prime}\left[\sim 20 \mathrm{~km}^{2}\right]$ and $30^{\prime \prime}\left[\sim 1 \mathrm{~km}^{2}\right]$ ).

Modelled substrate temperatures on average varied more than measured temperatures. Previous studies have noted a $2-4{ }^{\circ} \mathrm{C}$ difference in modelled soil temperatures compared to empirical measured data (Kearney et al. 2014a, b; Carter et al. 2015), but this variation will depend on, among other things, soil type. Measuring the temperature of a substrate with depth such as rock is complex. Boulder beaches are typically not uniform in surface level compared to a sand or soil substrate due to the distinctive variation in shape and size of boulders. For example, daily temperature variation tends to be greater in the upper soil layers (e.g. Kristensen 1959), yet in complex terrain (e.g. boulder fields) defining precisely where the surface level begins is subject to measurement error. Therefore, interpreting comparisons between temperatures measured in the field (e.g. data loggers) and modelled temperatures must be done with care and should be considered as a guide because in some cases direct comparisons may not be accurate.

\subsubsection{Model limitations}

A species fundamental niche includes a range of climate conditions and food resources that permit individuals to survive. Microclimates are strongly influenced by the interaction of abiotic and biotic factors which need to be quantified at a high spatial resolution (Carter et al. 2015). I address two important abiotic factors (vegetation cover and substrate type as examples while acknowledging that there may be several others factors (e.g. competition, predation, habitat modification) to consider.

NicheMapR uses a shading mechanism to simulate the cooling effects of vegetation and currently does not integrate the insulating effect of, for example, low growing plants (Oliver et al. 1987). The insulating effect of low-growing plants can lower surface temperatures, particularly for dark substrates (e.g. Qiu et al. 2013). Model predictions maybe of limited value if the insulating effect and the shading mechanism lowers the surface temperature further than the shading mechanism alone. If the climate data does not reflect the environmental conditions an organism experiences (Sears et al. 2011), model 
outputs can misclassify suitable areas as unsuitable. Collecting fine scale microhabitat data (e.g. temperature data loggers) are important for habitat suitability assessments because species may be able to persist in unsuitable conditions during extreme weather events (Kearney et al. 2014b; Varner and Dearing 2014). O. suteri are have limited suitable habitat within sites in which to disperse and the insulating effect of low growing plants may provide a refuge where they can survive summer heat stress or during times of environmental change (Keppel and Wardell-Johnson 2012; Varner and Dearing 2014). However, the limited temporal and spatial scales of empirical measurements, at which microhabitat data are sampled, can be unrealistic for sparsely distributed populations/species, prone to sampling error and bias and may not noticeably improve model predictions (Carter et al. 2015) particularly under novel climates predicted due to climate change.

In this study I ran the microclimate model parameterised with generalised values for rock (e.g. thermal conductivity, bulk density). Microclimate conditions within soils can vary with depth and soil type. For example, sandy soils can experience high maximum and low minimum surface temperatures. An important aspect of Rangitoto is the substrate, comprised of a volcanic rock whereas Motutapu is predominantly sedimentary rock. Different substrates will have fundamentally different thermal properties. For example, maximum temperatures experienced at the rock surface are controlled by 'internal' and 'external' conditions; the thermal properties of the rock (e.g. colour/albedo, specific heat capacity, and thermal conductivity) represent the 'internal' controls and the external control is mainly solar radiation intensity, but also latitude, altitude, orientation and inclination of the exposed surface (McGreevy 1985). The temperature below the rock at the rock-sand boundary will be subject to the thermal conductivity of the rock itself. Integrating knowledge of specific rock properties when running the model with adjustments to specific soil mineral content (e.g. thermal conductivity, specific heat, bulk density) for each type of rock (e.g. volcanic, sedimentary) may improve model accuracy, but comes at a cost of time, increased field/lab work and increased computation. Additionally, differences between rock and air temperatures can be significant (Whalley et al. 1984) or vary over relatively short distances. Measurement of certain critical microclimatic conditions such as temperature and humidity can be captured via deployment of temperature data loggers (Suggitt et al. 2011; Gillingham et al. 2012). However, field studies that monitor rock temperatures are often 
spatially limited because data loggers are not always in positions to reasonably compare temperature regimes at different rock surface orientations and inclinations (Whalley et al. 1984) or depth.

\subsubsection{Model applications}

My findings highlight that it is possible to reduce spatial resolution of terrain data from $1 \mathrm{~m}$ to $20 \mathrm{~m}$ of modelled soil temperatures to generate thermally-mediated maps of suitable conditions for $O$. suteri nesting. I have shown that soil temperatures can be modelled within a small spatial extent with accuracy comparable to microclimate models that use higher spatial resolution. Model accuracy at 100 and $200 \mathrm{~mm}$ depths is comparable to models with higher spatial resolution ( $\leq 1 \mathrm{~m}$, Carter et al. 2015) as model values were within $3-5^{\circ} \mathrm{C}$ of observed values, therefore it may be possible to reduce the number of individual sites, computation requirements and time needed for developing high-resolution microclimate surfaces.

High-resolution models incorporating microclimatic variation as well as suitable fineresolution data can be used to assess current conservation status more realistically than coarse-resolution models (Williams et al. 2003; Gillingham et al. 2013), for example, to identify suitable habitat and map the distributions for cryptic species (Leathwick and Austin 2001), find new sites with suitable habitat for translocations and reintroductions, detect thermally-driven shifts in distributions (Thomas et al. 2010), refine estimates of available land for complex terrain from coarse resolution maps, and map climatic refugia in heterogeneous landscapes where a species may be most buffered against habitat loss due or the effects of climate change (e.g. Struebig et al. 2015). Conservation management actions can be adapted and directly targeted at maintaining suitable microclimates for species within sites. My findings suggest that high spatial resolution (e.g. $20 \mathrm{~m}$ ) models parameterised with local daily weather data and high resolution terrain data can be used as an indicator of suitable nesting environments within a small spatial extent for $O$. suteri. High resolution spatial and weather data are freely available for many of the islands where $O$. suteri populations are located (e.g. Land Information New Zealand, www.linz.govt.nz and www.cliflo.co.nz), and my model could be expanded to evaluate further sites. Obtaining measurements from field sampling may help parameterise and improve model accuracy of further model runs, and allow field testing of model predictions for sites I have modelled. 
The microclimate model presented here has already been used for a range of ecological situations. For example, similar biophysical models that utilise NicheMapR have modelled range constraints on the dengue mosquito (Aedes aegypti) as a function of oviposition sites in Australia (Kearney et al. 2009a); a biophysical model combined with degree-days was used to assess thermal habitat quality of tuatara (Mitchell et al. 2008) and Fuentes and Porter (2012) used the Niche Mapper $^{\mathrm{TM}}$ microclimate model for projections of soil temperatures in sea turtle nests with various climate warming scenarios. Many reptile species have low population densities (e.g. rare or endangered species), which makes obtaining species-specific data difficult. Wider use of mechanistic SDMs remains a challenge in conservation biology because of the resources required in their construction, field and laboratory validation and because they require the collection of very specific data on an organism's traits over relatively short timeframes (Kearney et al. 2009a), as the climate may shift before sufficient physiological data can be collected (Evans et al. 2015). 


\section{Chapter 4: General summary of findings}

\subsection{General summary}

The fundamental constraints on the distribution of species are their physiological limitations. By incorporating knowledge about species-specific, temperature-mediated physiological traits with climatic conditions, species distributions can be predicted. My aim was to examine the spatial distribution and the impact of climate change on incubation duration of $O$. suteri. My research focused on the ways a microclimate model parameterised with local weather data can inform species distributions and predict incubation duration using degree-days. I predicted the number of days to hatch using a minimum development threshold for successful embryonic development of $O$. suteri eggs and applied this at two different spatial extents (national and a small island), using high resolution climate data. Here, I provide a summary of the findings of this research, the limitations of the model, a discussion of the use of the model and implications for conservation and management of $O$. suteri and other species.

\subsection{Chapter two}

\section{Modelled soil temperatures}

I evaluated the likely success of embryonic development along New Zealand's coastline, and effects of climate warming on oviposition timing and incubation duration for O. suteri. A considerable portion of New Zealand is outside the fundamental niche of $O$. suteri, and the distributional range of $O$. suteri is restricted, in part, by climatic constraints on embryonic development. $O$. suteri requires 616 degree-days above $13.8^{\circ} \mathrm{C}$ to complete successful embryonic development. The climate scenarios used were an average increase in mean temperature across the entire country. Any region that has insufficient degree-days available in the soil would be outside the fundamental niche of $O$. suteri.

Using a species distribution model with coarse spatial and climate data, it may be possible to predict where soil temperatures would be suitable for successful development along the New Zealand coastline, but successful population establishment may not be achievable. For example, on many parts of New Zealand's coast line, suitable habitats may not exist because of habitat modification, population fragmentation, competition and predation. Due to the disconnected nature of their habitat, individuals may not be able to 
disperse to other suitable habitat particularly with the presence of introduced mammalian predators. Sites that meet the developmental requirements would require sub-sampling to ensure other specific habitat characteristics (e.g. boulder beaches) are met.

\subsection{Chapter three}

\section{Spatially explicit microclimate model}

I applied a higher-resolution microclimatic approach to make projections of $O$. suteri incubation duration for Rangitoto/Motutapu Island, a scale that is relevant to conservation planning. Incubation duration varied across the island and with depth. The high-resolution microclimate model presented here can be used identify site-specific variation within those areas of interest at a finer-scale, refining estimates of available habitat for complex terrain missed from coarse resolution maps. Results showed that, incubation duration increased with depth, and incubation duration was relatively constant for Rangitoto. Sites on the eastern side of Motutapu had higher variation in incubation duration. Higher variation within sites towards the eastern side of Motutapu may be due to its greater exposure to the open ocean, sites higher in elevation above sea level and/or difference in substrate type.

High-resolution microclimate models can capture a greater level of detail than compared to lower resolution models when identifying suitable habitat (Leathwick and Austin 2001) especially for cryptic species. While the microclimate model in chapter two can identify suitable regions for successful embryonic development, it does not account for the level of variation in incubation duration within sites that the higher spatial resolution reveals. This level of detail is often needed when locating suitable habitat for translocations and reintroductions for species with small spatial distributions (e.g. $\left.<1 \mathrm{~km}^{2}\right)$. Likewise, if the aim of the study is detecting thermally-driven shifts in distributions (Thomas et al. 2010), generally, coarse resolution maps will include large areas that are unsuitable. Using fineresolution models incorporating microclimatic variation as well as other suitable highresolution data can assess current status more realistically than models with lowerresolution (Williams et al. 2003; Gillingham et al. 2013) and increase accuracy when mapping climatic refugia in heterogeneous landscapes where a species may be most buffered against the effects of climate change (e.g. Struebig et al. 2015). When data of the target species' ecology is collected (Sinclair et al. 2010), conservation management actions 
can be adapted and directly targeted at maintaining suitable microclimates for species within sites.

\subsection{Limitations}

While the use of Species Distribution Models (SDMs) has increased significantly in recent years, the limitations of species distribution models have been recognized. In the following I describe the two key limitations of the use of the models presented here. Firstly, an important difference between the national scale model (chapter two) and the island scale model (chapter three) is the different spatial resolution. The New Zealand wide distribution, spatial resolution is $15 \times 15 \mathrm{~km}$ compared to a $20 \times 20 \mathrm{~m}$ spatial resolution for Rangitoto/Motutapu. Low spatial resolution may over or under estimate distribution, and may not identify dispersal barriers or other factors (e.g. biotic interactions) relevant to the organism in question. Conversely, higher resolution models may overestimate habitat suitability if the scales used are inappropriate for the organism. Developing mechanistic models often requires more time, effort, and resources as well as field or laboratory data for model validation (Kearney et al. 2009a). Access to very high-resolution empirical data are less likely to be available for study areas that are relatively isolated or uninhabited (e.g. protected wildlife reserves), within a small geographical extent (e.g. small islands, Carter et al. 2015) or considered of low conservation priority. Furthermore, the results of any mechanistic SDM that uses high resolution Digital Elevation Maps (DEM) to derive soil-based landscapes remains largely dependent on the quality of the DEM (Gyasi-agyei et al. 1995; Thompson et al. 2001). This accuracy becomes increasingly important as the use of DEM data is extended for spatial prediction of soil attributes.

Secondly, the model does not include an upper thermal threshold. An upper thermal limit, at which point temperature becomes detrimental to embryonic development, is not known for $O$. suteri. Without accounting for temperature fluctuations above a critical threshold is problematic when extrapolating to novel environments such as those predicted under climate change. This may restrict $O$. suteri's distribution, as some potential sites predicted thermally suitable by the model may exceed the upper critical thermal threshold with climate warming. As a result, northern sites may be classified as suitable when in fact they may be or become unsuitable due to the limitations for successful embryonic development. Behavioural adaptations such as maternal nest site choice, may not adapt fast 
enough to keep pace with climate change thereby affecting embryo mortality and population viability from increased sub lethal effects (e.g. reduced growth rate of juveniles). As our model only included the minimum development threshold, addition of an upper thermal threshold is required to determine which sites may exceed an upper critical threshold for an extended period of time.

The requirement of detailed physiological data about individual species limits transferring mechanistic models to other species (Pearson and Dawson 2003). Additionally, species-specific data are lacking for many species meaning extensive field work would be required. Predicting species responses over time with climate change will prove to be significant challenge for the protection and conservation of many species. Ideally, a multiscale approach should be used if some kind of intervention is necessary for species survival, a component of which may include these models.

\subsection{Model applications}

\section{Conservation management}

The predictive ability of SDMs has become an increasingly important tool to address issues in ecology and biogeography, but also more recently in conservation biology (Guisan and Thuiller 2005), for assessment of conservation management issues such as reserve selection and planning (Ferrier 2002; Araújo et al. 2004) or mapping suitable sites for species translocations and reintroductions (Pearce and Lindenmayer 1998). The results of my two different scale approaches could identify other suitable thermal habitat for $O$. suteri where successful embryonic incubation is likely to be found, which can help inform restoration initiatives and identify new sites when other biotic and/or abiotic interactions are considered.

New Zealand has over 100 endemic species of reptile. Many of these species are now only found on off-shore, predator-free islands, mainland sanctuaries or in populations significantly smaller than their previous distribution (Towns et al. 1994; Towns et al. 2001). The conservation status of New Zealand reptiles was recently reassessed and highlighted that the number of nationally critical species dropped from 6 to 3 but the overall number of threatened species rose from 17 to 32 (Hitchmough et al. 2016). Despite some successes in the recovery through translocations of several endemic species (Hitchmough et al. 2016), 
translocation planning remains problematic particularly for populations with low densities, in difficult to access terrain or because of incomplete knowledge of species distributions (Lettink and Monks 2016). Species distribution models can be used to classify sites for reintroductions by identifying suitable habitat and predict changes in habitat suitability under current and future climates (Thomas 2011; Gusian 2013). For example, SDMs identified future potential translocation sites for Bighorn sheep (Ovis canadensis sierra; Johnson et al. 2007).

The modelling approach applied to $O$. suteri could be applied to other species of conservation concern that are temperature-dependent in New Zealand. For example, extensive data on the relationship between development rates and temperature (Mitchell et al. 2008), nest temperature data in natural nests (Nelson et al. 2004) and predicted incubation temperatures, hatchling sex-ratios and oviposition timing with climate warming scenarios at an island-wide extent (Carter 2015) are already documented for the tuatara. A national scale habitat suitability map would be of great value for conservation planning, especially for future climates, for native invertebrates, plants and reptiles. In addition, these models could be applied to predict potential invasion hotspots of suitable habitat available to the invasive species (Peterson 2003). One application of the using a degree-day model would be to calculate a development threshold for the invasive Rainbow skink (Lampropholis delicata) should they be identified as an important pest species (e.g. Kikillius et al. 2010) Regions that would allow an invasive species to persist and expand can be identified when matched with climate data finer scale models developed; the coarse scale model may over predict range estimates of an invasive species.

\subsection{Future directions}

Future research directions should include further validating the mode. For example: 1) validating the model output by finding nests from Rangitoto/Motutapu Island and measuring temperatures and total incubation duration (from oviposition to hatching) for a comparison with the incubation durations predicted by the model. 2) Testing the model predictions using a $20 \mathrm{~m}$ spatial resolution and applying the same methods to predict incubation duration for Korapuki Island to validate the model results and improve model accuracy. 3) Incorporating additional biotic processes and limits on top of model predictions 
to determine accurate range limits, for example, vegetation dynamics, interspecific interactions, dispersal, and disturbance (Kearney et al. 2010). 4) Measuring and including an upper thermal tolerance level for $O$. suteri. Such models will more closely reflect environmental limitations, environmental tolerances and other biotic factors that may limit species distributions at one or both ends of a latitudinal and/or temperature gradient.

\subsection{Conclusions}

Mechanistic species distribution models can be a powerful tool to use in an effort to meet the challenges faced under climate change. Understanding of the causes of a species' geographic range limits remains incomplete because empirical studies have lagged behind developments in theory (Gaston 2009). Advances in the field of species distribution models relies on the collection ecological data for validation of model predictions (Searcy and Shaffer 2016). Continual improvement of modelling methodologies and interpreting which model outputs are biologically informative is essential.

Increasingly, conservation efforts are reliant on the predictions made from distribution models (Sinclair et al. 2010). It is essential they are interpreted correctly, the level of accuracy of model outputs is explicit, the scales and resolutions used are appropriate to the question(s) and predictions are, where possible, validated with data about species biology. With more detailed species data and increased use of climate data at higher spatial and temporal resolutions the use and development of mechanistic models within a climate change framework will continue to provide more robust predictions than purely correlative models. Bridging the gap that exists between the amount of physiological data required to parameterise mechanistic models to improve model predictions and the applicability of correlative models to novel environments (Kearney et al. 2009a), will need to strike some level of balance between the obtaining results over a relatively short timeframe and model complexity. The rate at which climate is changing and the global threat that it imposes necessitates that models are collaborations between not only different scientific disciplines but also between scientist and conservation managers, key stakeholders and decision makers and politicians to ensure that model application and outcomes are conveyed explicitly and accurately and with full knowledge of limitations. 


\section{References}

Acevedo-Whitehouse, K., Duffus, A.L. 2009. Effects of environmental change on wildlife health. Philosophical Transactions of the Royal Society B: Biological Sciences, 364(1534), 3429-3438.

Ackerman, R.A., Lott, D.B. Deeming, D.C. 2004. Thermal, hydric and respiratory climate of nests. Reptilian incubation: environment, evolution and behaviour, 15-43.

Andrewartha, H.G., Birch, C. 1954. The distribution and abundance of animals. Chicago, University of Press.

Angilletta, M.J.J, Winters, R.S., Dunham, A.E. 2000. Thermal effects on the energetics of lizard embryos: implications for hatchling phenotypes. Ecology. 81, 2957-2968.

Angilletta, M.J. 2009. Thermal adaptation: a theoretical and empirical synthesis. Oxford University Press.

Araújo, M.B., Cabeza, M., Thuiller, W., Hannah, L., Williams, P.H. 2004. Would climate change drive species out of reserves? An assessment of existing reserve-selection methods. Global change biology, 10(9), 1618-1626.

Ashcroft, M.B., Gollan, J.R., Warton, D.I. Ramp, D. 2012. A novel approach to quantify and locate potential microrefugia using topoclimate, climate stability, and isolation from the matrix. Global Change Biology, 18(6), 1866-1879.

Austin, M.P. 2002. Spatial prediction of species distribution: an interface between ecological theory and statistical modelling. Ecological modelling, 157(2), 101-118.

Baek, S., Cho, K., Song, Y.H., Lee, J.L. 2008. Degree-day based models for forecasting the flight activity of adult Helicoverpa assulta (Lepidoptera: Noctuidae) in hot pepper fields. International Journal of Pest Management 54(4): 295-300.

Bale, J.S., Masters, G.J., Hodkinson, I.D., Awmack, C., Bezemer, T.M., Brown, V.K., ... \& Good, J.E. 2002. Herbivory in global climate change research: direct effects of rising temperature on insect herbivores. Global Change Biology, 8(1), 1-16.

Baskerville, G.L., Emin, P. 1969. Rapid estimation of heat accumulation from maximum and minimum temperatures. Ecology, 50(3), 514-517.

Bellard C., Bertelsmeier C., Leadley P., Thuiller W., Courchamp, F. 2012. Impacts of climate change on the future of biodiversity. Ecology Letters. 15, 365-377.

Bestion, E., Teyssier, A., Richard, M., Clobert, J., Cote, J. 2015. Live fast, die young: experimental evidence of population extinction risk due to climate change. PLoS Biol, 13(10).

Bickford, D., Howard, S.D., Ng, D.J., Sheridan, J.A. 2010. Impacts of climate change on the amphibians and reptiles of Southeast Asia. Biodiversity and conservation, 19(4), 1043-1062. 
Birchard, G.F., Deeming, D.C. 2004. Effects of incubation temperature. Reptilian incubation: environment, evolution and behaviour, 103-123.

Böhm, M., Williams, R., Bramhall, H.R., McMillan, K.M., Davidson, A.D., Garcia, A., ... \& Collen, B. 2016. Correlates of extinction risk in squamate reptiles: the relative importance of biology, geography, threat and range size. Global Ecology and Biogeography, 25, 391-405.

Both, C., M. Van Asch, Bijlsma, R.G., Van Den Burg, A.B., Visser, M.E. 2009. Climate change and unequal phenological changes across four trophic levels: Constraints or adaptations? Journal of Animal Ecology, 78, 73-83.

Both, C. 2010. Food availability, mistiming, and climatic change. Effects of climate change on birds, 129-147.

Booth, D.T., Burgess, E., McCosker, J. Lanyon, J.M. 2004. The influence of incubation temperature on post-hatching fitness characteristics of turtles. In International Congress Series (Vol. 1275, 226-233). Elsevier.

Brana, F.L., Ji, X. 2000. Influence of incubation temperature on morphology, locomotor performance, and early growth of hatchling wall lizards (Podarcis muralis). Journal of Experimental Zoology, 286(4), 422-433.

Buckley, L.B., Kingsolver, J.G. 2012. Functional and phylogenetic approaches to forecasting species' responses to climate change. Annual Review of Ecology, Evolution, and Systematics, 43, 205226.

Carslaw, H.S. and Jaeger, J.C. 1959. Conduction of heat in solids. Oxford: Clarendon Press, 1959, 2nd ed.

Carter, A. 2015. Modelling the incubation microclimate to predict offspring sex ratios and hatching phenology in tuatara (Sphenodon punctatus). PhD thesis, Victoria University of Wellington, New Zealand.

Carter, A., Kearney, M., Mitchell, N., Hartley, S., Porter, W., Nelson, N. 2015. Modelling the soil microclimate: does the spatial or temporal resolution of input parameters matter? Frontiers of Biogeography, 7(4).

Cahill, A.E., Aiello-Lammens, M.E., Caitlin Fisher-Reid, M., Hua, X., Karanewsky, C.J., Ryu, H.Y., ... \& Wiens, J.J. 2014. Causes of warm-edge range limits: systematic review, proximate factors and implications for climate change. Journal of Biogeography, 41(3), 429-442.

Chen, I.C., Hill, J.K., Ohlemüller, R., Roy, D.B., Thomas, C.D. 2011. Rapid range shifts of species associated with high levels of climate warming. Science, 333(6045), 1024-1026.

Chown, S.L., Gaston, K.J. 2008. Macrophysiology for a changing world. Proceedings of the Royal Society of London B: Biological Sciences, 275(1642), 1469-1478.

Cayton, H.L., Haddad, N.M., Gross, K., Diamond, S.E., Ries, L. 2015. Do growing degree days predict phenology across butterfly species?. Ecology, 96(6), 1473-1479. 
Clusella-Trullas, S., Blackburn, T.M. Chown, S.L. 2011. Climatic predictors of temperature performance curve parameters in ectotherms imply complex responses to climate change. The American Naturalist, 177(6), 738-751.

Cook, E.R., Palmer, J.G., d'Arrigo, R.D. 2002. Evidence for a 'Medieval Warm Period' in a 1,100-year tree-ring reconstruction of past austral summer temperatures in New Zealand. Geophysical Research Letters. 29 (14), 12.

Cuddington, K., Fortin, M.J., Gerber, L.R., Hastings, A., Liebhold, A., O'connor, M. Ray, C. 2013. Process-based models are required to manage ecological systems in a changing world. Ecosphere, 4(2), 1-12.

Davis, A.J., Jenkinson, L.S., Lawton, J.H., Shorrocks, B., Wood, S. 1998. Making mistakes when predicting shifts in species range in response to global warming. Nature, 391(6669), 783786.

Deeming, D.C., 2004. Post-hatching phenotypic effects of incubation in reptiles, in: D.C Deeming (Ed.), Reptilian Incubation: Environment, Evolution and Behaviour, Nottingham University Press, Nottingham, 229-252.

Deutsch, C.A., Tewksbury, J.J., Huey, R.B., Sheldon, K.S., Ghalambor, C.K., Haak, D.C. Martin, P.R. 2008. Impacts of climate warming on terrestrial ectotherms across latitude. Proceedings of the National Academy of Sciences, 105(18), 6668-6672.

DeWitt, T., Scheiner, S.M. 2004. Phenotypic Plasticity: Functional and Conceptual Approaches. Oxford University Press.

Dobzhansky, T. 1968. On some fundamental concepts of Darwinian biology. In Evolutionary biology, 1-34. Springer US.

Donnelly, A., Caffarra, A., Kelleher, C.T., Neill, B.O., Diskin, E., Pletsers, A., ... \& Hodkinson, T.R. 2012. Surviving in a warmer world: environmental and genetic responses. Climate Research, 53(3), 245-262.

Doody, J.S., Guarino, E., Georges, A., Corey, B., Murray, G., Ewert, M. 2006. Nest site choice compensates for climate effects on sex ratios in a lizard with environmental sex determination. Evolutionary Ecology, 20(4), 307-330.

Doody, J.S., Moore, J.A. 2011. Conceptual model for thermal limits on the distribution of reptiles. Herpetological Conservation and Biology, 5(2), 283-289.

Dormann, C.F. 2007. Promising the future? Global change projections of species distributions. Basic and applied ecology, 8(5), 387-397.

Dormann, C.F., Schymanski, S.J., Cabral, J., Chuine, I., Graham, C., Hartig, F., Kearney, M., Morin, X., Römermann, C., Schröder, B. and Singer, A. 2012. Correlation and process in species distribution models: bridging a dichotomy. Journal of Biogeography, 39: 2119-2131. 
Dowd, W.W., King, F.A., Denny, M.W. 2015. Thermal variation, thermal extremes and the physiological performance of individuals. Journal of Experimental Biology, 218(12), 19561967.

Easterling, D.R., Meehl, G.A., Parmesan, C., Changnon, S.A., Karl, T.R., Mearns, L.O. 2000 Climate extremes: observations, modeling, and impacts. Science 289, 2068-2074.

Elliot, M., Neall, V., Wallace, C. 2005. A late Quaternary pollen record from Lake Tangonge, far northern New Zealand. Review of Palaeobotany and Palynology, 136(3), 143-158.

Elith, J., et al. 2006. Novel methods improve prediction of species distributions from occurrence data. Ecography 29, 129-151.

Elith, J., Leathwick, J.R. 2009. Species distribution models: ecological explanation and prediction across space and time. Annual review of ecology, evolution, and systematics, 40, 677-697.

Elith, J., Kearney, M., Phillips, S. 2010. The art of modelling range-shifting species. Methods in ecology and evolution, 1(4), 330-342.

Elphick, M.J., Shine, R. 1998. Long-term effects of incubation temperatures on the morphology and locomotor performance of hatchling lizards (Bassiana duperreyi, Scincidae). Biological Journal of the Linnean Society, 63(3), 429-447. 9-151.

[ESRI] Environmental Systems Research Institute. 2012. ArcGIS: 10.1 Redlands, CA, USA, 2012.

Evans, T.G., Diamond, S.E., Kelly, M.W. 2015. Mechanistic species distribution modelling as a link between physiology and conservation. Conservation Physiology, 3(1), p.cov056.

Ferrier, S., Watson, G., Pearce, J., Drielsma, M. 2002. Extended statistical approaches to modelling spatial pattern in biodiversity in northeast New South Wales. I. Species-level modelling. Biodiversity \& Conservation, 11(12), 2275-2307.

Ford, K.R., Ettinger, A.K., Lundquist, J.D., Raleigh, M.S., Lambers, J.H.R. 2013. Spatial heterogeneity in ecologically important climate variables at coarse and fine scales in a high-snow mountain landscape. PloS one, 8(6), p.e65008.

Franklin, J., 2010. Mapping species distributions: spatial inference and prediction. Cambridge University Press.

Franks, S.J., Weber, J.J., Aitken, S.N. 2014. Evolutionary and plastic responses to climate change in terrestrial plant populations. Evolutionary Applications, 7(1), 123-1.

Garnier, B.J. 1958. The Climate of New Zealand. Arnold, 191.

Gaston, K.J. 2003. The structure and dynamics of geographic ranges. Oxford Univ. Press on Demand.

Gaston, K.J. 2009. Geographic range limits: achieving synthesis. Proceedings of the Royal Society B: Biological Sciences, 276, 1395-1406.

Geiger, R., Aron, R.H. 2003. The climate near the ground, 2nd edn. Harvard Univ. Press, Cambridge, Mass. 
Georges, A., Beggs, K., Young, J.E., Doody, J.S. 2005. Modelling development of reptile embryos under fluctuating temperature regimes. Physiological and Biochemical Zoology, 78(1), 18-30.

Gill, B., Whitaker, T. 1996. New Zealand frogs and reptiles. Auckland, David Bateman. pp. 112

Gillingham, P.K., Palmer, S.C., Huntley, B., Kunin, W.E., Chipperfield, J.D., Thomas, C.D. 2012. The relative importance of climate and habitat in determining the distributions of species at different spatial scales: a case study with ground beetles in Great Britain. Ecography, 35(9), 831-838.

Guisan, A., Zimmermann, N.E. 2000. Predictive habitat distribution models in ecology. Ecological modelling, 135(2), 147-186.

Gyasi-Agyei, Y., Willgoose, G., De Troch, F.P. 1995. Effects of vertical resolution and map scale of digital elevation models on geomorphological parameters used in hydrology. Hydrological Processes, 9(3-4), 363-382.

Hannah, L., Flint, L., Syphard, A.D., Moritz, M.A., Buckley, L.B., McCullough, I.M. 2014. Fine-grain modeling of species' response to climate change: holdouts, stepping-stones, and microrefugia. Trends in ecology \& evolution, 29(7), 390-397.

Hare, K.M., Daugherty, C.H., Cree, A. 2002. Incubation regime affects juvenile morphology and hatching success, but not sex, of the oviparous lizard Oligosoma suteri (Lacertilia: Scincidae). New Zealand Journal of Zoology, 29(3), 221-229.

Hare, K.M., Longson, C. G., Pledger, S., Daugherty, C. H. 2004. Size, growth, and survival are reduced at cool incubation temperatures in the temperate lizard Oligosoma suteri (Lacertilia:

Scincidae). Copeia, (2), 383-390.

Hare, K.M., Pledger, S., Daugherty, C.H. 2008a. Low incubation temperatures negatively influence locomotor performance and behavior of the nocturnal lizard Oligosoma suteri (Lacertidae: Scincidae). Copeia, (1), 16-22.

Hare, K.M., Daugherty, C.H., Chapple, D.G. 2008b. Comparative phylogeography of three skink species (Oligosoma moco, O. smithi, O. suteri; Reptilia: Scincidae) in northeastern New Zealand. Molecular Phylogenetics and Evolution, 46(1), 303-315.

Hardy, G.S. 1977. The New Zealand Scincidae (Reptilia: Lacertilia); a taxonomic and zoogeographic study. New Zealand journal of zoology, 4(3), 221-325.

Hartley, S., Lester, P. 2003. Temperature-dependent development of the Argentine ant, Linepithema humile (Mayr) (Hymenoptera: Formicidae): a degree-day model with implications for range limits in New Zealand. New Zealand Entomologist, 26, 91-100.

Hayward, B.W. 1986. Origin of the offshore islands of northern New Zealand and their landform development. The offshore islands of northern New Zealand. Department of Lands and Survey information series, 16, 129-138.

Hayward, B.W., Murdoch, G., Maitland, G. 2011. Volcanoes of Auckland: The Essential Guide. Auckland University Press. 
He, K.S., Bradley, B.A., Cord, A.F., Rocchini, D., Tuanmu, M.N., Schmidtlein, S., Turner, W., Wegmann, M., Pettorelli, N. 2015. Will remote sensing shape the next generation of species distribution models? Remote Sensing in Ecology and Conservation, 1(1), 4-18.

Helmuth, B., Kingsolver, J.G., Carrington, E. 2005. Biophysics, physiological ecology, and climate change: does mechanism matter? Annu. Rev. Physiol., 67, 177-201.

Hellmann, J.J., Byers, J.E., Bierwagen, B.G. Dukes, J.S. 2008. Five potential consequences of climate change for invasive species. Conservation biology, 22(3), 534-543.

Hewitt, J.E., Thrush, S.F., Lundquist, C. 2009. Scale-dependence in Ecological Systems. eLS.

Hijmans, R.J., Cameron, S.E., Parra, J.L., Jones, P.G. Jarvis, A. 2005. Very high resolution interpolated climate surfaces for global land areas. International journal of climatology, 25(15), 19651978.

Hijmans, R.J., Graham, C.H. 2006. The ability of climate envelope models to predict the effect of climate change on species distributions. Global change biology, 12(12), 2272-2281.

Hitchmough, R., Anderson, P., Barr, B., Monks, J., Lettink, M., Reardon, J., Tocher, M., Whitaker, T. 2013. Conservation status of New Zealand reptiles, 2012. New Zealand threat classification series, 2, 16.

Hitchmough, R.A., Adams, L.K., Reardon, J.T., Monks, J.M. 2016. Current challenges and future directions in lizard conservation in New Zealand. Journal of the Royal Society of New Zealand, 46(1), 29-39.

Huey, R.B. 1982. Temperature, physiology, and the ecology of reptiles. In Biology of the Reptilia.

Hutchinson, G.E. 1957. Concluding remarks. Cold Spring Harbour Symposium on Quantitative Biology 22, 415-427.

Ikemoto, T., Takai, K. 2000. A new linearized formula for the law of total effective temperature and the evaluation of line fitting methods with both variables subject to error. Environmental Entomology. 29, 671-682.

IPCC. 2007. Summary for Policymakers. In: Climate Change 2007: The Physical Science Basis.

Contribution of Working Group I to the Fourth Assessment Report of the Intergovernmental Panel on Climate Change. Solomon, S., Qin, D., Manning, M., Chen, Z. Marquis, M., Averyt, K.B., Tignor, M. Miller, H.L. (Eds.), Cambridge University Press, Cambridge, United Kingdom and New York, NY, USA. Available at http://www.ipcc.ch/ipccreports/ar4-wg1.htm.

IPCC, 2013: Climate Change 2013: The Physical Science Basis. Contribution of Working Group I to the Fifth Assessment Report of the Intergovernmental Panel on Climate Change [Stocker, T.F., D. Qin, G.-K. Plattner, M. Tignor, S.K. Allen, J. Boschung, A. Nauels, Y. Xia, V. Bex and P.M. Midgley (eds.)]. Cambridge University Press, Cambridge, United Kingdom and New York, NY, USA, 1535. 
IPCC, 2014: Climate Change 2014: Synthesis Report. Contribution of Working Groups I, II and III to the Fifth Assessment Report of the Intergovernmental Panel on Climate Change [Core Writing Team, R.K. Pachauri and L.A. Meyer (eds.)]. IPCC, Geneva, Switzerland, 151 pp.

Irschick, D.J., Garland Jr, T. 2001. Integrating function and ecology in studies of adaptation: investigations of locomotor capacity as a model system. Annual Review of Ecology and Systematics, 32(1), 367-396.

Jeffree, E.P., Jeffree, C.E. 1994. Temperature and the biogeographical distributions of species. Functional Ecology, 640-650.

Jetz, W., Sekercioglu, C.H., Watson, J.E. 2008. Ecological correlates and conservation implications of overestimating species geographic ranges. Conservation Biology, 22(1), 110-119.

Johnson, H., Bleich, V.C., Stephenson, T.R. 2007. Modelling Sierra Nevada Bighorn Sheep habitat: applying resource selection functions to species recovery. California Department of Fish and Game, Bishop, CA.

Keppel, G. Wardell-Johnson, G.W. 2012. Refugia: keys to climate change management. Global Change Biology, 18(8), 2389-2391.

Kikillus, K., Hare, K., Hartley, S. 2010. Minimizing false-negatives when predicting the potential distribution of an invasive species: a bioclimatic envelope for the red-eared slider at global and regional scales. Animal Conservation 13:5-15.

Kingsolver, J.G., Diamond, S.E. Buckley, L.B. 2013. Heat stress and the fitness consequences of climate change for terrestrial ectotherms. Functional Ecology, 27(6), 1415-1423.

Kearney, M., Porter, W.P. 2004. Mapping the fundamental niche: physiology, climate, and the distribution of a nocturnal lizard. Ecology 85, 3119-3131.

Kearney, M., Porter W.P. 2009. Mechanistic niche modelling: combining physiological and spatial data to predict species' ranges. Ecology Letters, 12, 334-350.

Kearney M.R., Shine, R., Porter, W.P. 2009. The potential for behavioural thermoregulation to buffer "cold-blooded" animals against global warming. Proceedings of the National Academy of Sciences, USA 106, 3835-3840

Kearney, M., Simpson, S.J., Raubenheimer, D., Helmuth, B. 2010. Modelling the ecological niche from functional traits. Philosophical Transactions of the Royal Society of London B: Biological Sciences, 365(1557), 3469-3483.

Kearney, M.R., Isaac, A.P., Porter, W.P. 2014a. microclim: Global estimates of hourly microclimate based on long-term monthly climate averages. Scientific data, 1.

Kearney, M.R., Shamakhy, A., Tingley, R., Karoly, D.J., Hoffmann, A.A., Briggs, P.R. Porter, W.P. 2014b. Microclimate modelling at macro scales: a test of a general microclimate model integrated with gridded continental-scale soil and weather data. Methods in Ecology and Evolution, 5(3), 273-286. 
Kearney, M.R. Porter, W.P. 2016. NicheMapR - an R package for biophysical modelling: the microclimate model. Ecography 39: 000-000 (ver. 1).

Koepke, P., Hess, M., Schult, I., Shettle, E.P. 1997. Global aerosol data set. MPI Meteorologie Hamburg Rep, 243, p.44.

Kristensen, K.J. 1959. Temperature and heat balance of soil. Oikos, 10(1), 103-120.

Leadley, P. 2010. Biodiversity scenarios: projections of 21st century change in biodiversity, and associated ecosystem services: a technical report for the global biodiversity. outlook 3 (No. 50). NEP/Earthprint.

Leathwick, J.R., Austin, M.P. 2001. Competitive interactions between tree species in New Zealand's old-growth indigenous forests. Ecology 82:2560-2573.

Legendre, P. 2014. Imodel2: Model II Regression. R package version 1.7-2. http://CRAN.Rproject.org/package=Imodel 2 .

Lettink, M., Monks, J.M. 2016. Survey and monitoring methods for New Zealand lizards. Journal of the Royal Society of New Zealand, 46(1), 16-28.

Martínez-Freiría, F., Sillero, N., Lizana, M., Brito, J.C. 2008. GIS-based niche models identify environmental correlates sustaining a contact zone between three species of European vipers. Diversity and Distributions, 14(3), 452-461.

Meehl GA, Tebaldi C. 2004. More intense, more frequent, and longer lasting heat waves in the 21st century. Science 305, 994-997

McCullough, E.C., Porter, W.P. 1971. Computing clear day solar radiation spectra for the terrestrial ecological environment. Ecology, 52, 1008-1015.

McGreevy, J.P. 1985. Thermal properties as controls on rock surface temperature maxima, and possible implications for rock weathering. Earth Surface Processes and Landforms, 10(2), 125-136.

Miller, J.R., Turner, M.G., Smithwick, E.A., Dent, C.L., Stanley, E.H. 2004. Spatial extrapolation: the science of predicting ecological patterns and processes. BioScience, 54(4), 310-320.

Ministry for the Environment [MfE], 2016. Climate Change Projections for New Zealand: Atmosphere Projections Based on Simulations from the IPCC Fifth Assessment. Wellington: Ministry for the Environment. http://www.mfe.govt.nz/publications/climatechange/climate-change-effects-and-impacts-assessment-guidance-manual-local-51

Mitchell, N.J., Kearney, M., Nelson, N.J., Porter, W.P. 2008. Predicting the fate of a living fossil: how will global warming affect sex determination and hatching phenology in tuatara? Proc. Biol. Sci. Series B, 275, 2185-2193.

Morin, X., Thuiller, W. 2009. Comparing niche- and process-based models to reduce prediction uncertainty in species range shifts under climate change. Ecology, 90 (5)1301-13. 
Nelson, N.J., Thompson, M.B., Pledger, S., Keall, S.N. Daugherty, C.H. 2004, December. Do TSD, sex ratios, and nest characteristics influence the vulnerability of tuatara to global warming?. In International Congress Series (Vol. 1275, 250-257). Elsevier.

Newman, D.G., D.R. Towns. 1985. A survey of the herpetofauna of the northern and southern blocks, Great Barrier Island, New Zealand. Journal of the Royal Society of New Zealand, 15, 279-287.

NIWA, National Institute of Water and Atmospheric Research, 2016. Managing New Zealand's climate: A resource and a hazard. Wellington, New Zealand.

Noble, D.W.A., McFarlane, S.E., Keogh, J. S., Whiting, M.J. 2014. Maternal and additive genetic effects contribute to variation in offspring traits in a lizard. Behavioral Ecology, 25(3), 633640.

Parmesan, C., Yohe, G. 2003. A globally coherent fingerprint of climate change impacts across natural systems. Nature, 421(6918), 37-42.

Parker, S.L., Andrews, R.M. 2007. Incubation temperature and phenotypic traits of Sceloporus undulatus: implications for the northern limits of distribution. Oecologia, 151(2), 218-231.

Parrish, G.R., Gill, B.J. 2003. Natural history of the lizards of the Three Kings Islands, New Zealand. New Zealand Journal of Zoology, 30, 205-220.

Pearce, J., Lindenmayer, D. 1998. Bioclimatic Analysis to Enhance Reintroduction Biology of the Endangered Helmeted Honeyeater (Lichenostomus melanops cassidix) in Southeastern Australia. Restoration Ecology, 6: 238-243.

Pearson, R.G., Dawson, T.P. 2003. Predicting the impacts of climate change on the distribution of species: are bioclimate envelope models useful?. Global ecology and biogeography, 12(5), 361-371.

Pearson, R.G. 2007. Species' distribution modeling for conservation educators and practitioners. Synthesis. American Museum of Natural History, 1, 1-50.

Pickard, C.R., Towns, D.R. 1988. Atlas of the amphibians and reptiles of New Zealand. Conservation sciences publication 1 .

Porter, W.P., Mitchell, J.W., Beckman, W.A., DeWitt, C.B. 1973. Behavioral implications of mechanistic ecology - thermal and behavioral modeling of desert ectotherms and their microenvironment. Oecologia, 13, 1-54.

Porter, W.P. 1989. New animal models and experiments for calculating growth potential at different elevations. Physiological Zoology 62:286-313.

Porter, W.P., Budaraju, S., Stewart, W.E., Ramankutty, N. 2000. Calculating climate effects on birds and mammals: impacts on biodiversity, conservation, population parameters, and global community structure. American Zoologist 40:597-630.

Porter, W.P., Sabo, J.L., Tracy, C.R., Reichman, O.J. Ramankutty, N. 2002. Physiology on a landscape scale: plant-animal interactions. Integrative and Comparative Biology, 42, 431-453. 
Potter, K.A., Woods, H.A., Pincebourde, S. 2013. Microclimatic challenges in global change biology. Global Change Biology, 19, 2932-2939.

Price, T.D., Qvarnström, A. Irwin, D.E. 2003. The role of phenotypic plasticity in driving genetic evolution. Proceedings of the Royal Society of London B: Biological Sciences, 270(1523), 1433-1440.

Qiu, G.Y., LI, H.Y., Zhang, Q.T., Wan, C.H.E.N., Liang, X.J., Li, X.Z. 2013. Effects of evapotranspiration on mitigation of urban temperature by vegetation and urban agriculture. Journal of Integrative Agriculture, 12(8), 1307-1315.

Randin, C.F., Dirnböck, T., Dullinger, S., Zimmermann, N.E., Zappa, M., Guisan, A. 2006. Are nichebased species distribution models transferable in space? Journal of Biogeography, 33(10), 1689-1703.

Refsnider, J.M., Janzen, F.J. 2010. Putting eggs in one basket: ecological and evolutionary hypotheses for variation in oviposition-site choice. Annual Review of Ecology, Evolution, and Systematics, 41, 39-57.

R Development Core Team. R: A language and environment for statistical computing (R Foundation for Statistical Computing: Vienna, Austria, ISBN 3-900051-07-0, 2012).

Romijn, R.L. Hartley, S. 2016. Trends in lizard translocations in New Zealand between 1988 and 2013. New Zealand Journal of Zoology, 1-20.

Root, T.L., Price, J.T., Hall, K.R., Schneider, S.H., Rosenzweig, C. Pounds, J.A. 2003. Fingerprints of global warming on wild animals and plants. Nature, 421(6918), 57-60.

Schulte, P.M., Healy, T.M. Fangue, N.A. 2011. Thermal performance curves, phenotypic plasticity, and the time scales of temperature exposure. Integrative and comparative biology, p.icr097.

Schwanz, L.E. 2016. Parental thermal environment alters offspring sex ratio and fitness in an oviparous lizard. Journal of Experimental Biology.

Sinclair, S.J., White, M.D., Newell, G.R. 2010. How useful are species distribution models for managing biodiversity under future climates. Ecology and Society, 15(8).

Searcy, C.A., Shaffer, H.B. 2016. Do Ecological Niche Models Accurately Identify Climatic Determinants of Species Ranges? The American Naturalist, 187(4), 423-435.

Seo, C., Thorne, J.H., Hannah, L., Thuiller, W. 2009. Scale effects in species distribution models: implications for conservation planning under climate change. Biology Letters, 5(1), 39-43.

Sexton, J.P., McIntyre, P.J., Angert, A.L., Rice, K.J. 2009. Evolution and ecology of species range limits. Annual Review of Ecology, Evolution, and Systematics, 40, 415-436.

Sinervo, B., Mendez-De-La-Cruz, F., Miles, D.B., Heulin, B., Bastiaans, E., Villagrán-Santa Cruz, M., Lara-Resendiz, R., Martínez-Méndez, N., Calderón-Espinosa, M.L., Meza-Lázaro, R.N., Gadsden, H. 2010. Erosion of lizard diversity by climate change and altered thermal niches. Science, 328(5980), 894-899. 
Shabani, F., Kumar, L. and Ahmadi, M. 2016. A comparison of absolute performance of different correlative and mechanistic species distribution models in an independent area. Ecology and Evolution, 6(16), 5973-5986.

Sherley, G.H., Stringer, I.A., Parrish, G.R. 2010. Summary of native bat, reptile, amphibian and terrestrial invertebrate translocations in New Zealand (No. 303). Department of Conservation.

Shine, R. 1987. Reproductive mode may determine geographic distributions in Australian venomous snakes (Pseudechis, Elapidae). Oecologia, 71(4), 608-612.

Shine, R. 2004. Seasonal shifts in nest temperature can modify the phenotypes of hatchling lizards, regardless of overall mean incubation temperature. Functional Ecology, 18(1), 43-49.

Shine, R. 2005. Life-history evolution in reptiles. Annual Reviews of Ecology, Evolution, and Systematics, 36, 23-46.

Strasburg, J.L., Kearney, M., Moritz, C., Templeton, A.R. 2007. Combining phylogeography with distribution modeling: multiple Pleistocene range expansions in a parthenogenetic gecko from the Australian arid zone. PLoS One, 2(8), p.e760.

Struebig, M.J., Fischer, M., Gaveau, D.L., Meijaard, E., Wich, S.A., Gonner, C., Sykes, R., Wilting, A. Kramer-Schadt, S. 2015. Anticipated climate and land-cover changes reveal refuge areas for Borneo's orang-utans. Global change biology, 21(8), 2891-2904.04-209.

Sunday, J.M., Bates, A.E., Dulvy, N. K. 2012. Thermal tolerance and the global redistribution of animals. Nature Climate Change, 2(9), 686-690.

Sykes, M.T., Prentice, I.C. Cramer, W. 1996. A bioclimatic model for the potential distributions of north European tree species under present and future climates. Journal of Biogeography, 203-233.

Tait, A. 2008. Future projections of growing degree days and frost in New Zealand and some implications for grape growing. Weather and Climate, 28, 17-36

Terblanche, J.S., Hoffmann, A.A., Mitchell, K.A., Rako, L., le Roux, P.C., Chown, S.L. 2011. Ecologically relevant measures of tolerance to potentially lethal temperatures. Journal of Experimental Biology, 214(22), 3713-3725.

Telemeco, R.S., Elphick, M.J. Shine, R. 2009. Nesting lizards (Bassiana duperreyi) compensate partly, but not completely, for climate change. Ecology, 90(1), 17-22.

Thuiller, W. 2004. Patterns and uncertainties of species' range shifts under climate change. Global Change Biology, 10(12), 2020-2027.

Thuiller, W., Münkemüller, T., Lavergne, S., Mouillot, D., Mouquet, N., Schiffers, K., Gravel, D. 2013. A road map for integrating eco-evolutionary processes into biodiversity models. Ecology letters, 16(s1), 94-105.

Thomas, C.D., Cameron, A., Green, R. E., Bakkenes, M., Beaumont, L. J., Collingham, Y. C., ... Hughes, L. 2004. Extinction risk from climate change. Nature, 427(6970), 145-148. 
Thomas, C.D. 2011. Translocation of species, climate change, and the end of trying to recreate past ecological communities. Trends in Ecology \& Evolution, 26(5), 216-221.

Thompson, J.A., Bell, J.C. Butler, C.A. 2001. Digital elevation model resolution: effects on terrain attribute calculation and quantitative soil-landscape modeling. Geoderma, 100(1), 67-89.

Towns, D.R. 1975a. Reproduction and growth of the black shore skink, Leiolopisma suteri (Lacertilia: Scincidae), in north-eastern New Zealand. New Zealand journal of zoology, 2(4), 409-423.

Towns, D.R. 1975b. Ecology of the black shore skink, Leiolopisma suteri (Lacertilia: Scincidae), in boulder beach habitats. New Zealand Journal of Zoology, 2(4), 389-407.

Towns, D.R., Daugherty, C.H. 1994. Patterns of range contractions and extinctions in the New Zealand herpetofauna following human colonisation. New Zealand journal of zoology, 21(4), 325-339.

Towns, D.R., Daugherty, C.H., Cree, A. 2001. Raising the prospects for a forgotten fauna: a review of 10 years of conservation effort for New Zealand reptiles. Biological Conservation 99:3-16

Towns, D.R., Neilson, K.A., Whitaker, A.H. 2002. North Island Oligosoma spp. skink recovery plan 2002-2012. Threatened Species Recovery Plan, 48, 1-61.

Towns, D.R., Parrish, G.R., Westbrooke, I. 2003. Inferring vulnerability to introduced predators without experimental demonstration: case study of Suter's skink in New Zealand. Conservation Biology, 17(5), 1361-1371.

Van Damme, R., Bauwens, D., Verheyen, R.F. 1987. Thermoregulatory responses to environmental seasonality by the lizard Lacerta vivipara. Herpetologica, 405-415.

Van Hooidonk, R., Huber, M. 2009. Quantifying the quality of coral bleaching predictions. Coral Reefs, 28(3), 579-587.

Varner, J. Dearing, M.D. 2014. The importance of biologically relevant microclimates in habitat suitability assessments. PloS one, 9(8), p.e104648.

Visser, M.E., Van Noordwijk, A.J., Tinbergen, J.M., Lessells, C.M. 1998. Warmer springs lead to mistimed reproduction in great tits (Parus major). Proceedings of the Royal Society of London B: Biological Sciences, 265(1408), 1867-1870.

Visser, M.E. 2008. Keeping up with a warming world; assessing the rate of adaptation to climate change. Proceedings of the Royal Society of London B: Biological Sciences, 275(1635), 649659.

Vitt, L.J., Caldwell, J.P. 2013. Herpetology: an introductory biology of amphibians and reptiles. Academic Press.

Walther, G.R., Post, E., Convey, P., Menzel, A., Parmesan, C., Beebee, T.J., Fromentin, J.M., HoeghGuldberg, O., Bairlein, F. 2002. Ecological responses to recent climate change. Nature, 416(6879), 389-395. 
Whitaker, A.H. 1968. Leiolopisma suteri (Boulenger), an oviparous skink in New Zealand. New Zealand Journal of Science 11, 425-32.

Williams, S.E., Bolitho, E.E. Fox, S. 2003. Climate change in Australian tropical rainforests: an impending environmental catastrophe. Proceedings of the Royal Society of London B: Biological Sciences, 270(1527), 1887-1892.

Wilson, L.T., Barnett, W.W. 1983. Degree Days: An Aid in Crop and Pest Management. California Agriculture, 37, 4-7.

Wilson, A.T., Hendy, C.H., Reynolds, C.P. 1979. Short-term climate change and New Zealand temperatures during the last millennium. Nature, 279 (5711), 315.

Wisz, M.S., Pottier, J., Kissling, W.D., Pellissier, L., Lenoir, J., Damgaard, C.F., Dormann, C.F., Forchhammer, M.C., Grytnes, J.A., Guisan, A. Heikkinen, R.K. 2013. The role of biotic interactions in shaping distributions and realised assemblages of species: implications for species distribution modelling. Biological Reviews, 88(1), 15-30.

Worthy, T.H. 1987. Osteological observation on the larger species of the skink Cyclodina and the subfossil occurrence of these and the gecko Hoplodactylus duvaucelii in the North Island, New Zealand. New Zealand journal of zoology, 14, 219-229.

Wratt, D., Mullan, B., Salinger, J., Allan, S., Morgan, T., Kenny, G. 2004. Climate Change Effects and Impacts Assessment. A guidance manual for Local Government in New Zealand.

Zurell, D., Jeltsch, F., Dormann, C.F., Schröder, B. 2009. Static species distribution models in dynamically changing systems: how good can predictions really be?. Ecography, 32(5), 733744. 


\section{Appendices}

Appendix 1 Incubation duration comparing data loggers and 5 sites from model output for three depths. Incubation duration is calculated from 1 January using the methods from chapter 2. A dash indicates that the data logger did not reach the degree-day minimum (616) by 1 April. Model depths from comparative sites predicted from the microclimate model were approximately the 5 nearest points to the field sites in Fig 1.

\begin{tabular}{|l|c|c|c|c|c|c|c|c|c|c|}
\hline \multirow{2}{*}{ Depths } & \multicolumn{4}{|c|}{ Rangitoto (site 1) } & \multicolumn{5}{c|}{ Model sites (Rangitoto) } \\
\cline { 2 - 11 } & DL 1 & DL 2 & DL 3 & DL 4 & Site 1 & Site 2 & Site 3 & Site 4 & Site 5 \\
\hline $0 \mathrm{~mm}$ & 84 & - & - & 89 & 57 & 58 & 57 & 58 & 57 \\
\hline $100 \mathrm{~mm}$ & 86 & 76 & 63 & 83 & 60 & 61 & 60 & 61 & 60 \\
\hline $200 \mathrm{~mm}$ & 84 & 83 & 64 & 86 & 64 & 64 & 64 & 64 & 64 \\
\hline & \multicolumn{5}{|c|}{ Motutapu (site 2) } & \multicolumn{5}{|c|}{ Model sites (Motutapu) } \\
\hline & DL 1 & DL 2 & DL 3 & DL 4 & & Site 1 & Site 2 & Site 3 & Site 4 & Site 5 \\
\hline $0 \mathrm{~mm}$ & - & 79 & 90 & - & & 68 & 76 & 72 & 67 & 70 \\
\hline $100 \mathrm{~mm}$ & 84 & 69 & - & - & & 71 & 80 & 75 & 70 & 73 \\
\hline $200 \mathrm{~mm}$ & - & - & - & - & 74 & 87 & 79 & 73 & 76 \\
\hline
\end{tabular}


Appendix 2 Hourly soil temperatures for three months from both data loggers and microclimate model for the two sites at Rangitoto and Motutapu (Fig. 1). Each graph contains the 3 depths for every hour over the three-month period starting from midnight of 1 January ending on 23:00 of 31 March. Model soil temperatures are for the nearest point to each site.

Model temperatures at site 1 (Rangitoto)

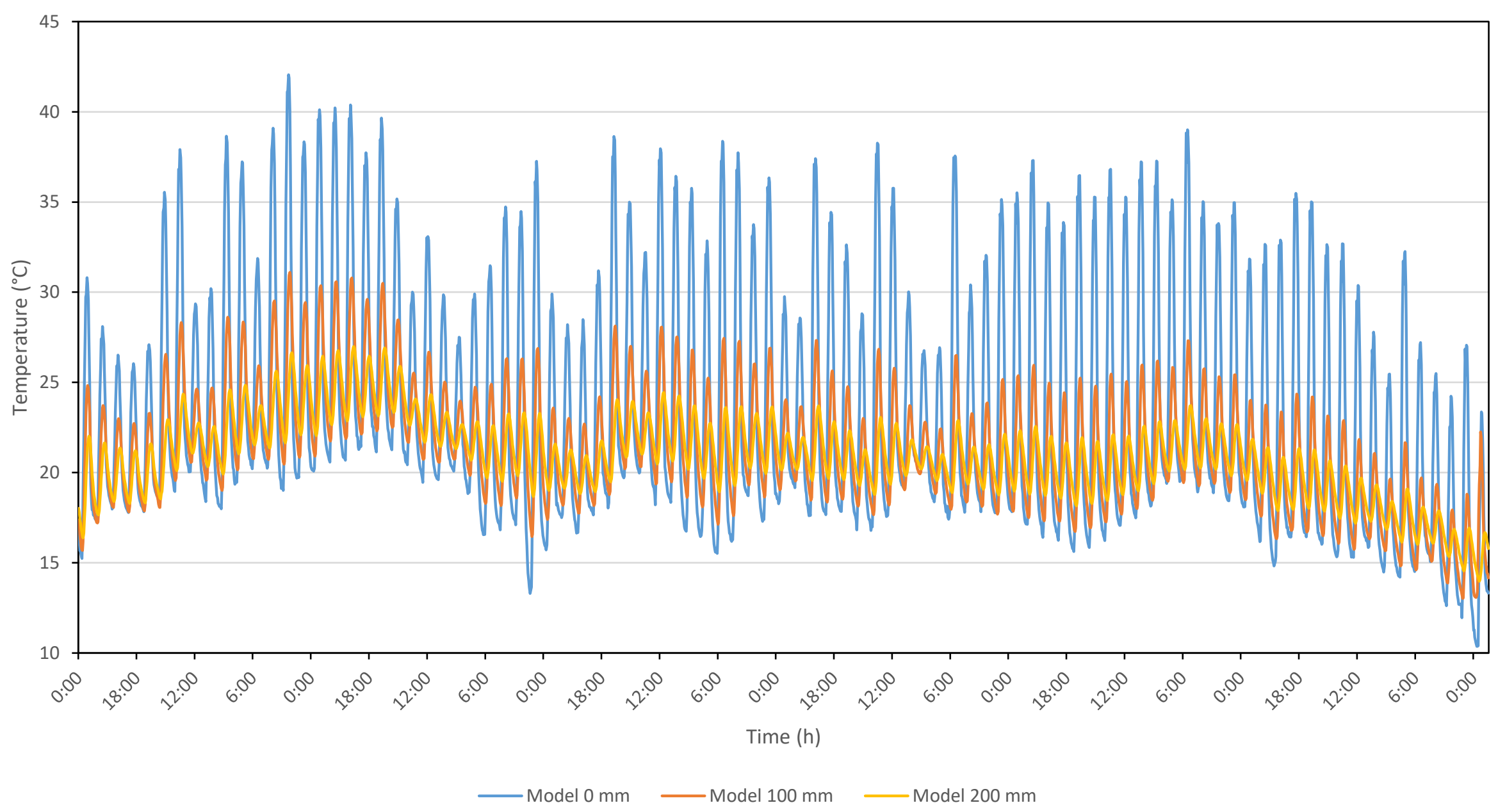


Data loggers \#2 (site 1)

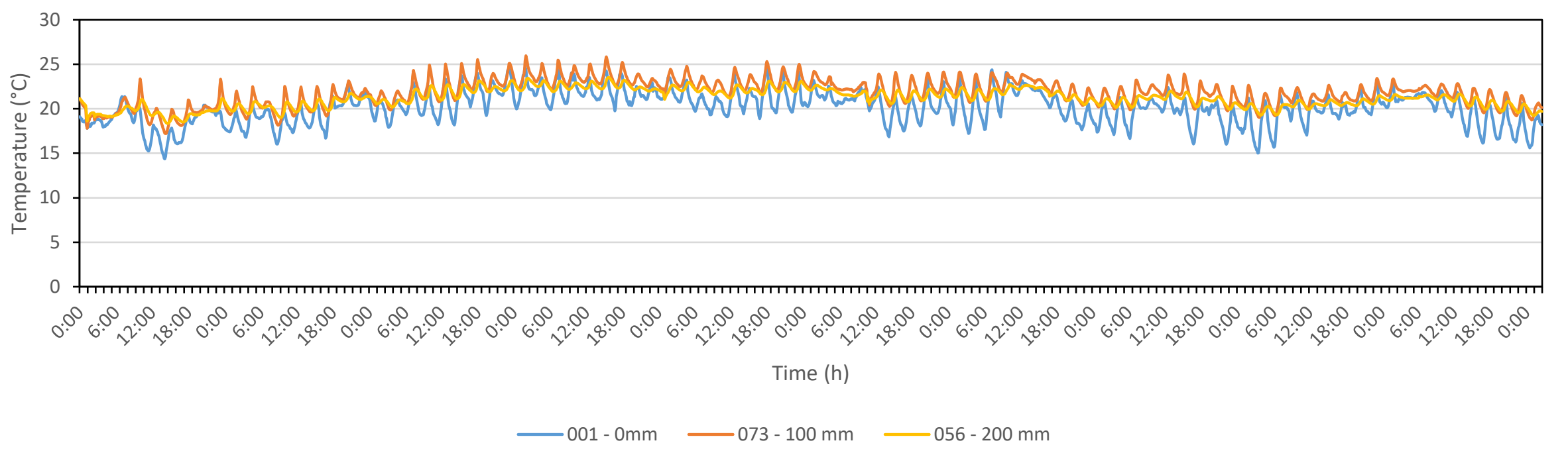

Data logger \#1 (site 1)

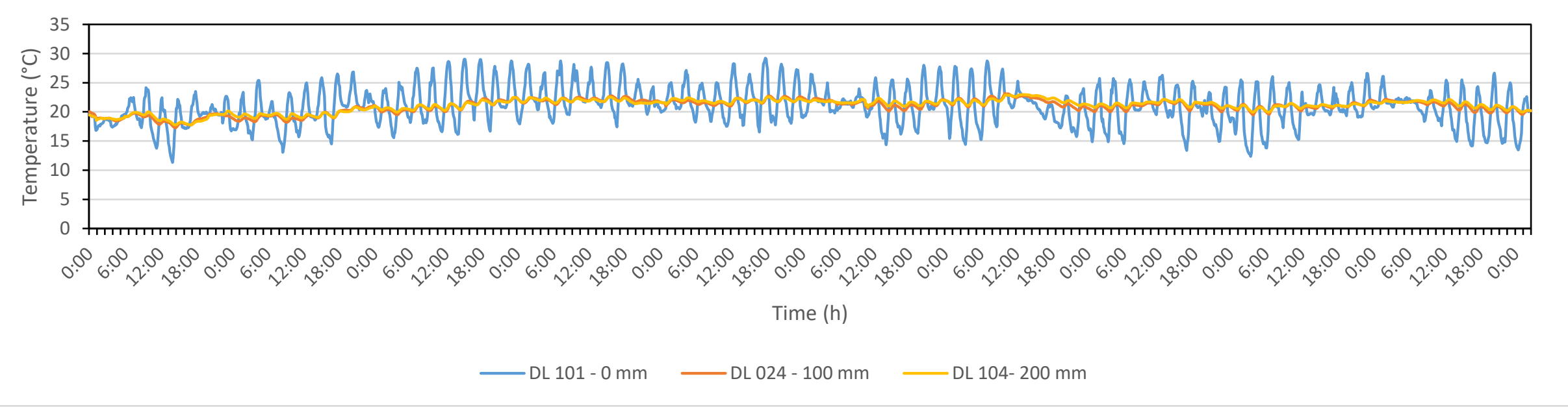


Data logers \#3 (site 1)

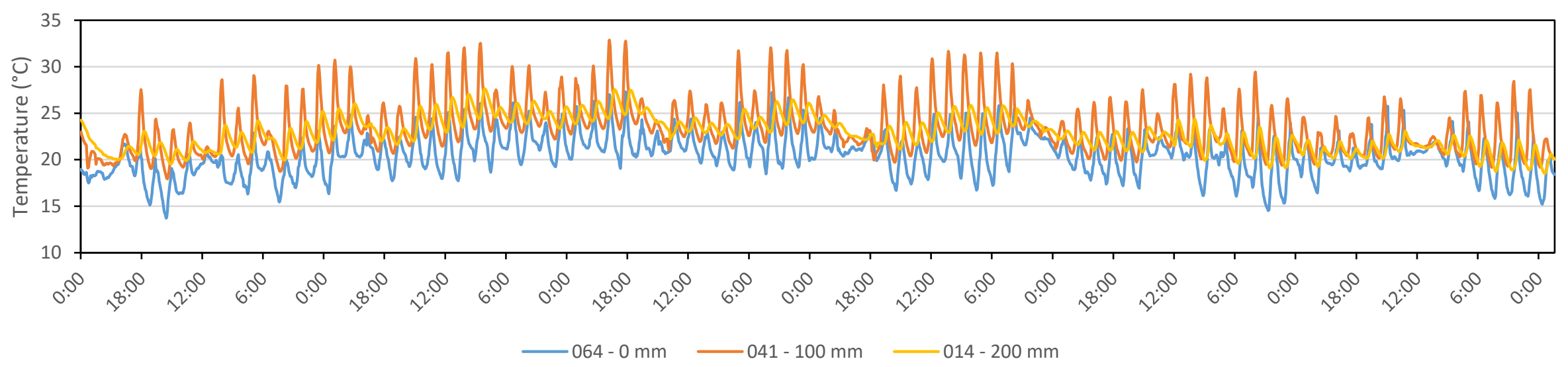

\section{Data loggers \#4 (site 1)}

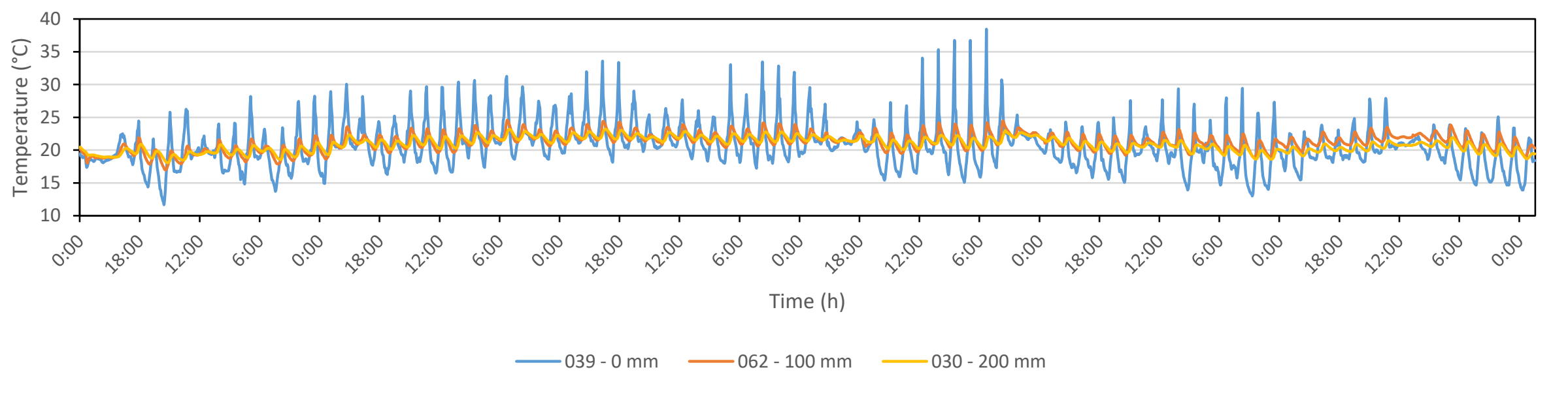


Model site 2 (Motutapu)

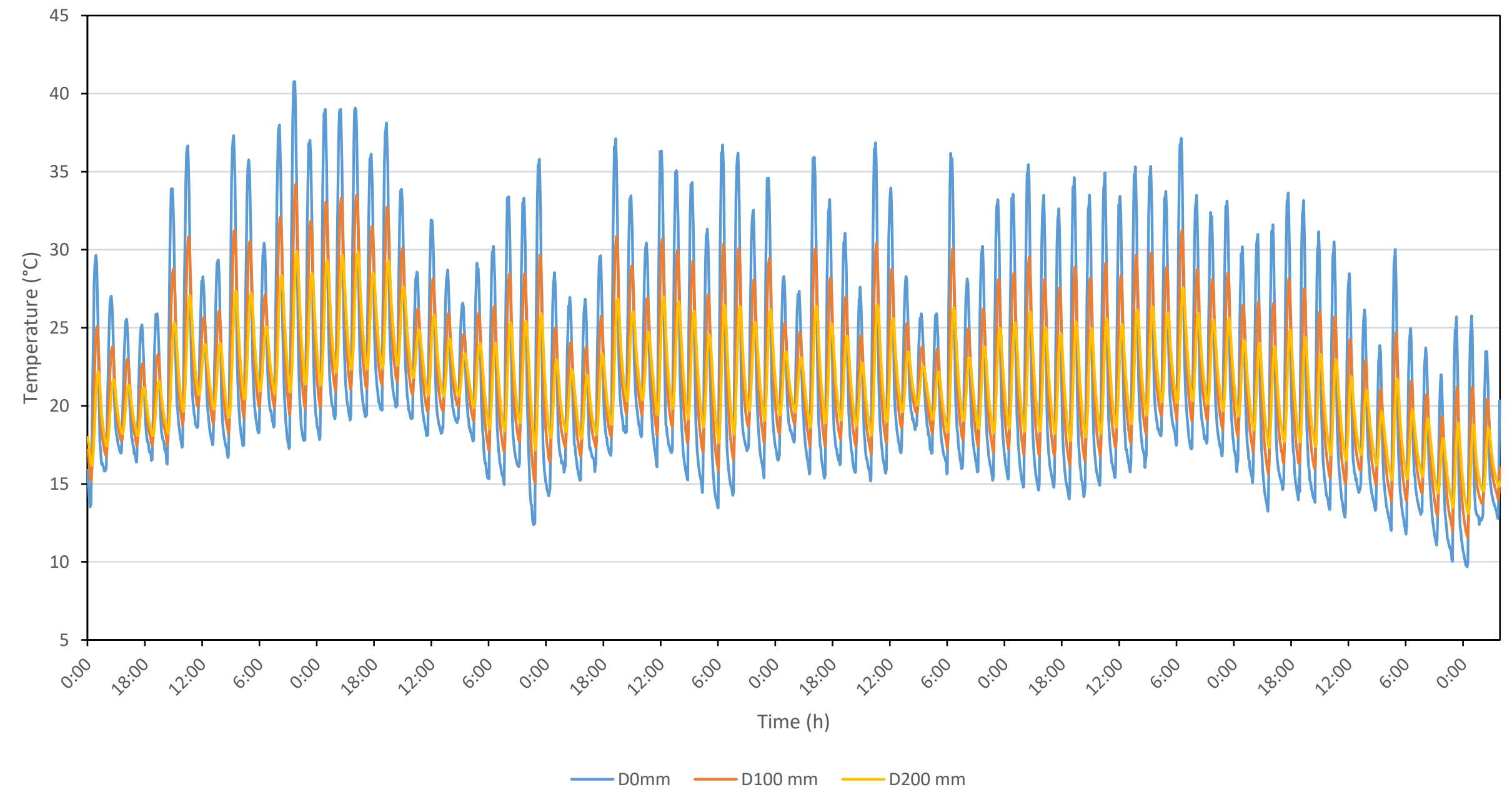


Data logger \#1 (Site 2)

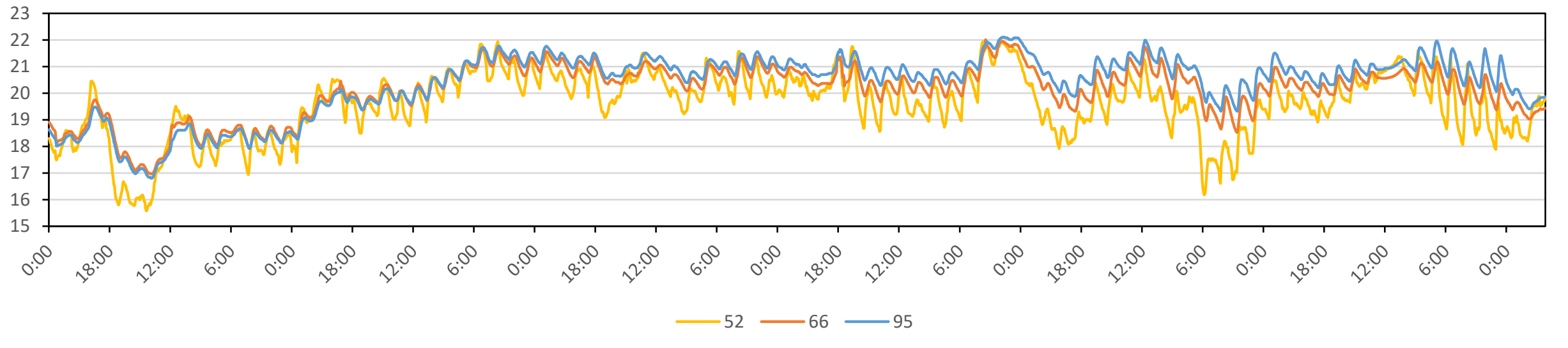

Data logger \#2 (Site 2)

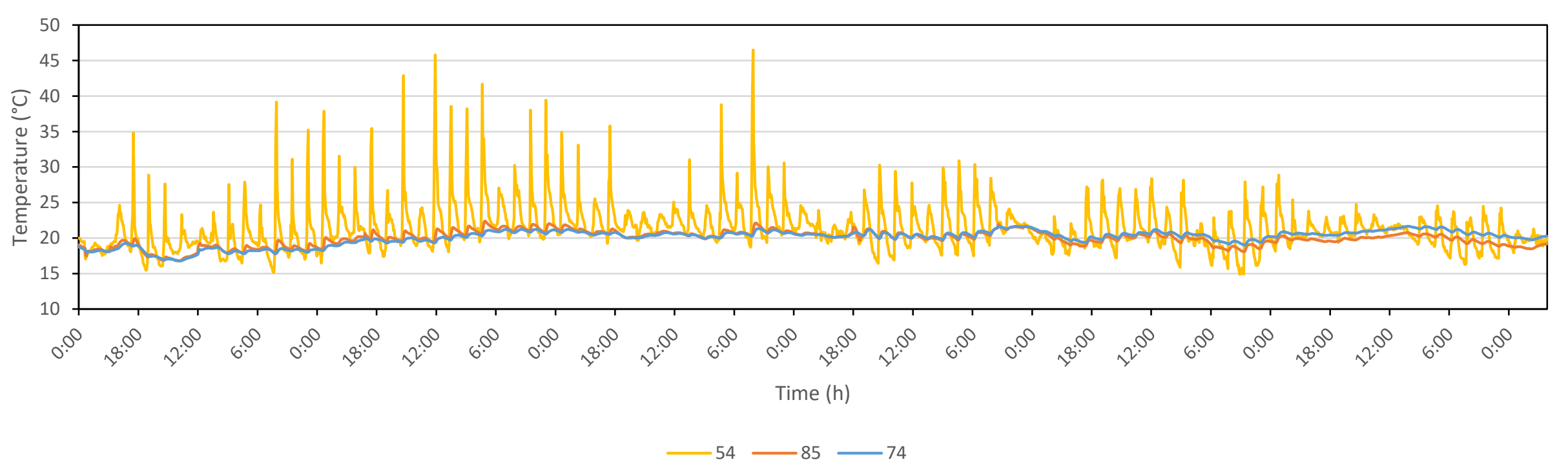


Data logger \#4 (Site 2)

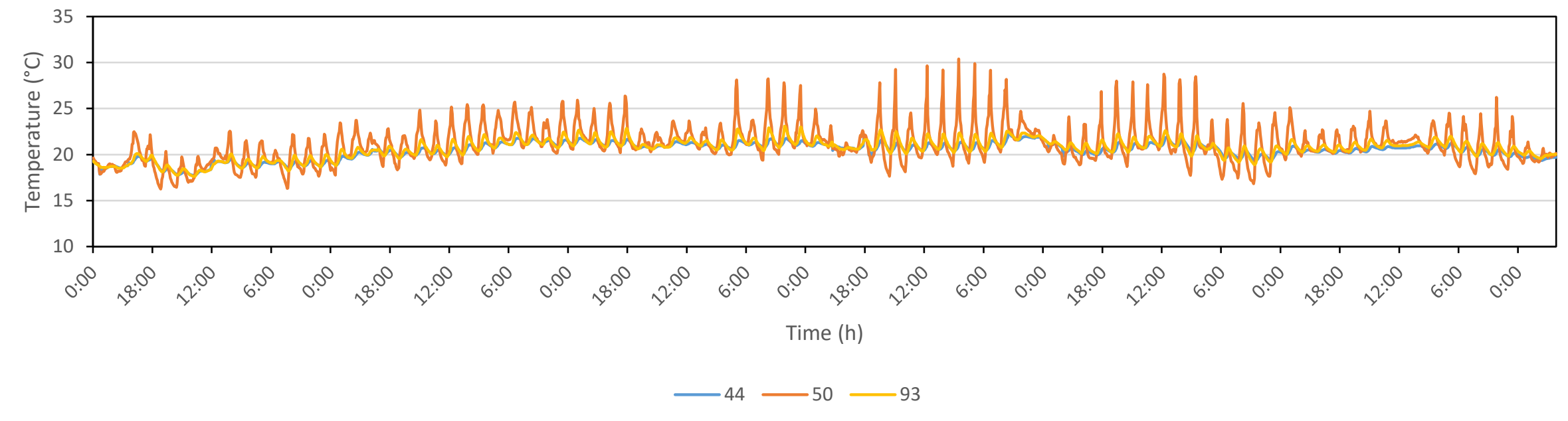

Data logger \#3 (Site 2)

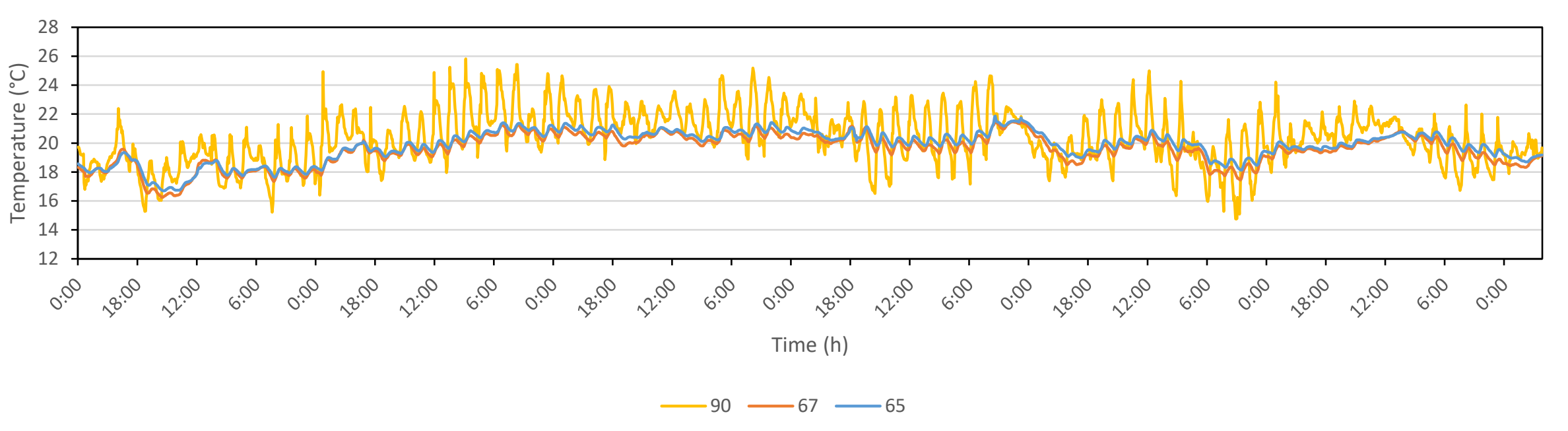


Appendix 3 data logger array at Rangitoto/Motutapu Island. Data logger ID is each individual data logger set at each of the three depths (0, 100 and $300 \mathrm{~mm}$ ). Minimum, maximum and average data logger temperatures are in degrees $\left({ }^{\circ} \mathrm{C}\right)$.

\begin{tabular}{|c|c|c|c|c|c|c|c|c|c|c|c|}
\hline $\begin{array}{l}\text { Data } \\
\text { logger ID } \\
(0 \mathrm{~mm})\end{array}$ & Minimum & Maximum & Average & $\begin{array}{l}\text { Data } \\
\text { logger ID } \\
(100 \mathrm{~mm})\end{array}$ & Minimum & Maximum & Average & $\begin{array}{l}\text { Data } \\
\text { logger ID } \\
(200 \mathrm{~mm})\end{array}$ & Minimum & Maximum & Average \\
\hline 1 & 14.36 & 24.67 & 20.02 & 24 & 17.15 & 23.2 & 20.7 & 104 & 17.51 & 22.96 & 20.83 \\
\hline 101 & 11.32 & 29.21 & 20.86 & 73 & 17.2 & 25.96 & 21.62 & 56 & 18.27 & 23.52 & 18.27 \\
\hline 64 & 13.71 & 27.3 & 20.25 & 41 & 17.93 & 32.87 & 23.24 & 14 & 18.5 & 27.62 & 22.74 \\
\hline 39 & 11.66 & 38.44 & 20.49 & 62 & 16.69 & 24.58 & 20.99 & 30 & 17.6 & 23.2 & 20.7 \\
\hline 93 & 16.91 & 23.08 & 20.44 & 50 & 15.36 & 30.39 & 20.92 & 44 & 16.93 & 22.393 & 20.233 \\
\hline 52 & 15.41 & 21.96 & 19.42 & 66 & 16.72 & 22.01 & 19.91 & 95 & 16.67 & 22.1 & 20.12 \\
\hline 54 & 14.62 & 46.48 & 21.28 & 85 & 16.6 & 22.39 & 19.79 & 74 & 16.6 & 21.65 & 19.86 \\
\hline 90 & 14.4 & 25.81 & 20.17 & 67 & 16.03 & 21.46 & 19.35 & 65 & 16.34 & 21.86 & 19.61 \\
\hline
\end{tabular}


Appendix 4 Temperatures recoded from data loggers on Korapuki Island. A dash indicates the data logger no temperature was recorded due to data logger failure.

\begin{tabular}{|c|c|c|c|c|}
\hline Data logger array (Korapuki) & Degree-days (4 days) & Average temperature & Maximum & Minimum \\
\hline AWC012 (1) & 35.43 & 21.07 & 26.072 & 16.082 \\
\hline AWC021 (2) & 26.22 & 19.27 & 22.058 & 16.987 \\
\hline AWC026 (3) & 33.38 & 20.76 & 26.695 & 17.13 \\
\hline AWC057 (5) & 29.78 & 20.04 & 25.744 & 15.796 \\
\hline AWC061 (6) & 24.02 & 18.80 & 19.963 & 18.033 \\
\hline AWC071 (7) & 26.71 & 19.38 & 22.369 & 17.011 \\
\hline AWC040 (10) & - & - & - & - \\
\hline AWC087 (11) & - & - & - & - \\
\hline AWC002 (12) & 27 & 17.9 & 21.8 & 19.3 \\
\hline \multicolumn{5}{|l|}{ Actual Nest data loggers } \\
\hline AWC023 (10) & 42.56 & 22.46 & 27.35 & 17.32 \\
\hline AWC070 (16) & 42.61 & 22.2 & 28.89 & 17.796 \\
\hline \multicolumn{5}{|l|}{$\begin{array}{l}\text { Representative nest sites within } \\
\text { the same location }\end{array}$} \\
\hline AWC097 (18) & 44.51 & 22.502 & 31.052 & 17.32 \\
\hline AWC036 (19) & 37.81 & 20.33 & 28.59 & 17.98 \\
\hline AWC055 (20) & 35.12 & 20.74 & 27.76 & 17.89 \\
\hline
\end{tabular}


Appendix 5 Incubation duration in days for each depth predicted by the microclimate model. Minimum and maximum number of days to hatch generated by the microclimate model for all depths and across all sites for Rangitoto/Motutapu.

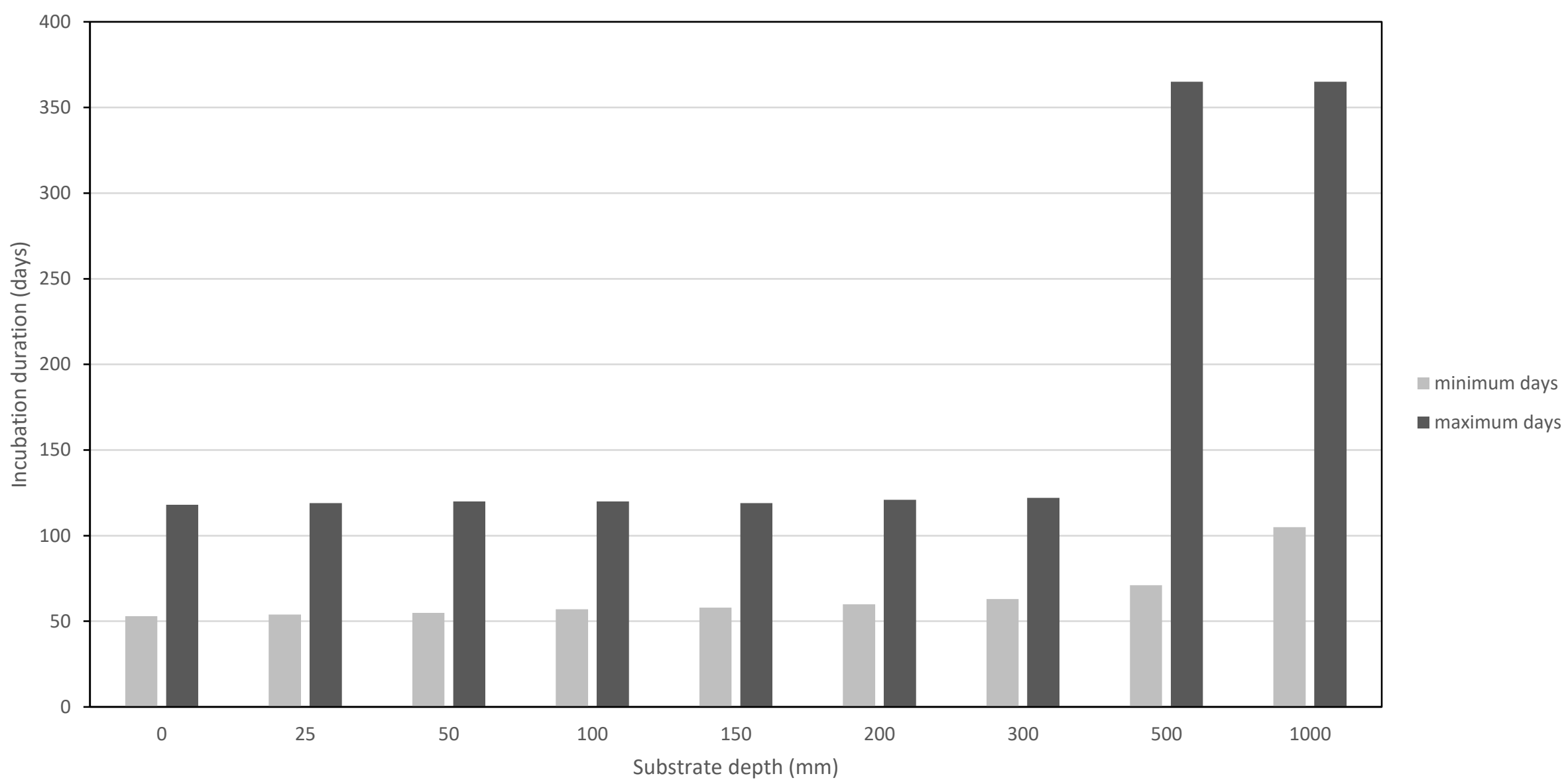


Appendix 6 Incubation duration predicted Rangitoto/Motutapu Island using a $20 \mathrm{~m}$ spatial resolution from chapter two which includes the two additional depths (500 and $1000 \mathrm{~mm}$ ).

A) $0 \mathrm{~mm}$

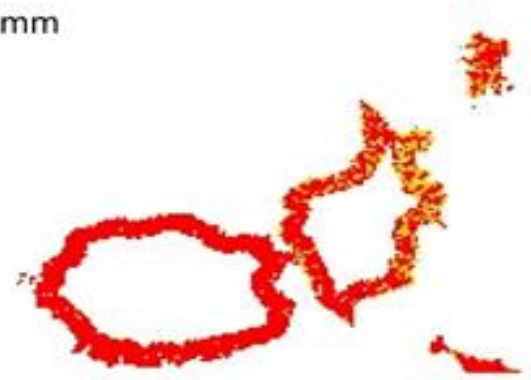

C) $50 \mathrm{~mm}$

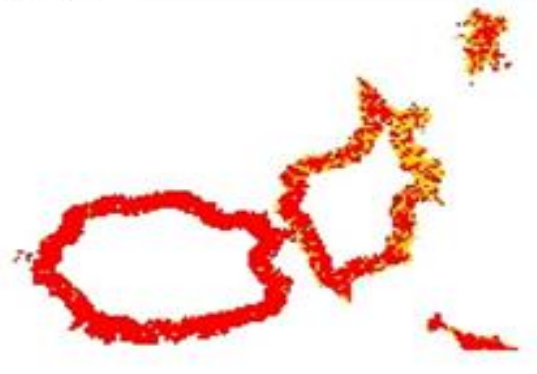

E) $150 \mathrm{~mm}$

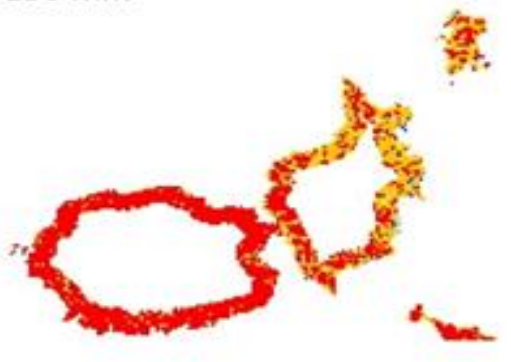

G) $300 \mathrm{~mm}$

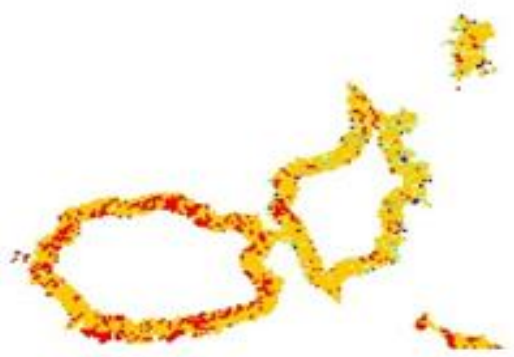

I) $1000 \mathrm{~mm}$
B) $25 \mathrm{~mm}$

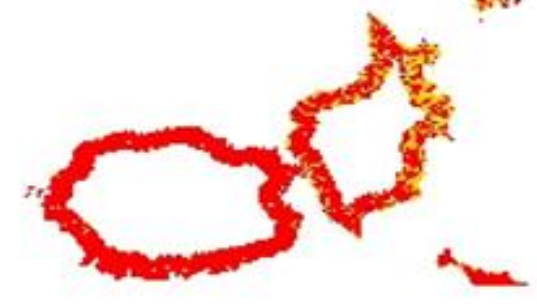

D) $100 \mathrm{~mm}$

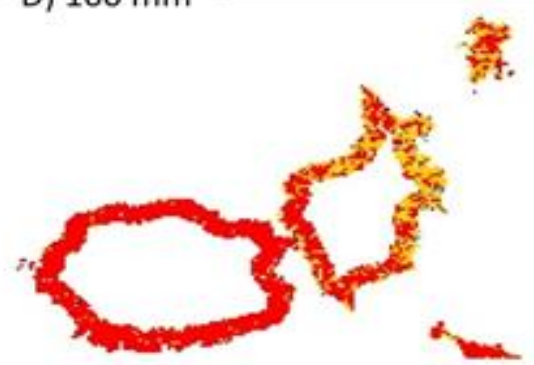

F) $200 \mathrm{~mm}$

trat.

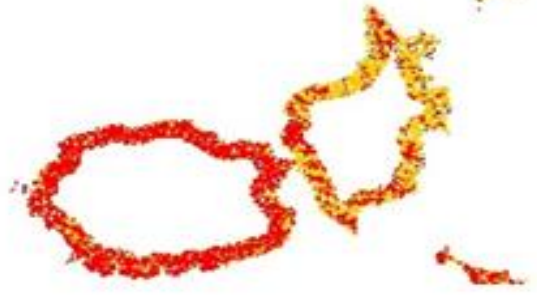

H) $500 \mathrm{~mm}$

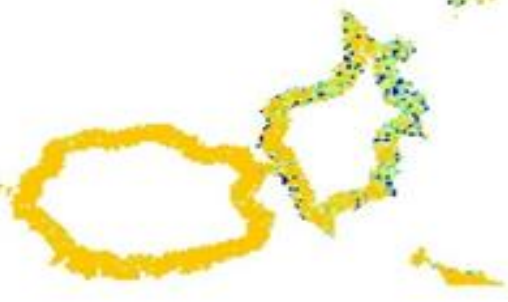

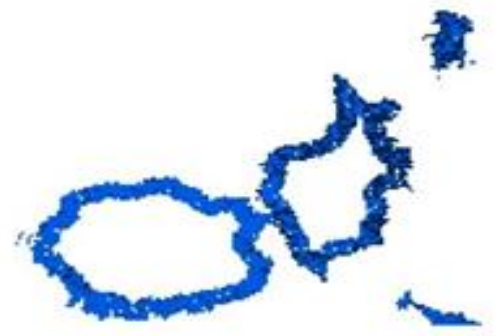

